\title{
What's Left?
}

An exploration of social movements, the Left and activism in New Zealand Today.

\author{
By \\ Dylan Taylor
}

A thesis

submitted to Victoria University of Wellington in fulfilment of the requirements for the degree of

Masters in Sociology

Victoria University of Wellington

2008 



\section{Abstract}

Surveys of the situation and prospects of the contemporary Left over the past three decades have frequently underscored themes of fragmentation, decline, even terminal demise. This thesis explores the question of the contemporary Left through interviews conducted with participants in New Zealand social movements. The general theoretical literature around the Left and social movements has consistently bighlighted a number of social changes and challenges facing the Left today: the split between old and new Lefts following the rise of the new social movements; economic transformation (for instance, post-Fordism), and changes in class composition; the rise of neo-liberalism, and the dislocating effects of globalization; intellectual challenges, such as the demise of Marxism and the rise of post-modern philosophy; challenges to the state, and the arrival of a "post-political" condition. Analysis of the New Zealand literature around the Left and social movements shows congruent arguments and themes, as well as suggesting Antipodean specificities. To examine these contentions, a series of interviews were conducted with participants in "Left" social movements. These interviews suggest both congruence with some of the arguments in the literature and complexities that do not confirm these generalizations. In particular, the suggestion that a third phase of the Left is emerging, characterized by the joining of culturalist and materialist emphases, appears somewhat confirmed. In addition, a number of the challenges signalled in the literature were singled out by interviewees as pressing-for instance, neo-liberalism and the mediatisation of politics. With respect to the modes of action of social movements connected to the Left, there was here too some confirmation of themes from the literature-for instance, the importance of networking. On the other hand, the widespread theme of the wholesale decline of collective actions was put into question by those interviewed. While no definitive conclusions can be drawn from such a study, the interviews suggest the Left may be entering a period of renewal. 


\section{Acknowledgments}

I wish to acknowledge and thank those people who contributed to this thesis:

Dr Chamsy el-Ojeili, for taking my interest in writing a thesis "on something to do with resistance" and helping me shape it into the topic explored in the following pages. From the time of my writing a proposal, to the final full stop in the conclusion, his help has been instrumental in the production of this thesis. His own work and vast knowledge has served as a source of great inspiration.

Dr Sandra Grey, who seemed to always have time for the endless torrent of drafts and questions I barraged her with. Always able to unpick the problems I found myself tangled in, and never short of motivating words and thoughts, her help and supervision were invaluable in my reaching the end of my thesis.

Erin Taylor and Mark Derby for proof-reading draft copies, your suggestions, advice, and most importantly friendship, have been of great value to me.

Dr Robert Deuchars, who generously shared advice and ideas, and productively distracted me with long afternoons in the Staff Club when I was showing signs of stress.

My house mates, Glen Maw, Laura Callaghan, Kriyavidya, Robert Larson and Tyagmurti for taking the walking shadow who entered the house each evening and giving it nourishment.

Anna Taylor, your love and support bore the emotional weight of my Masters with grace, I am eternally grateful to you.

My parents and sister, without family support I imagine everything in life would be harder.

Catherine Benland, Barbie Cole, Nicky Hager, Torrance Hodgson, Matt McCarten, Robina McCurdy, Frans Muter, Simon Oosterman, Keith Orr, Nandor Tánzcos, Teanau Tuiono and Philip Vincent, for generously sharing your time and opinions with me-I hope I have done you all justice in my work. 


\section{Contents}

Introduction: Renewal or Decline? 4

Chapter One: From Old Left to Empire $\quad 7$

Anti-Systemic Movements, the Old Left and its Divisions 8

1968, the New Left and New Social Movements $\quad 10$

Changes to the Economy $\quad 12$

Changes to Politics $\quad 15$

$\begin{array}{ll}\text { Changes in Theory } & 18\end{array}$

Contemporary Challenges to Capital 19

A Rejuvenating Left? 25

Conclusion-the Path Ahead 29

Chapter Two: A Brief History of the Left in New Zealand 31

From Early Settlement and its Discontents to Labour in the 1950s 32

The Turn-New Zealand in the 1960s 35

The Peace Movement 37

The Environmental Movement 39

The Anti-Apartheid Movement 41

The Maori Protest Movement $\quad 43$

The Women's Movement $\quad 47$

Labour, the Left, Neoliberalism 49

Interim Summary $\quad 52$

$\begin{array}{ll}\text { Methodology } & 53\end{array}$

The Participants $\quad 55$

$\begin{array}{ll}\text { Analysis } & 57\end{array}$

Chapter Three: The Left in New Zealand Today 58

Issues for Considering a Contemporary Left in New Zealand Today 58

New-Unionism and the Continued Saliency of Class 69

Conclusion $\quad 76$

Chapter Four: Extra-Parliamentary Politics in New Zealand Today 78

Post-Politics and 'Mainstream' New Zealand $\quad 78$

Effective Action $\quad 81$

Organisational Issues and the Activist Strata 87

Intentional Communities and a Constructive Programme for the Left 91

$\begin{array}{ll}\text { Conclusion } & 97\end{array}$

Conclusion: Renewal 99

$\begin{array}{ll}\text { Bibliography } & 102\end{array}$ 


\section{Introduction: Renewal or Decline?}

Is the Left today in a state of decline or renewal? Perry Anderson famously stated, at the turn of the millennium, that "the only starting-point for a realistic Left today is a lucid registration of historic defeat," with there being "no collective agency able to match the power of capital...on the horizon" (2000: 16/17). His pessimism followed a decade that was marked, for Anderson, by the uncontested diffusion and consolidation of neoliberalism, a decade that had opened with the fall of communism and Francis Fukuyama's (2002) assertion that liberal democracy and free market capitalism marked the end point of humanity's ideological evolution.

Yet, in the same year Anderson wrote of defeat Michael Hardt and Antonio Negri unabashedly wrote of the "irrepressible lightness and joy of being communist" (2001: 213). From their position, global capital's ascendancy through 'Empire' was threatened by the 'multitude.' The rise of the alternative-globalisation movement-a networked body of resistance stretching from the global South to anti-capital groups in the North-gave some credence to Hardt and Negri's optimism, indicating renewal might be on the horizon.

Questions of decline and renewal in the Left appear throughout this thesis, reflecting, in part, what I view as the Left's passage through three broad transitive phases. The first phase is characterised by intense divisions between anarchists and Marxists over the state form. A second phase arose when a 'New Left' challenged the Old in the 1960s and '70s, with the Left's energies taking a variety of paths through various cause-focused social movements (against the Old Left's universalist critique of capital). The third phase of the Left, I suggest, is the contemporary one, in which Old and New Left themes may be converging.

My thesis will explore the contemporary phase, especially within the context of New Zealand. No definitive answers are sought. Despite Fukuyama's attempt, history cannot be closed to prove an argument. It is "open ended" (DeLanda 2008), as I consider the third phase to be. Therefore the following pages do not seek to predict where this phase leads, rather they will explore major themes in the literature around the situation of the Left today, and use information from interviews conducted with New Zealand activists to explore these themes. 
"The Left" in these pages is conjectured to be a very broad category. I find David McKnight's notion of it including "supporters of Labour, Democrat and Green parties, the unions and community groups and unaffiliated progressive opinions" (2005: 15) to be a suitably broad point from which to begin. Another incredibly broad theoretical category is that of "social movements." Irreducible to a single group, a social movement is composed from a number of actors who retain their autonomy while engaging in sustained action towards a common goal (Della Porta and Diani 2006).

My interest is in social movements from the Left, although it is acknowledged social movements exist across the whole political spectrum (Klatch 2002). Throughout the three phases of the Left, social movements have been the vehicles in which the values of the Left are carried towards the greater populace. My work focuses on the wider context of social movements and the Left, rather than on the technical details of social movements.

Chapter One approaches social movements and the Left from a broad theoretical and historical perspective: encompassing the rise of the Left and antisystemic social movements in the mid-nineteenth century (the first phase of the Left); the 1960s and '70s, when the Left fractured with the rise of new social movements (the second phase); through to the contemporary era (the third phase). I survey the literature on the challenges and changes (economic, political and theoretical) since the 1960s, as a background to the analysis of the interview data.

Chapter Two explores the literature around the Left and social movements in New Zealand. Attention will be given to the development of the country's peace, environmental, anti-apartheid, Maori protest and women's movements. I underscore some of the particularities of the New Zealand context-such as the resistance to colonialism, the near absence of the first phase of the Left and the role of the state. Methodological issues will be discussed and interview subjects introduced.

Chapter Three draws on this background in order to examine 'the Left,' in its conjectured third phase, in New Zealand today. Questions around the fragmentation of the Left, the theorised decline of collective action, the suggested re-convergence of Old Left and New Left themes, the role of the Labour party and more generally the impacts of neoliberalism on the Left will be considered. More specifically, these issues will be explored through considerations of unions and the notion of 'new unionism.'

Chapter Four opens with some considerations of the space in which the 
contemporary New Zealand Left and social movements operate in relation to parliamentary politics, the role of the media, and 'mainstream' New Zealand. The tactics used within this space are explored, with questions raised about 'expressive' and 'instrumental' forms of action. This leads to questions about the organisational structures assumed by movements today and the tensions between movements. The more particular space of intentional communities is then explored: do they present a constructive project for the Left, and where do they fit within wider social movement networks?

Despite the limits of such an exploratory work, I hope to contribute towards debates around the current situation and possible renewal of the Left. Further, I hope to explore possible divergences and correlations between New Zealand and the international context. Ultimately, it is hoped this work will provide a starting point for further, in-depth study of the issues explored. 


\section{From the Old Left to Empire}

The term 'Left' originated from the seating arrangements of the French National Assembly following the revolution of 1789. Those on the left of the chamber sought to implement the goals of the revolution-liberty, equality and fraternity-against the opposition of those from the right of the chamber (Eley 2002). It is the achievement of these values that sets the liberatory agenda of the Left. As the $19^{\text {th }}$ century progressed, the Left developed a social critique that emphasised the oppressive, dehumanising nature of capitalism (Boltanski 2002). The radical Left advanced what Alain Badiou calls the 'communist hypothesis,' which held it was possible to create a society in which the subordination of labour to the logic of a dominant class was not inevitable; rather, a different form of collective organisation could be achieved that would eliminate the inequality of wealth and the division of labour. A coercive state separate from civil society, it was conjectured, would no longer be necessary under a communist society (Badiou 2008).

Originally the Left was consolidated around the state-focused antisystemic movements of the $19^{\text {th }}$ century. Marxists favoured this state-focused approach, while anarchists rejected it-I have characterised this split as the 'first intensive phase of the Left.' By the mid 20th century the hopes pinned upon the state form appeared, to some degree, unfounded. The Left fragmented-in what I term the 'second intensive phase of the Left' - and a New Left arose in the 1960s, leading to an explosion of new social movements. These social movements were cause-focused and rooted in the politics of everyday life-issues of identity and lifestyle trumped the Old Left's materialist focus. This fragmentation, as well as a range of economic, political and social changes, ushered in a period often viewed as one of defeat and fragmentation for the Left (witnessing the rise of neoliberalism, a decline in civil society and a crisis in democracy).

After an apparent hiatus of resistance, recent years have seen the rise of an alternative-globalisation movement, the World Social Forum and numerous resistance movements are emerging within the South to challenge neoliberalism. The contemporary period, I propose, is the 'third intensive phase of the Left,' one in which the branches of 
the Left that had diverged during the second phase are re-converging — the result being a renewed optimism about the future of the Left.

This chapter explores the literature surrounding these three phases of the Left and social movements, alongside the literature on the many social changes and challenges faced by the Left. It will then be used as a backdrop for examining the Left and social movements within a New Zealand context in following chapters.

\section{Anti-Systemic Movements, the Old Left and its Divisions}

Wallerstein coined the term 'antisystemic movement' to refer to two, often competing, movement forms - the 'social' (communism and social democracy) and 'national.' Social movements sought to further class struggle primarily through trade unions and socialist parties, while national movements fought to create a nation state. After much internal debate, antisystemic movements settled on a 'state-orientated' approach in the late 19th century, seeing this as the 'immediate source of real power': the first step was to take this power, the second to "transform the world" (Wallerstein 2002: 30). Arguments around 'revolution' versus 'reform' as a means of enacting this change led, within the Left, to a split between social democrats in core states, and communists within peripheral states (Arrighi et al 1989).

While the Left's ambitions had always been internationalist, the state-reformist approach of social democrats forced them to deal with questions of 'national interest.' This led to compromises between the class interests of the proletariat and those of "certain strata of the bourgeois hegemonic structure in each country" (Hardt and Negri 2001). Further, the implementation of the welfare state and Keynesian economic policies, following the Depression of the 1930s, allowed reformist states to diffuse the volatility of mass unemployment (Hobsbawm 2006). Yet, inequality both within and between states still existed, democratic participation had not increased, and alienating wage labour practices were still the norm (Wallerstein 2002). While the social democratic Left were influential within the core, the periphery and semi-periphery were the domain of communist and national liberation movements.

Communism became a bureaucratic machine for building socialism. A centralised party-state elite, the nomenklatura, mobilised populations within the Soviet Union to rapidly modernise. However, the shining communist future was paradoxically intertwined 
with the nomenklatura's immediate use of instrumental violence over their own population (Chubarov 2001). The nomenklatura are seen to have become prey to their own 'class' interests, at the expense of the wider population and the diminution of their initial revolutionary thrust. The fate of national liberation movements, which had gained power across vast swathes of both Africa and Asia, proved little better. Both the revolutionary and reformist Left, along with national liberation movements, found themselves constrained by the interstate system-while they had been able to take the state, they were unable to take the second step and transform the world (Wallerstein 2002).

This inability to "transform the world" appeared to vindicate the anarchist position, which had long held that the path to liberation would not run through the state. Within the radical Left Marxists and anarchists shared the same objective, the advancement of a libertarian communism where class, exploitation and the state had ceased to exist (Hobsbawm 1973a). However, beyond this point consensus was near impossible to reach. A major source of contention concerned organisational forms. While Marx himself had strong anti-authoritarian and anti-bureaucratic tendencies (Miliband 1989), Marxism developed towards centralisation, the indispensability of leadership, strong organisation and discipline, while anarchists leaned towards spontaneity (Hobsbawm 1973a). Anarchists saw within the instincts of the masses the direction in which freedom lay; and they favoured communal institutions, unsullied by power relations, over Marxist organisational forms (Thomas 1980). The turn towards the politics of the state by antisystemic movements meant the marginalisation of anarchists within the broader socialist movement.

Any engagement with the state was antithetical to anarchists who saw the very notion of governance as the root cause of human disharmony (Bakunin 1972). A further point of contention within the Left was the composition of the revolutionary body. Bakunin objected to Marx's exclusive emphasis on the organised working class, believing this ignored the possibility of other revolutionary groups and implied the domination of one class, the industrial proletariat, over the masses, the 'lumpenproleteriat' and the peasantry (Carter 1971). Such conflicts, along with a falling out over different interpretations of the Paris Commune, saw an acrimonious split between Marxists and anarchists in the First International (Arrighi 1990), a split which was central in shaping the first phase of the Left as it became, predominantly, focused upon the state.

Following this split the Second International excluded anarchists and focused on 
organisation, with workers in a number of countries becoming organised into trade unions and political labour parties (Novack et al. 1974), yet the Second International was unable to overcome the plurality inimical to the movement. The Left never went beyond being a loose federation of autonomous and tightly organised national bodies (Braunthal 1966). While unable to overcome this organisational plurality, Marxist notions of organisation were hegemonic, a hegemony Giovanni Arrighi (1990) attributes to the close fit between predictions made by the Communist Manifesto and historical developments between 1848 and 1896. However, by 1968, the antisystemic movements had peaked and the first phase of the Left had reached its limits.

The Left that emerged from this phase will be referred to in the following pages as the 'Old Left.' Old Left groups and organisations are considered to be focused on and around the state form, to have strong centralising tendencies and to tend towards institutionalisation - therefore both communist parties and social democratic parties are considered to belong to the Old Left, while anarchism, despite its shared heritage, is not.

\section{8, The New Left and New Social Movements}

The Old Left was caught off guard by the events of 1968 (Hobsbawm 1973b). Following the Tet Offensive in Vietnam there was a worldwide surge in protest activity, at the forefront of which were students (Ali 2008). This moment has been characterized as a "world revolution" (Arrighi et al 1989) in which both the US and Soviet Union were challenged, along with the Old Left—who was seen to be "not part of the solution but part of the problem" (Wallerstein 2002: 33).

A 'New Left' emerged, rising from the ground up, incorporating the needs and aspirations of popular movements from around the world. Its diversity defies easy categorisation, although some trends can be discerned: its aim was to transform everyday life; it sought to free subjectivities from racial, political and patriarchal domination; the struggle was not simply against material or economic hardship-it sought to create new human beings, glorified spontaneity, and argued for individual autonomy against economic and bureaucratic domination; plurality was celebrated and the monism of the Old Left rejected; an enlarged base of revolution was developed-the New Left's constituency embraced students, young people, national minorities and the lumpenproleteriat; direct action was elevated above the party and programme (Katsiaficas 
1987). The emergence of the New Left also saw the re-emergence of anarchism (Hobsbawm 1973c).

Associated with the rise of the New Left is the proliferation of new social movements in the 1970s. These movements were generally cause-focused-directed towards such issues as peace, women's rights, race, the environment and championing the interests of minorities. Instead of the redistributive goals traditionally associated with the Old Left, these movements tended towards goals that recognised identity or 'different' ways of being; notions of solidarity with the working class, and of putting differences aside in favour of achieving common goals, were challenged.

It is widely held by those operating within the lineage of the Old Left that this change in focus fractured the Left's unitary goals-and has been labelled by some, loosely, as the "cultural turn." Judith Butler summarises the general perception of the Old Left towards this turn:

That the cultural focus of left politics has abandoned the materialist project of Marxism, that it fails to address questions of economic equity and redistribution, that it fails as well to situate culture in terms of a systematic understanding of social and economic modes of production; that the cultural focus of left politics has splintered the left into identitarian sects, that we have lost a set of common ideals and goals, a sense of common history, a common set of values, a common language and even an objective and universal mode of rationality; that the cultural focus of left politics substitutes a self-centered and trivial form of politics that focuses on transient events, practices, and objects rather than offering a more robust, serious and comprehensive vision of the systematic interrelatedness of social and economic conditions (Butler 1998: 34).

For proponents of the Old Left, the legacy of the cultural turn, or the turn towards identity politics, has led to a fragmentation of the Left from which it has yet to recover (Anderson 2000).

Wallerstein (2002) considers new social movements to have become divided by the early 1980s into revolutionary and reformist factions-with the reformists emerging victorious. As a result new social movements came to resemble social democratic parties, albeit with different emphasises, such as the environment, racism and sexism. Overall, little differentiated these new social movements from the Old Left. Despite such a trajectory, the values of the new social movements permeated throughout society 
(Katsiafacas 1987), remaining longer than many of the movements that bore them (Arrighi et al 1989).

I consider the challenge posed to the Old Left by the New Left and new social movements to have ushered in the second phase of the Left - a phase the following chapter will show is evidenced in the New Zealand context. Further, I argue this second phase produced a Left unable to constructively respond to the rise of neoliberalism and changes to the economy. Below, I will explore the manner in which changes to the economy, politics and theory have been treated in literature concerned with social movements and the Left. It is hoped such an exploration will reveal some of the prominent changes that have impacted upon the Left as it has passed through the second phase toward the third.

\section{Changes to the Economy}

Concurrent with the theorised changes taking place within the Left, it is held by some literature that there have been significant changes in the economic realm. The tumult unleashed by the New Left was seen by theorist Daniel Bell to be the birth pangs of a new society, a 'postindustrial society' —one based on knowledge and technocratic governance (Dyer-Witherford 1999). Central to this changing order was a move from material production to a service based economy, with an attendant shift from manual labour towards professional and technical work. It was held that a 'knowledge class' would emerge, composed of scientists, engineers and administrators lodged within government and academia who would be equipped to manage the increased organisational and technological complexity of postindustrial society (Dyer-Witherford 1999). Figures within the radical New Left opposed such a cybernetic turn (Vaneigem 2006), seeing within the changing systems of production processes intensifying alienation (Touraine 1971).

The label 'post-Fordism' has captured these and other economic changes. Fordism was the entwinement of industry with the bureaucratic Keynesian welfare state, and was grounded in the consumption of standardised mass produced commodities within nuclear family households (Amin 1995). Within Fordist regimes of production workers benefited from a long-term contractualisation of the wage relationship, with rigid redundancy rules, along with monitored increases in salaries relative to general productivity and prices (Lipietz 1997). The state oversaw these wage relations, integrating 
capital and consumer goods industries. It supported 'responsible' trade unionism, collective bargaining, and the consolidation of the partnerships between big businesses and wider society. The welfare state filled cracks in the Fordist edifice, held it together on its outer limits and was in turn fed from the taxes generated by high employment. Taking place within relatively closed economies, the relations between capital and the state formed a "virtuous cycle" (Jessop 1995). New social movements attacked such standardised patterns of work and leisure, weakening the foundations of Keynesianism (Bowring 2002).

Unrest within the core was coupled with external shocks to the system such as the 1973 oil crisis. Radical economic restructuring was initiated, production was internationalised and flexible labour practices were introduced in the core-such flexibility involved the overturning of labour regulations, the decline of trade unionism, attacks on social welfare and the proliferation of insecure jobs (Lipietz 1997). The new identities associated with the increased flexibility of labour are seen to have eroded old solidarities and block identities, leading to social fragmentation and increased pluralism (Amin 1995). It is argued that the industrial working class was undermined, with it no longer appearing as the agent of social transformation (el-Ojeili 2007).

Faced with such changes, it has been held that those within the Left who still identified inequality with material conditions and class conflict were unable to challenge the ascendancy of neoliberalism, which has been the most potent ideology of the last thirty years. Neoliberalism has some theoretical overlaps with the New Left, for instance the celebration of spontaneity: Friedrich Hayek condemned the conscious organisation of society, which he saw as a spontaneous order beyond human comprehension (Kukathas 1998). Neoliberals and much of the New Left rejected the control of a centralised state, leading the generation who had grown up under the full social support of core states to cast it aside (Robinson 2006). Under attack, the state restructured, discarded Keynesianism and concentrated on ensuring the most favourable market conditions - with the market given priority over all other social relations (Gamble 2006). Changing social relations are seen to have induced widespread individualisation (Gauchet 2000), prompting some to hold that the probability of sustained collective social movement action has diminished greatly (el-Ojeili 2007). In place of collective action, since the close of the 1970s, political freedom has come to be equated with economic freedom (Friedman 1980). Neoliberalism, and its celebration of the individual above the 
social, it is argued, has become the dominant orthodoxy.

Neoliberalism is seen to be the driving force behind 'globalisation,' a ubiquitous term within contemporary theory. Globalisation has been referred to, variously, as a process of increased internationalisation (cross-border transactions), or liberalisation (of trade, with decreased government interference), or universalisation (the spread of various objects and experiences to all corners of the globe), or Westernisation (especially Americanisation) and as deterritorialisation (the diminishing influence of geographical specificity on actions) (Scholte 2001). A general definition holds it to be "a historical process which transforms the spatial organisation of social relations and transactions, generating transcontinental or interregional networks of interaction and the exercise of power" (Held and McGrew 2002). A prominent feature of theorisation around globalisation has been the diminishing power and credibility of the state-whose territorial integrity has been challenged by flows of global capital.

As characterised by Manuel Castells, the state has become just one of many points of power within a global 'network society.' Following theorisations around postindustrial society and post-Fordism, Castells considers the contemporary era one in which information has become the raw material on which technology operates. Capitalism is 'informationalism,' imbued with a networking logic that facilitates a high degree of flexibility within human relations (Castells 2005a). Today's is a 'network society,' with power residing within global networks of wealth and power. These networks have two movements: the first integrative, with all valuable peoples and sections of territories linked together; the second exclusive, with peoples and territories of no value switched off from the network, resulting in their marginalisation. Inclusion within network society is dependent on the ability to communicate in the codes of capital and to produce value (Castells 2005b).

The destructive nature of global capitalism has been a consistent theme for many theorisations from the Left. While limitations of space prevent the tracing of the full range of Leftist theoretical reactions to globalisation, the dominant interpretation from both European and American theorists portrays the contemporary global order as (almost) totally dominated by capital, which cements its global rule through the commoditisation of culture. The entire global sphere is seen to have been subsumed by the logic of capital, the result being the homogenisation of the world, which has been variously referred to as the rise of McWorld (Barber 2001), the globalisation of 'Nothing' 
(Ritzer 2004) a global simulacrum (Baudrillard 2005), or the totalising 'society of the spectacle' (Debord 2008). From this perspective it is held that while globalisation is a process generally favouring the North (especially the USA) and the capital flows extending from it, it is also seen to simultaneously provoke resistance-the most striking example of this being 9/11, which can be viewed as an attack against US imperialism, the complicity of capital in this process (the symbolic strike against the WTO) and, in considering the notion of jihad more generally, a rejection of the homogenising flows of culture involved within globalisation (although the "homogenisation" thesis has been challenged (Thompson 1996; Tomlinson 1998)). Considerations of economic globalisation cannot be easily separated from theorised cultural changes that have taken place within the core states under neoliberalism.

Overall, a compelling argument arises from the literature, in which the changing relations of production within the core, coupled with challenges from the New Left, are seen to have opened a space in which neoliberalism was able to gain purchase. It has been argued that neoliberalism, as an ideology, has reigned supreme during a period in which the social has become individualised and fragmented, with the market taking priority over the social. Neoliberalism has supposedly sped the processes of economic globalisation, which in turn has contributed to the decline of state power. The issues raised by theorists above will be explored in the New Zealand context in later chapters.

\section{Changes to Politics}

While it has been argued the economy has undergone profound changes from the 1960s onwards, changes have also been widely documented in the political sphere. As shown earlier, new social movements are considered to have marked a generalised loss of faith in the state and political parties as means of enacting progressive social change (Wallerstein 2002). This critique, combined with the rise of neoliberalism and globalisation, has, the literature suggests, seen a profound change in state power. Novel to current political perspectives is the manner in which the sovereign state is seen to have been intersected by a vast array of international regimes and organisations, which seek to manage transnational activity (such as trade, financial flows, crime etc.) and global policy problems (Held and McGrew 2002). It is held governments are now restrained by the unrepresentative and un-elected forces of economic power, national identities are undermined by unbounded global media, and that pressing environmental concerns 
know no boundaries (Held 2000). While the powers of the state are still presented as considerable, especially in regulating the flows of people, they are not absolute.

Changes to the nature of power in the era of globalisation and neoliberal dominance have raised concerns over the health of democracy, leading to suggestions of a 'crisis in democracy' (Castells 2005b) or a 'post-democracy' paradigm (Crouch 2004). This takes place against vapid celebrations of the "new democratic wave sweeping the world" (Heraldo 2006: 1). Before celebrating the spread of democracy, it pays to pause and ask how healthy democracy is within the states exporting it. As does Boaventura de Sousa Santos, who considers the hegemonic European notion of democracy to have failed. He argues that with the dismantling of the welfare system through much of the West in the 1980s the state has lost the ability to mediate tensions between capitalism and democracy; the supposed redistributive effects of democracy have shown themselves unconfirmed. Democracy is seen to be suffering from two pathological traits: those of participation and representation (Santos \& Avritzer 2005). It is conjectured that there has been a double movement within the party form of democracy: citizens have ceased to support political parties, and these parties are run by an elite that aims to govern rather than represent the electorate- these governors become a "self-perpetuating elite" that administers "passive or privatised masses of people" (Mair 2006). Neoliberalism is considered to be the main culprit behind democracy's decline, with the state having become ever more the domain of a capital-focused elite since the 1990s (Crouch 2004; Santos \& Avritzer 2005). A picture emerges in which neoliberalism, tied to economic globalisation, has diminished the capacity of the state to react to capital-a situation that is seen to be exacerbated by the capture of state and global politics by an elite.

As an ideology, neoliberalism has been accused of being a theory with a deeply ingrained streak of elitism. Hayek was long sceptical of state democracy, as it must be acknowledged were many Left thinkers, but while theory on the Left generally tended towards the development of systems favouring mass rule and the development of a more direct democracy, neoliberalism leads in the opposite direction. "More often than not," argued Hayek, "it is the minority who are enlightened, and it is its capacity to lead the majority that brings progress" (in Kukathas 1998: 25). As the supposed dominant ideology of our times, neoliberalism is seen to have created, in many instances, its own elitist political class - a politico-business oligarchy growing throughout the 1980s into the 1990s (Robinson 2006). The rise of this elitist political view, it is argued, has led to the 
redistributive role of the state being minimised and the will of the majority being ignored, with the dictates of capital rising above other voices within the political/social sphere. Indeed, neoliberal prizing of the actions of self-interested individuals is considered to come at the expense of civil society-which for classic liberals had been an important counterweight to the market (Robinson 2006).

The decline of civil society is conjectured to go hand in hand with the crisis of democracy. Civil society is considered to have been torn asunder by a steely individualism-resulting, it is argued, in an atomised society where individuals fail to engage with one another (Putnam 2000). Following the Frankfurt School's pessimism (Adorno 1989), consumer culture is accused of feeding a state of profound civic alienation (Barber 2001). Both the Tocquevillian notion of American civil society (a mobilised citizenry against dominant state and economic power) and the Gramscian view of European civil society (employers and organised workers in a consensual relationship upholding the state's military, political and economic goals [as seen within Keynesianism/Fordism]) (Cox 2005) are seen to have withered under a neoliberal onslaught of individualism, consumerism and elitist rule-all of which work to compound problems with democracy.

The media is assigned a major part in the narrative of democratic decline (Bagdikian 1997; Barber 2001). Elections today within the West are seen to have become tightly controlled spectacles where expert techniques of persuasion manipulate a "passive, quiescent, even apathetic" public within an "electoral game;" with politics really being shaped by private interactions between governments and business elites (Crouch 2004: 4). A media, saturated with the ethos of advertising, is seen to have forgone communicating the complexity of politics in favour of seeking emotional pull over rational deliberation-in a style that tends to gravitate towards the personalisation of politics, focusing on charismatic individuals rather than larger political issues (Crouch 2004). It is an era of 'informational politics'-politics conforming to media logiclapsing into sound bites, scandal and personalities (Castells 2005b).

It is argued that the parliamentarian, social democratic Left has been transformed within this contemporary political era. For Colin Crouch (2004) it has become cut off from its constituency and has lost many of the advances it made in the past (the Keynesian compromise, the welfare state etc.), has become prone to corruption and is generally cynical towards the whole political process. Within the political sphere it is held 
that the Left has long ceased to be radical and it is the Right who are now radical through their promotion of neoliberalism (McKnight 2005). The parliamentarian Left is seen to fulfil a conservative role, holding on to the last vestiges of the welfare state (Giddens 1996). This is a role it struggles to fulfil, holds Crouch (2004), through it being separated from its traditional constituency and with the public at large turning away from political parties_leading the political Left to lapse into an elitist politics little differentiated from those of the Right. A point has been reached where it appears any challenge to the rule of the market has long been discarded by the parliamentary Left-instead they are asked to "decide what kind of capitalist you are" (my italics) and to then get on with the process of managing the economy while trying to blunt the sharper edges of neoliberalism (Cornford \& Hewitt 1994: 252). Ultimately, it is held the public does not look to the parliamentary Left for any serious change. While people still vote, this is seen to achieve nothing beyond the maintenance of the established order - an essentially conservative act (Badiou 2008). The capture of politics by a parliamentarian elite is considered close to total.

From my perspective, calls to move 'Beyond Left and Right' suffer from conflating the 'Left' too much with the parliamentary Left and its decline. As presented by the literature, the rise of neoliberalism and the concomitant decline of state power, coupled with the crises of democracy, presents a challenge to the Left on the political front. Rather than signalling an end of the Left, I see this as a prompt towards reconceptualising what it means to be of the 'Left' - a question that will be reviewed in the New Zealand context in subsequent chapters.

\section{Changes in Theory}

Alongside discussions of political and economic changes, there has been much discussion of accompanying changes in theory and in the way the world is mapped. The unrest of the 1960s and "70s affected the academy as much as other parts of society, leading to what Wallerstein has called "shifts in the structures of knowledge" away from scientific universalism—challenging Eurocentrism, objectivity, universal laws, determinism, the canons and the very notion of progress (el-Ojeili 2007). A cultural turn is considered to have developed in theory, in tandem with the changes seen to have taken place within the New Left in the 1970s (Denning 2004). For some, this cultural turn has replaced outmoded materialist means of classification and analysis, providing an orientation better 
able to map the transformation of the social. For others, changes in the theoretical realm have been negative, the signal of defeat.

The advent of postmodern thought has been key to these changes. Centred on the French intellectual scene following 1968, postmodern thought asked why insurrection had failed and traditional notions of revolution were no longer (if ever at all) possible (Shukaitis \& Graeber 2007). For example, any politics addressing alienation were dismissed on the grounds that there was no natural state from which to be alienated, and it was held there was no centralised power to strike against, as power was fragmented and shifting (Shukaitis \& Graeber 2007).

Further, following Lyotard's proclamation of postmodernism being "incredulity towards metanarratives" (in Wicks 2003: 248) modernity, and its notions of 'progress,' were denounced-giving the death knell to Marxism, tied to modernity as it is (Therbon 2007). As held by Fredric Jameson (2005) postmodernism saw the loss of any redemptive (or catastrophic) vision of the future. Instead a "hermeneutics of suspicion" arose which saw reality as "at once multiple, local and temporal, and without demonstrable foundation" (Tarnass 1991: 401). The broad brushstrokes of Marxism depicting class and capital locked in conflict, with the perspective drawing the eye towards a utopian communist horizon, were scratched from the canvas; all this at a time when Marxists argued that conditions validated Marx's theory more than ever before (Mandel 1990). Postmodernism, it has been argued, is for an academic 'ex-Left,' who have turned their eyes from material deprivation and have done little to respond to the immiseration unfolding under neoliberalism (Therbon 2007).

Taken together, the changes discussed above-the rise of new social movements, neoliberalism, globalisation, the crises of the state and democracy, alongside changes in theory — have been presented by the literature as amounting to a long retreat for the Left, possibly even its demise. However, from the middle of the 1990s many observers claimed that a new period of Left thinking and practice was emerging. I view this as the third phase of the Left.

\section{Contemporary Challenges to Capital}

While many of the changes to the economy, politics and theory outlined above can induce a high degree of pessimism from Leftist critics, there is also some degree of optimism towards changing politics; this is especially the case in considering social movements. While Crouch (2004) maintains the political party is the surest vehicle for 
delivering egalitarian outcomes within the state, he sees social movements playing the vital role of widening the space in which parties can act-freeing the party from the mire of corporate lobbying. Santos (2005a) also sees social movements as a means of expanding the space of politics, and of citizenship, through drawing in the traditionally excluded. He imagines social movements capable of introducing such a degree of experimentalism to the state that it can, itself, become a social movement (Santos 2005a), as has been the case in Venezuela (Gindin 2006). Further, social movements are seen as a means of rejuvenating civil society (Alexander 2006). A more Marxian conception of the issue (Cox 2005) sees within social movements forces capable of either transforming civil society or destroying it. As held by Castells (2005b), some degree of trepidation is needed in considering the transformative potential of social movements. Others caution that they are not always progressive, and can attract backlash (Faludi 1992). Nevertheless, social movements do provide the most likely challenge to the conjectured current rule of global neoliberal elites.

Along with hopes attributed to social movements, there has been a burst of optimism around the potential of the Internet to rejuvenate democracy. While serving an important communicative role the Internet is seen to simultaneously play a constitutive role (Castells 2005c)-leading to the construction of political communities that strengthen the voice of alternative or previously marginalized groups (Dahlberg \& Siapera 2007). Old configurations of power can be challenged and new ones produced, allowing for new forms of democratic representation, accountability and legitimacy-the outmoded concepts of democracy attached to nation-states can, it is held, be bypassed by 'new formats of politics' more suited to the world of networks (Dean et al 2006). While the hopes pinned by some on the Internet may be, at times, overly enthusiastic, they do indicate the form re-democratisation may take, along with providing important networking tools for those seeking to challenge neoliberal globalisation.

One of the most striking challenges posed to neoliberal globalisation has been presented by the alternative-globalisation movement (AGM), which has foregrounded the emergence of a range of counter-hegemonic initiatives, as well as giving rise to a range of new theoretical developments. Within the AGM a re-convergence is taking place between the two strains of Left thought that had separated through the 1960s and '70s, with the result that a diverse range of identities, tactics and ways of life have converged to attack capital as it appears in the form of neoliberal globalisation. Predictably, the 
AGM has been labelled the 'anti-globalisation movement,' but for those associated with the movement this misconstrues its true purpose, which is to challenge neoliberalism. If globalisation is considered to represent the free movement of people, possessions and ideas, along with the effacement of borders, then it is held the AGM is more supportive of globalisation than the institutions normally associated with it, such as the IMF or the WTO (Graeber 2002). The challenge to neoliberalism emerged in the South, where it was treated at first by neoliberal elites as a series of isolated events_-among the earliest being the popular revolt in Venezuela in 1989, and the most famous being the 1994 Zapatista uprising in Mexico (Ballvé 2006). These at first unrelated events became incorporated within the lineage of the AGM as it emerged in the West, and dramatically caught the public's attention during the Seattle protests in 1999-which Naomi Klein (2001) labelled a 'coming out party' for a global resistance movement. The target of this resistance, beyond neoliberalism itself, extends for some into a direct challenge to capitalism (Munck 2007). After the hiatus of left oppositional movements within the West, the rise of the AGM heralds a return to the spirit of ' 68 , with many figures from that period playing prominent roles within the movement (Flacks 2006).

The movement is heterogeneous in composition, and for this reason has been labelled a 'movement of movements' (Klein 2001). Its diverse components include: environmentalists; those concerned about the effects of global trade; NGOs in solidarity with the world poor, and humanitarian NGOs; workers and trade unions; farmers and peasants; indigenous people and their solidarity networks; women's movements; revolutionary artists; anarchists and autonomous groups from different ideologies and traditions; young people in violent revolt against society; and political parties of the Old Left (Castells 2005b). The AGM represents a deliberate attempt to establish the control of society over its own institutions following the failure of democratic controls under the globalisation of wealth and power.

Through the AGM's novel organisational form anarchism has, some commentators argue, shown itself to be a leading ideology within the movement. For some anarchists, the development of new forms of organisation within the AGM represents the movement's commitment to creating new forms of democracy-it aims to create horizontal networks rather than top-down structures (Graeber 2002). In a return to the arguments of the late $19^{\text {th }}$ century, and to currents visible within 1960s-70s radicalism, there is again a push for decentralised organisational structures, egalitarianism, 
suspicion of authority (especially that of the state), rejection of leaders, an emphasis on consensus based decision making, a push for direct action and a call for individuals to be committed to their own sensibilities (Munck 2007; Ross 2002; Ward 2005). For Graeber (2002), the new forms of organisation being experimented with are the ideology of the movement itself.

While the anarchist model of organisation can be seen as dominant within the AGM, it has not gone unchallenged-the age-old organisational tensions of the Left show no sign of abating. From the socialist quarter, Stephanie Ross argues that the fragmented nature of the movement is not a deliberate tactic, but rather a reflection of a consciousness deliberately fostered by capital "so as to break down forms of collective action which posit a universal interest" (Ross 2002: 289); the sacrosanct autonomy of the local is seen to come at the expense of mutual understanding and the management of the contemporary Left's differences; avoidance of conflict within affinity groups, it is argued, leads to the continuous formation of smaller and smaller groups, at the expense of learning how to work together; autonomous groups are considered undemocratic as there is no mutual accountability-interests can remain locally rooted without regard for the impact of one group's decisions upon another's; the anarchist commitment to a leaderless movement is seen, by Ross, to be more rhetoric than reality, leaders always emerge in movements out of practicality — when this happens informally there is a lack of accountability or democratic restraints on leaders; the diversity of tactics of the movement is also seen as problematic, the decisions of a minority group during an action can impact negatively on all other groups (as when the Black Blocks become involved in violent tussles with the police, who are able to then use this as an excuse to violently repress all groups involved in an action); finally, consensus decision making is critiqued by Ross for its "tyranny of endurance," with those able to hold out long enough getting to make decisions (Ross 2002: 289-98). This organisational tension between anarchistinfluenced positions and other more 'mainstream' approaches is one found within the contemporary New Zealand context, as will be explored in Chapter Four. In respect to the AGM, while aspects of the above critique are applicable it cannot be forgotten that, as far as anarchists are concerned, the processes guiding the AGM are open-ended ones. The process itself is as important as the outcomes. As David Graeber writes: "This is very much a work in progress, and creating a culture of democracy among people who have little experience of such things is necessarily a painful and uneven business, full of 
all sorts of stumbling and false starts" (Graber 2002: 72).

The AGM is an important feature in the contemporary landscape. It represents the first major challenge to neoliberalism on a global scale-although the degree to which it can be considered a serious threat is open to debate. That the movement shows no sign of abating was witnessed in the G8 protests held in Heiligendamm in Germany, where a multinational coalition of protesters came together to physically prevent the G8 summit taking place, with upwards of 16,000 protesters matched by an equal number of riot police (Barkham 2007). The ratio of police to protesters is indicative of the seriousness attributed to the AGM by its opponents.

The AGM is held to operate within the wider sphere of Global Civil Society (GCS). A widely inclusive definition of GCS, given by Mary Kaldor, holds it to be a platform inhabited by activists, neoliberals, NGOs, national and religious groups, where arguments are conducted for (or against) the processes arranging and shaping global developments - it is a space of radical diversity (Kaldor 2005). GCS is also considered, by some, to be a counterweight to neoliberalism (Kaldor et al 2003). As a conceptual space, GCS is "a sphere of ideas, values, organisations, networks, and individuals located primarily outside the institutional complexes of family, market, and state, and beyond the confines of national societies, polities, and economies" (Kaldor et al 2003: 4). The notion of the network, as advanced by Castells, is active within theorisations of GCS. Campaigns in the 1980s around human rights, violence against women, or for the environment, are seen by Kaldor to have pioneered the use of networks to pursue transnational social justice issues (Kaldor 2003), with the AGM representative of the later phase of these developments.

It is argued that GSC, following a history rooted within the new social movements of the 1970s, is entering a new phase. Richard Falk considers this phase to follow the end of the cold war, and involves the emergence of two fronts within global civil society: the AGM, and the global justice movement-both of which resist the neoliberal world economy and US imperialism. Falk considers this phase, which emerged in the early 1990s, to involve the entrenchment of "network-building networks" within GCS (Falk 2005). Within this contemporary phase of GSC, following the developments in civil society in Latin America and East European countries in the late 1970s early 1980s, it is realised change needs to be driven from below-the spirit of ' 68 is seen to continually infuse the development of GCS (Kaldor 2005). 
The attribution of a movement from below, as encapsulated within some GCS theory, is contentious for those who question the role of NGOs. The extensive diffusion of NGOs throughout GCS is considered to have sapped it of its strength (Kaldor 2005). They are critiqued for not being democratic or radical enough, for not providing a space for debate and to have become co-opted and tamed by the institutions for which they now act as service providers (Albrow \& Anheir 2007). While NGOs stabilise elements of the anti-capital movement within GCS, this has come at the expense of connection to politics from below - to such a degree that NGOs are seen by some to represent a summation of the internal doubts of the capitalist elite (Heartfield 2005). From this viewpoint, GCS becomes a space where tensions between anti-capital NGOs and elite institutions are engaged in a dialogue which works to stabilise conflictual elements within the global sphere-a point Baudrillard (2005) developed to such an extent that he considered NGOs (in general) to be one of the two prongs driving the expansion of neoliberalism (the other being American imperialism). It is from this perspective that many within the AGM would seek to separate themselves from any notion of the GSC (and any NGOs appearing within their own body) —as the purpose of this movement is to build alternative networks, rather than stabilise existing ones.

Against this exploration of change taking place within the global sphere, Castells draws the gaze back to the local as the space where resistance is most likely to emerge, a resistance grounded within identity. Castells holds there are three different kinds of identity today: legitimising identities, resistance identities, and project identities. Legitimising identities are "introduced by the dominant institutions of society to extend and rationalise their domination vis a vis social actors" (Castells 2005b: 8). It is within this category that the dominant neoliberal elite could be situated. Resistance identities are, for Castells, potentially the most important identity of our age: they invert the terms of oppressive discourse in the name of "the exclusion of the excluders by the excluded" (Castells 2005b: 9). Jihad is an extreme example of a resistance identity, but these identities are not solely restricted to claims based on "traditional" values, they also embody proactive social movements whose autonomy is established through communal resistance-resistance identities build communes or communities. This is an important aspect of resistance identities, as they may eventually become project identities. Project identities are seen to have the potential to construct a new form of civil society, and maybe even of the state (Castells 2005b). These identities emerge from the local. 
Against the decline of civil society and the crises of democracy, localism presents a means of reclaiming a stake in power and the production of meaning; a turn towards communal organisations offers a sense of belonging and cultural identity against wider atomistic trends. Ultimately, localism can consolidate actors who will coalesce, in time, into larger social movements (Castells 2005b). Through resisting previous social trends on behalf of alternative sources of meaning, actors rooted in the local may be able to bypass the individualising trends inherent to global capital. Further, those whose resistance is rooted in the local, operating free from the constraints of civil and political institutions, are potentially able to direct themselves towards the construction of new social institutions from the ground up (Castells 2005b). Chapter Four will explore Castells' claims around the local with reference to intentional communities.

\section{A Rejuvenating Left?}

To this point, a review of the literature around the Left has presented a case for viewing the Left as having passed through a series of radical transitions, and these transitions have been seen as aligned, in part, to the activities of social movements. It would appear that the contemporary era is one in which there has been an increase in the activities of social movements addressing the shortcomings of neoliberalism. In the sense that these social movements represent a diverse range of actors and causes, but are aligned in their critique of the material and cultural conditions foisted upon the social under neoliberalism, it might be suggested that the two strands of the Left (the materialist and the cultural) that parted ways in the 1970s are re-converging. While the re-convergence of the Left may impact on the state form of politics — and in the process rejuvenate party politics - this is not necessarily the target of actions. With the diminishing sovereignty of the state under globalisation, or through rejection of the state all together, movements are acting within the global sphere more readily. This does not mean the abandonment of local issues, but rather the linking of the local to the global, the construction of alternative networks. This would seem to be a central feature of what I call the third phase of the Left. The work of Santos, and of Hardt and Negri, will be explored to present some trends as to how this third phase has been understood and theorised.

Santos' work concerns itself a great deal with the construction of alternative networks, along with addressing the many issues continuing to face the Left, a Left he considers to have been in crises for the last forty years. Echoing sentiments found within 
Castells' work, Santos sees the major counter-hegemonic forces today as rooted within the local. For instance, the alternative forms of production and new labour internationalism documented in Another Production is Possible emerge from local communities — as this is where actors are mobilised politically through being rooted in niches of solidarity that are eventually linked with transnational advocacy networks (Santos 2005b). New networks are being formed which, while still maintaining some links to the dominant networks of capital and power-flows, possess emancipatory potential, as it is held these experiments in alternative production open spaces for further transformations of capitalist values and socioeconomic arrangements. The scope of the economy and development can be broadened to include: democratic participation; environmental sustainability; social, gender, racial and ethnic equality; and transnational solidarity (Santos 2006). A counter-hegemonic globalisation can be built through coupling alternative production networks with radical developments in democracy.

The World Social Forum (WSF) is presented by Santos as a means of challenging the reigning hegemonic order, an order that has, over the past few decades, "intensified exclusion, oppression, destruction of the means of subsistence and discrimination of large numbers of people, leading them to situations where inaction or conformism would mean death" (Santos 2006: 6). Acts of resistance are now taking place throughout the world, to consolidate a counter-hegemonic globalisation needing to be linked from below-a function Santos sees the World Social Forum (WSF) fulfilling. First held in Porte Allegro in 2001, in opposition to the World Economic Forum, the WSF presents itself as:

an open meeting place where social movements, networks, NGOs and other civil society organizations opposed to neo-liberalism and a world dominated by capital or by any form of imperialism come together to pursue their thinking, to debate ideas democratically, to formulate proposals, share their experiences freely and network for effective action (World Social Forum 2008).

It is a non-partisan, non-governmental forum characterised by plurality and diversity that seeks to oppose neoliberal globalisation.

Neoliberal globalisation, asserts Santos, is rooted within the hegemony of Western thought. Against this the WSF can promote the epistemological diversity of the 
world, one which recognises all forms of knowledge as valid, not just scientific forms. The 'sociology of absences' operates within the forum, according to Santos (2006), to show how hegemonic thought has actively produced the 'non existent' and smothered the world in monocultures. These monocultures, propagated by neoliberal globalisation, can be replaced by 'ecologies' of knowledge, scale, time, difference and productivity. The second epistemological function of the WSF, the 'sociology of emergences,' helps develop these ecologies: it aims to identify and enlarge possible future experiences ignored by hegemonic knowledge, seeking knowledges, practices and agents in which the tendencies of the future might lie and to intervene to increase the probability of their emergence. Santos sees a diversity of knowledges and aspirations within the South integral to the development of a counter-hegemonic globalisation.

The WSF is seen to be a movement of the Left(s), rejuvenating the Left after years of crises. However, echoing concerns raised earlier around the theorisation of the Left, it is held by Santos (2006) that there are no long-term strategies present within the Left; rather there is a plethora of overlapping immediate struggles. What vision lies behind these struggles? Do they oppose neoliberalism alone, or capitalism as a whole? The effectiveness of the Left in addressing such questions is aggravated by a discrepancy between theory and practice, a discrepancy polarising the Left along three axes: the first is the debate around the subjects of social transformation? - is it the working class and its allies or the multitude?; second, are the goals of the struggle pro- or anti-power, statist or anti-statist?; third, the age-old organisational problems-centralisation, decentralisation, or no organisation at all? Such theoretical polarities are set to intensify the mutual intelligibility between struggles, potentially undermining attempts to build new organisational forms or collaborations. Despite these antagonisms Santos is optimistic, as the WSF shows the different sections of the Left converging, not to synthesise but to create contexts for debate; a new internationalism is being built around an inclusive, yet pluralistic, emergent politics of the South (Santos 2006).

However, the WSF is not progressing smoothly (Flaherty 2007). Others see the internal polarisations Santos talks of as increasing, especially around questions of the state (Callinicos \& Nineham 2007). While there may be a space for renewed optimism, the networks developed within the WSF towards a counter hegemonic globalisation appear frail.

A second major interpretative strand concerning the contemporary Left is found 
in the work of Hardt and Negri. Their work emerges from the Autonomia movement in Italy where, arguably, the trends seen within the recent re-convergence of the two arms of the Left were first exhibited in the 1970s (before the movement was forcefully repressed by the Italian state). Integrating the energy of new social movements into a reinterpretation of Marxism, Autonomia was a diverse meta grouping, which included "immigrant workers, skilled workers unhappy with the work imposed on them, the unemployed, over-exploited women, ecologists... mental patients, homosexuals, the elderly, the young, etc" (Guattari 2007: 109). Such diversity saw the movement develop unique forms of "war-fair"—such as pranks, squats, collective reappropriations (pilfering), self reductions (rent, electricity, etc.), pirate radios and sign tinkering-which worked to extend struggles over a broad social landscape (Lotringer 2007). The creative energy seen in such tactics was considered a transformative force (Negri 1987) provided it was not recuperated by capital—as had been the case with the New Left in the US (Lotringer \& Marazzi 2007).

Autonomia theory saw the working class (broadly defined) at the centre of resistance, with capital on the outskirts, scrabbling to re-appropriate the energy unleashed by struggles in order to fuel its own development. The revolutionary counter-project sought to disengage itself from capital and rupture its recuperative movement (DyerWitherford 1999). An example of this struggle is the revolt of 1968, which was pitched (in Italy) against Keynesian control and the factory system in the name of individual freedom; capital is seen to have stumbled, and to then have "turned the rebels' weapons against them saying, in effect, 'You want freedom? We'll show you freedom! You want flexibility? We'll show you flexibility!"' (Shukaitis \& Graeber 2007: 26) — the outcome of this being the long hiatus of the radical Left under neoliberalism. Hardt and Negri have revived Autonomia theory at a point in time coinciding with an upturn in contemporary resistance, with Empire- a work labelled by some as today's Communist Manifesto (Zizek 2001)—released shortly after the emergence of the AGM. Their work joins the growing number of voices calling for a strengthening of the Left, which they want to see "resurrected and reformed... on the basis of new practices, new forms of organisation, and new concepts" (Hardt and Negri 2004).

The two major concepts they offer the contemporary Left are 'Empire' and 'multitude.' Empire can be seen as an updated, or 'super-sized,' version of the Autonomist's 'social factory' (the total subsuming of society to systems of production, as 
also theorised by the Frankfurt School (McLellen 1980) or the Situationists (Debord 2004)). Empire is, in short, the new mode of sovereignty supporting the globalisation of productive networks. It casts a widely inclusive net across the globe, seeking to envelop all power relations within its order; the result being that nearly all of humanity is now absorbed within, or subordinated to, networks of capitalist exploitation (Hardt and Negri 2001). Empire is a radical theorisation of Castells' network society.

The 'multitude' builds upon an aspect of Spinoza's work. Hobbes had originally depicted the multitude as the antithesis of 'the people:' shunning political unity, resisting authority and refusing to submit their natural rights to the sovereign. Spinoza saw such attributes as positive, regarding the multitude as a form of social and political existence for 'the many,' as opposed to 'the one' drawn together by the centrifugal force of the state (Virno 2004); a force now compromised by the centripetal forces of neoliberal globalisation. Resistance to neoliberalism lies within the multitude due to Empire's dependence upon it. The multitude is the real productive force of the social world, while Empire is a mere apparatus of capture, "a vampire regime" (Hardt and Negri 2001: 62). The degree to which the multitude is exploited is the degree to which it bears the potential to resist; the most potent form of resistance for the multitude being that of exit- the emptying out of the enemy's power.

Such bold assertions are indicative of a rising optimism among some sections of the Left. Hardt and Negri's rejuvenation of Autononmia asserts again the importance of combining critiques of capital with theorisations around the importance of diversity and plurality. This would appear an important feature in considering the notion of a third phase of the Left—one that will be explored in the New Zealand context in upcoming chapters alongside issues raised by Santos.

\section{Conclusion-the Path Ahead}

The purpose of this chapter has been to give an overview of the major changes that the Left and the social movements associated with it have undergone. I contend that there have been three phases of the Left: the first being the divergence of state-focused Marxists from anarchists; the second being the emergence of the New Left and new social movements, which saw a turn from capital to culture for much of the Left, and resulted in a profound change to the social order; the third phase being the contemporary one, in which the divergent arms of the capital-focused Left and the cultural-focused Left 
have re-converged to challenge neoliberalism—as seen within the AGM and the WSF.

In the third and fourth chapters I will explore these narratives of change, challenge, and the emerging character of the Left within the New Zealand context. I am seeking to examine the fit between the theoretical literature and the experiences of activists involved in the contemporary New Zealand Left. As a prelude to this I will turn to the New Zealand literature on the Left and social movements, in the next chapter, in order to think through the specificities characteristic of the New Zealand context, and in later chapters to explore both the global and New Zealand literature. 


\section{A Brief History of the Left in New}

\section{Zealand}

The New Zealand experience both conforms with and diverges in some fundamental ways from the arguments developed in the first chapter. The first intensive phase of the Left was virtually non-existent here. The energies fuelling antisystemic movements elsewhere were absorbed into the state particularly early in New Zealand. While there was substantial Maori resistance to colonialism, the state had effectively repressed this by the close of the $19^{\text {th }}$ century. New Zealand's Left did pass through the second intensive phase. As elsewhere, the Vietnam War was a radicalising force. A New Left arose here with its energies dispersed through various new social movements. The most prominent of these-the peace movement, the environmental movement, the anti-apartheid movement, the Maori protest movement and the women's movement-will be explored in some detail in this chapter. This shows that while these movements shared many trends with those overseas, there was a more pronounced predilection here for direct involvement within the state form-mostly through the Labour Party, while given negative impetus to act by National.

As shown in the first chapter, the rise of the New Left here cannot be separated from considerations of the onset of neoliberalism, which has been particularly pronounced in this country. This is partially due to its introduction by Labour, a party that had frequently adopted and adapted the issues raised by new social movements. The predilection of sections of the New Zealand New Left to align with Labour caught them off guard when the party swerved to the Right.

From this narrative of the Left and social movements in New Zealand examples of successful social movement campaigns in the 1960s and 70s emerge. These appeared to be successful due to their ability to attract and mobilise a wider public, and to utilise a wide range of tactics. The tactics and issues of this era, set against the more general narrative of this chapter, will be used to foreground explorations of the contemporary Left in New Zealand in chapters three and four. At the close of this chapter an outline of 
the methodology applied to subsequent chapters will be given.

\section{From Early Settlement and its Discontents to Labour in the 1950s}

Colonial history is the point from which to depart when seeking to understand what is particular to the New Zealand context. Early settlers saw New Zealand as a land of great promise, "but the presence of a hostile race retarded progress," the solution being the Land Wars (Hutchinson 1916: 3). A paradigmatic case of the mindset fuelling the Land Wars can be seen in the story of Parihaka in Taranaki, where, as elsewhere in New Zealand, violence between settlers and Maori was used as a justification by the government to confiscate land, often from those who were not even involved in skirmishes (Locke 1992). Novel forms of protest and direct action to oppose the government were developed at Parihaka, such as the ploughing and cultivating of confiscated land, building fences across government roads and pulling out surveyors' pegs (Scott 1987).

The government responded to this peaceful protest forcefully. A militia was dispatched-with ranks swollen by settlers smarting from the impact of the 1870s depression and eager for free land—who, after raping and looting razed the village (Scott 1987). Confiscated land went to Pakeha settlers, and the mass protest marches led by Te Whiti (one of Parihaka's charismatic leaders) through the area, while again a novel tactic, came to no avail (Sinclair 1973). However, the example of Parihaka has stretched through the years to inspire later generations of protesters, such as James K. Baxter (Millar 2005) and founding members of Nga Tamatoa (Scott 2004)_ensuring that Maori resistance to colonisation has become a long standing feature of the New Zealand political landscape.

While anti-systemic movements were gaining impetus and consolidating themselves from the mid-19th century into the early $20^{\text {th }}$ century elsewhere in the world, particularly the labour movement within Europe, New Zealand was in the early days of settlement. There was little by way of intensive industry, with the country behind mostly agrarian. Consequently there was no major early labour movement here, although there were early assertions of workers' rights, with a campaign for the eight-hour day taking place as early as 1840 (Roth 1974). The Old Left (as aligned with the labour movement) in Europe had forged its identity, above all, through conflicts with liberals who bitterly resisted democratic citizenship-tied as this was to the possession of property (Eley 2002). Such tensions do not appear to have been so prominent in early New Zealand. 
Instead, what existed of an early labour movement in New Zealand came to a compromise with liberals, and by extension capital. Foregrounding this compromise was the country's early drift towards semi-feudalism under a few wealthy landholders, and the limited industrial development based on cheap labour due to the 1870 s depression. The inequalities settlers had sought to leave behind were being reproduced here. A Liberal party was formed to oppose these trends. It was composed of an alliance of trade union activists, middle-class intellectuals and the representatives of small farmers and business owners. Upon winning the 1890 election they initiated a "revolution," one that saw the co-operation of capital and labour under progressive state intervention (Trotter 2007) along with the early development of a welfare state. At a time of great labour unrest in Europe, commentators saw New Zealand as a political and sociological laboratory (Hutchinson 1916) where a unique form of "socialism," practical rather than ideological, was emerging (Lee 1938). This "socialist" approach saw most unions enmeshed within systems of industrial conciliation and arbitration that helped to stabilise the state (Hickey 1980). Leftist critics saw the country's 'socialism' as a progressive liberalism which used the state to control the working-class (Moloney 2002). Nevertheless, the progressiveness of the state diffused the unrest was associated with stimulating anti-systemic movements elsewhere in the world at this time.

A more radical Left did arise within the country — the first sign being a group cultivating ties with the First International in 1871 (Bendien 1980) —and came to converge around the notion of 'One Big Union' in 1912. This process was driven by the Federation of Labour (the 'Red Feds') who were modelled on the Industrial Workers of the World and who eschewed political activity, believing trade unionism would build "the structure of the new society in the shell of the old" (Sinclair 1973: 202). Despite the Red Feds strong anarchist tendencies (Boraman 2007) the tensions between Marxists and anarchists did not seem as pronounced as elsewhere. This united Left front was met head on with the power of the state under the conservative Prime Minister William Masseywho used a degree of force not seen since the Land Wars (Sinclair 1973) and brought the country to the brink of civil war (King 2003).

The first major confrontation was the Waihi miners' strike of 1912 where strike breakers, under police protection, lynched and killed a miner (Trotter 2007). The following year saw the 'great strike,' in which striking miners and waterside workers, backed by the Red Fed's, met with 'Massey's Cossacks'-a volunteer mounted 
constabulary under the protection of the armed forces (Dunstall 2002)—who broke the back of the union movement and saw its leaders jailed or exiled (Derby 2007).

Massey used fear of the Bolshevik revolution as pretence for censoring left wing material-jailing Leftists for importing books freely available only years before. New Zealand was the only country in the world banning such literature (Bendien 1980). An emergent peace movement was also violently repressed at this time, with conscientious objectors facing torture and death threats (Clements 1988) - treatment that, as with censorship, was the harshest meted out in the Commonwealth (Locke 1992).

Within Parliament a newly formed Labour Party stridently opposed wartime conscription. The Labour party was formed from a conglomeration of left wing groups in 1916 as a platform for union representation in Parliament (Bendien 1980). By the time of WWII Labour was in power, yet Leftist groups still found themselves harassed by censorship laws (Horton 1976). Complaints were also forthcoming from the waterfront, where it was held the War and talk of 'national interests' were being used to suppress the more radical elements of the trade union movement (Barnes 1998). That this happened under Labour was, for many on the Left, a bitter blow_as too was the party's backing of peacetime conscription following the war (Basset 1972). By this time the party's founding Marxist objectives had dropped away (Wood 2004). But to its credit the Labour Party built the most comprehensive social welfare state in the West during its first term of government (1935-49) (Sinclair 1973).

The extent of Labour's turn from the Left has been portrayed by some as the pragmatic price of power (Trotter 2007) and can also be attributed to shifting social climes, with the party following a similar trajectory to overseas reformist social democrat parties. New Zealanders in the 1950s were characterised as politically and philosophically conservative, materially focused, and disenchanted with the elderly and tired Labour leadership (King 2003). Labour could not develop radical policies and hope to regain power. Especially with the country entering its own 'McCarthy era' under Keith Holyoake's National Party, who used the Official Secrets Act of 1951 to harass Leftists (McNeish 2007).

Unrest was rising. The radical Waterside Workers Union (WWU) broke away from the Labour aligned Federation of Labour, founding the rival Trade Union Congress (Belich 2001), while the media fanned fears of Soviet led 'communists' on the waterfront (Bassett 1972). When a strike broke out in 1951 involving 25000 workers the state 
deployed great strength to break it, with peaceful protests meeting police violence (Scott 1952). The Right held that militant unionists had to be stopped from wrecking the economy, while the Left saw conservatives seeking to reassert political and economic control following a long period of Labour governance (Belich 2001). Whatever the motives of the state, after holding out for five months militant unionism was dealt a blow it was not to recover from until the 1970s.

With the strike of 1951 quashed, the 1950s stretched lazily into the 1960s for most of New Zealand. The period is presented as one of economic and social stability. Optimism and prosperity reigned. Men and women knew their places. The myth of an egalitarian and harmonious society wrapped itself tightly around social relations (Le Heron 1996). Materialism abounded, with good health and the acquisition of possessions at the forefront of most people's minds (Sinclair 1973). Industrial relations remained quiet following National's waterfront victory, and it was not until the 1960s that radicalism re-emerged in the country (Fyson 1972) and threatened New Zealand's 'Old Left.'

As shown, New Zealand's Old Left had been incorporated earlier than elsewhere into the state form following the 'revolution' initiated by the Liberal Party in 1890. A more radical movement from the Left did arise in the country early in the $20^{\text {th }}$ century, one centered on unions, which met violent state repression under conservative rule. The divergence between anarchists and Marxists over the validity of the state form-which I have as the first intensive phase of the Left-was not pronounced here and Socialism was largely dominant. This is seen in the formation of the Labour Party, which included elements of the more radical Left, and carried labour struggles into the state form. Like social democratic parties elsewhere it did not "transform the world," although it did build a comprehensive welfare state. Overall, it can be seen that from early in the country's history, voices from the Left have generally been diverted into the state form, while any radical fringe was repeatedly crushed by force. While the first intensive phase of the Left was not pronounced, the second intensive phase did leave its indelible mark upon New Zealand's Left.

\section{The Turn-New Zealand in the 1960s}

As was the case elsewhere in the world, the 1960s represented a turning point for New Zealand society. James K. Baxter characterised it as a period in which "the young [took] 
on their backs the guilt of a history which their elders tried to bury," with demonstrations and protests being an effort to regain communal sanity, following the long displacement of guilt over the corpses of the Land Wars (Baxter 1971: 18). The young challenged society's myths, broke oppressive norms and shouted with new voices into the repressive silence reigning in 'God's Own.' As was the case elsewhere, the Left fragmented into new social movements (Quayle 1984).

A New Left sought to move beyond the authoritative and bureaucratic Old Left processes associated with Labour, the Communist Party of New Zealand (CPNZ) and trade union bureaucracy (Boraman 2007). The tired reformist Labour Party was seen as antithetical to the new generation's values. Little separated Labour from the conservative National party: both had the same economic goals, were concerned with full employment and supported the US's battle against communism (Boraman 2002). Society as a whole was seen to be profoundly conservative, lacking serious concern for civil liberties and readily deferring to authority (Powles 1975). Dissent was often met with violence from the public (Shadbolt 1971). Further, New Zealand was a country grounded on rigid gender differentiation. The national identity was a male one (Sinclair 1986). A new generation of New Zealanders who had come of age in an affluent society desperately sought to shake off the constraints that came with it- the "smug and conservative" country with its "perverse sense of national pride" had to be challenged (Jesson 1976). As elsewhere in the world, students led the charge (Fyson 1972).

The New Left in New Zealand differed to no great extent from elsewhere in the West-a reason for this being the internationalist nature of the New Left. Just as the importation of radical literature vitalised the radical Left earlier in the century (Derby 2007), the impact of films, music and literature on the emergence of the New Left cannot be overlooked here. As elsewhere the anarchist spirit played a prominent role within this emergent scene (Boraman 2007). A feature of New Zealand's New Left that is, to some degree, unique was the lack of a sharp associative divergence between its groups and those of the Old Left (Boraman 2002). Also, as will be shown, the causes championed by New Left were deftly incorporated into the Labour Party. There was an almost cyclic nature to protest waves in the country between the late 1960s and early 1980s-National governments would provoke protest, the aims of which Labour would then incorporate into policy. While the more radical edge of the protest movement did not necessarily wish to see such reformist outcomes, the majority of that movement seemed to be 
composed largely of middle class liberals (Rata 1996) who were happy to see reform.

The ideas of the New Left in New Zealand, as elsewhere in the world (as shown in Chapter One) were expressed through new social movements. Some of the most important and influential social movements to have emerged were the peace movement, the anti-apartheid movement, the environmental movement, the Maori protest movement and the women's movement.

In order to gain an understanding of the NZ Left and new social movements, I will consider the emergence of these movements and the issues that shaped them. By comparing the NZ experience with the international one described in Chapter One I hope to pave the way for an examination of the contemporary Left in New Zealand in chapters three and four.

\section{The Peace Movement}

Foremost amongst the factors politicising a new generation of protesters, and therefore adding impetus to other movements within the country, was the peace movement's opposition to the Vietnam War-at the forefront of which was a radicalised student body (Fyson 1972). The peace movement had been slowly building from the late 1950s, chiefly around opposition to nuclear weapons, an initiative of the British Campaign for Nuclear Disarmament (CND), which was seen here as "vaguely subversive and definitely radical" (Clements 1988: 99). Such radical connotations disappeared when the incoming second Labour government (1957) adopted an oppositional position against nuclear weapons. But the movement again gained a radical edge when National, which supported the nuclear option, was re-elected in 1960 (Hadley 2005). In response CND increased their activities and in the process revived street protest in New Zealand (Fyson 1972). The wider peace movement intensified when National sent New Zealanders to support the US in Vietnam in 1964. At this point the growing peace movement is seen to have come to emulate the development of the movement in the US (Clements 1988).

As was the case elsewhere in the world, the pivotal year of 1968 saw increased radicalisation within New Zealand (Fyson 1972). Historian Kevin Clements considers the war to have "precipitated a convulsion of consciousness," with many concerned about the country's international standing. It imprinted "itself negatively on intellectuals, trade unions, students, and the Labour Party-it challenged New Zealanders' positive view of themselves" (Clements 1988: 104). When these aggrieved parties took their cause to the 
streets they were met, as past protests had been, with a hostile police force under conservative government rule (Locke 1992). Protest groups' houses were raided and peaceful protests met police violence (Shadbolt 1971; Locke 1992).

When the third Labour government came to power in 1972 it promptly withdrew troops from Vietnam. It is revealing of the nature of the protest movement here that actions were intensified after the withdrawal; an anti war mobilisation taking place months later attracted 30,000 people (Fyson 1972). It was a protest movement unconfined by national boundaries - a trend correlating with assertions made in Chapter One about the internationalist nature of the New Left, and some might argue of the Old Left.

However the New Zealand peace movement was not without its local focusNational's intention in 1968 to allow the US to build a military installation in the Southern Alps drew heated protest (Fyson 1972); as did other planned installations in proceeding years (Locke 1992; Wilkes 1973). Anti-base campaigners rejected the US military machine and the nuclear ramifications that came with it (Robie 1986). Along with the bases, French nuclear tests in the Pacific and nuclear ship visits became the target of protest-protest that was supported by the Labour government under Norman Kirk (Hadley 2005). When National came to power in 1975 under Muldoon it opened harbours to nuclear visits (Newnham 1986) and in doing so initiated a new phase of protest activity. The Peace Squadron was formed in Auckland, who deployed passive resistance tactics on the water-using a flotilla to block the harbour-to oppose visits from nuclear vessels (seven visits were opposed between 1976 and 1983) with concomitant protests on land. Despite the non-violent nature of the protests they were met with violence from the state (Newnham 1986).

By 1984, with escalating numbers of nuclear ship visits under National, it was feared the country was being 'softened up' for the eventual establishment of a US naval base in New Zealand. The protest effort increased and 'prestige crews,' drawn from the ranks of 'respectable society,' saw local body and opposition politicians taking an active role in protests (Newnham 1986).

Alongside the protests taking place around the Peace Squadron, a massive initiative was underway to develop 'nuclear free zones.' By 1984 65\% of New Zealanders lived within 94 self declared nuclear free zones, leading to increased pressure on the government to declare the whole country nuclear free (Clements 1988). These zones were the result of mass organised petition drives by committed peace activists 
throughout the country (Foote 1997). Clements attributes the success of the anti-nuclear initiative to the diverse and heterogeneous composition of the peace movement; the high degree of support from professionals and the middleclass is seen as exorcising the 'communist bogey' from the peace movement (Clements 1988).

This ability (or desire) to mobilise wider society—or the 'masses'—will be considered in light of contemporary movements in proceeding chapters. Further, the manner in which the peace movement was able to mobilise so many people and sustain such large protests to achieve the outcomes it did, will be contrasted in Chapter Four with the current virtual absence of a mass-protest movement.

\section{The Environmental Movement}

Alongside the growth of the peace movement, environmentalism was an emerging force in the late 1960s and early 70s. The first successful large scale environmental campaign here in 1970, "Save Manapouri," shows how the more 'conservative' elements of society were just as likely to be mobilised around environmental issues as 'radical' ones; as with other social movements of the time it permanently changed public perceptions. The campaign employed marches, public meetings, media publicity, brochures, rallies, letter writing, submissions and, what was for the time, a record breaking petition of 265,000 signatures (Peat 1994). It also had its radical elements and boasts were made by one group that "it could knock out 100 pylons in the West-Arm Invercargill transmission line in 30 minutes" (Peat 1994: 61). Overall, the campaign's success would seem to be due to the diverse range of tactics and support it was able to mobilise.

A more radical environmental movement was developing internationally at the time, loosely based around the philosophy of deep ecology (Castells 2005b). Within New Zealand, this followed the New Left drift towards incorporating politics into everyday life, with environmental consciousness finding expression through a "return to the land," often into communes-a process supported by the Kirk government's Ohu Ohu scheme, which allotted land for founding communes in 1973 (Sargisson and Sargent 2004). This scheme provided a space to enact the utopian urges fuelling the revolutionary visions of some within the New Left who sought to construct models for an alternative social order-the outcomes of such initiatives will be considered in Chapter Four.

The environmental movement in New Zealand had perhaps one of its most cogent expressions in the 1970s through the Values Party—the first national Green Party 
in the world (Dann 2000). Tony Brunt's manifesto for Values, A Blueprint for Our Future, released in 1972, presented in an accessible format the way in which social justice issues were intertwined with environmental sustainability. Within a very short period of time a large body of people coalesced around Values (by 1975 there were close to 30 branches of the party around the country). I argue that Values embodies many of the themes attributed to the second intensive transitive period of the Left explored within the first chapter, while also displaying New Zealand's predilection for pursuing social justice issues through the state. This can be seen within the 1975 Manifesto, Beyond Tomorrow, which finds inspiration for what is possible in the previous examples of the Liberal government of 1890, and the Labour government of 1935 (Values 1975).

Values contained all the vital energies associated with the rise of the New Left, although it was not explicitly of the 'Left' (Fitzsimmons 2008), and its composition very much reflected the era's penchant for movement politics (Dann 2000). When interviewed for this thesis Catherine Benland (previously Wilson) considered Values, in 1972, to have attracted "every idealist of every kind," some with anarchist leanings who pushed for Values to be a "movement" rather than a party, opposed having leaders, and questioned the notion of running for parliament. Despite such internal misgivings, Values adopted a more or less conventional party form in 1974, leading some to follow a pragmatic approach to politics, which conflicted with the 'idealists' within the party. Others however pushed for a more 'hard-line,' 'doctrinaire' and 'bureaucratic' approach which, for Benland, "smacked of centralised government;" an approach at odds with Values' emphasis on decentralisation (Values 1975). That three such approaches vied to direct the course of Values is paradigmatic, to my eyes, of the diffuse ideologies and energies of the period.

Despite Values' decline in the late 1970s it left a lasting legacy. It influenced other parties who, for instance, copied Values' popular format for manifestos. Further, Values inspired overseas Green Parties (Dann 2000) and was a direct forerunner of the contemporary Green Party (Fitzsimmons 2008). In this sense Values can be attributed with having played an important role in institutionalising environmental awareness in New Zealand politics (if only in other parties' rhetoric).

Values provides an example of the way in which the energy of the New Left and social movements became absorbed into national politics. While Labour had been adept at absorbing earlier unrest around nuclear and anti-apartheid issues Values stimulated 
them to go further. While members of Values were often critical of the parliamentary process, and were in fact deeply concerned about the health of democracy in the country (Values 1978), the fact that they chose to participate in these systems in the hope of reforming them shows that radicalism rarely extended to extra-parliamentary revolutionary activity in this country—while the form of the state is critiqued, its existence rarely is.

\section{The Anti-Apartheid Movement}

One of the most radical protest movements in New Zealand's history developed to oppose playing rugby with the South Africa's Springbok national rugby team during that country's apartheid era (Pringle 2002). Since the success of the 'Originals' tour of the UK in 1905, rugby has been one of the pillars of New Zealand's national identity. The antiapartheid protests against playing rugby with the Springboks raised awkward questions around New Zealand's own underlying racism (Newnham 1989) and challenged the country's egalitarian myths. As remarked by one protester: "New Zealanders like to consider themselves racially non-prejudiced. Our job was to keep reminding them in every way possible of the enormous contradiction" (Shadbolt 1971: 160). A long cycle of protests culminated in 'The Tour' of 1981, which led to a mass confrontation between Police and protesters on New Zealand streets.

While the anti-apartheid movement is generally seen as emerging in the late 1960s, protest dates back to a South African tour in 1921 (Richards 1999). A proposed All Black tour of South Africa in 1960, from which Maori players were excluded, saw wide public outcry. A petition was signed by 153,000 people and protesters took to the streets-leading to what was considered the revitalisation of protest after the slumber of the 1950s (Fyson 1973). Momentum from this wave of protests led to the cancellation of a proposed tour in 1967. Another tour in 1970 included Maori as 'honorary whites,' but opposition continued against the very notion of apartheid (Harris 2004).

Simultaneous with the escalating opposition to the Vietnam War, opposition to apartheid fuelled the radicalisation and internationalisation of youth (Fyson 1973). The groups Citizens Advice for Racial Equality (CARE-founded 1964) and Halt All Racist Tours (HART_founded 1969) became valuable organs for raising awareness of racism, and how to oppose it. CARE held large public meetings, hosted international speakers and gave talks at schools to attract wider support for anti-apartheid protest. Networks 
were quickly developed with academics, Maori activists, church leaders, student organisations, some trade unions and a number of Labour MPs (Newnham 1989). Camps were also run to instruct protesters in non-violent resistance. HART-which was "rebellious, internationalist, confident, [and] optimistic" (Richards 1999)—also developed successful non-violent means of disrupting tours. Like CARE, it boasted a diverse membership with active members from the churches, trade unions, United Nations associations, Maori activists, students and representatives from CARE-it also developed links with African governments (Richards 1999).

HART and CARE, along with other groups, presented a formidable front and the promise of civil disobedience when a Springbok tour of New Zealand was planned in 1973. This, along with a groundswell of public opinion, saw Labour PM Norman Kirk reluctantly cancel the tour. Following a now familiar pattern, Labour's concessions to protest movements were overturned by Muldoon's National government in 1975 when sports contacts with South Africa were resumed (Templeton 1998). This led to increased protest against tours, which reached an apogee in 1981, when over 150,000 people protested in 28 centres over an eight week period. Early in the tour protesters invaded pitches and met with violence from fans. Protests intensified when riot police began to use new, more violent tactics against protesters. This led to "running battles between protesters, the police and rugby fans... [making it look] as if New Zealand was on the brink of civil war" (Harris 2004: 108). More than 2000 protesters were arrested while the tour took place at the cost of the country's international standing and internal social harmony (Templeton 1998).

The anti-tour protest movement proved fertile ground for developing both the Maori and women's movements. Protest gave women the opportunity to express their hostility to the male practices and values embodied in, and supported through, the dominance of rugby in New Zealand culture (James and Saville-Smith 1994). Also, the early tour protests in the 1960s heralded the first rumblings of race relations disturbance in the ears of the wider Pakeha community. Opposition to these tours nurtured elements of the Maori protest movement (Sharp 1997). Furthermore, the collaboration between Maori protesters and Pakeha led to a spike in active Pakeha support at Waitangi protests (Harris 2004). Or, as Bruce Jesson (2005a) notes, Maori radicals shamed the antiapartheid movement into "tidying up our own back yard," leading groups such as HART to directly address local issues. 
Donna Awatere (1984) attributed the tour with showing New Zealanders a "creeping fascism," which in fact had always been present-as expressed in the separate development for Maori people and a national white hatred for Maori-forcing the country to face its own apartheid, in which Maori were held back by "white hatred". While this overlooks many Pakeha initiatives to try to address such issues (Archie 1995) it is true that the tours forced New Zealand to address its own race relations. The movement also radicalised a large number of middleclass New Zealanders (Clements 1988). However, Bruce Jesson (2005a) warned against conflating this with a radical Left, as the middleclass was never so much radically 'Left,' as radically liberal.

The anti-apartheid movement, the Save Manapouri campaign and the anti-nuclear movement all succeeded in generating support from the wider public, building coalitions and networks for mass support that extended beyond isolated protests. As will be shown in chapters three and four contemporary movements struggle to find such wide and sustained support. The role of the middle-class in protest movements proves to be an ongoing concern, and the question will be posed: has the neoliberal tide swept away the last vestiges of mass concern for social justice?

\section{The Maori Protest Movement}

One of the myths widely propagated in New Zealand is that it is, and always has been, a racially harmonious country. It was easy to propagate this myth from the early to mid twentieth century when Maori lived predominantly in the country-where it can be imagined they remained, for most Pakeha, an intriguing element of the country's fauna. With the hostile years of the Land Wars behind them, the government pursued an assimilative policy towards Maori from the late 19th century (although in 1935 Labour formed the Department of Maori Affairs to address specific economic and social issues) (Spoonley 1993). Race relations were generally not an issue in the country until the Maori urban drift became consolidated in the 1960-70s (10\% of Maori lived in cities in 1936, and 76 percent by 1976).

By the 1960s the common story of the two races existing in mutual respect, cooperation and integration was being revealed as a fiction (Sharp 1997). This was no surprise to Maori who had long faced institutional and petty forms of racism. Through the 1950s and 60s there were reports that Maori and Pacific Islanders faced restricted 
access to restaurants, hotels, cinemas, barbers and accommodation, as well as being saddled with negative stereotypes (Harris 2004). Racial discrimination also affected employment (Newnham 1989). A widely reported incident of the time, in which a Maori doctor was refused service by a racist publican, led to a public outcry in which two dominant voices could be heard: that of Pakehas dismayed that such discrimination took place, and Maori exasperation over such obliviousness to racism (Newnham 1989). This lack of awareness is attributed to an inability amongst most Pakeha to recognise the long standing impacts of assimilative public policy upon Maori culture, language and identity; a lack of visible hostility from Maori; and such practices as intermarriage (Vasil 2000). What was perceived as racial harmony was racial and cultural hegemony.

The Left within New Zealand provided few means for Maori to challenge this hegemony. While Labour had taken some steps to address issues for Maori since the 1930s, it had focused mostly on addressing symptoms rather than causes. For the more radical elements of the Old Left Maori were generally only seen as potential allies in class struggle (Taylor 2002). While New Left organisations like HART began to address issues of racism in the late 1960s, it was not until Maori consolidated their own protest movement that the issues they faced could be effectively addressed.

This movement was born, in part, from urban Maori discontent over their deprivation relative to Pakeha (Sharp 1997). They met capital's demand for cheap labour in the unskilled/low skilled sectors of industry, where they were placed within a superiority/inferiority schema classified by race (Spoonley 1993). Such negative employment relations, along with petty racism and police harassment (Spoonley 1993) radicalised a growing proportion of young urban Maori. The heat of racism and inequality ignited the will to protest in a form bypassing the more staid forms of redress followed by Maori in the past (Sharp 1997).

A radical movement began to emerge in the late 1960s, while a more conservative arm of Maori activism, focussed on issues like health and education, sought change through influencing government policy (Walker 1983). The new radical arm of protest felt the government was failing to address Maori aspirations (Harris 2004). The two arms addressed similar issues_-implementing the Treaty of Waitangi, reviving the Maori language, Maori sovereignty, the land and separate Maori identity (mana motuhake)—but the radical arm revived forms of action not used by Maori since the 19th century; such as pickets, occupations, demonstrations and hikoi. Despite this historical continuity, Maori 
activism was very much part of the 'social movement industry' of the 1960s (Harris 2004). Consistent with other movements, the radical arm had an international outlook. Links were developed with indigenous peoples in North America (Sharp 1997), and tactics and rhetoric from the Black Power movement in America were also adopted (although less by Maori than by the Polynesian Panthers in New Zealand (Anae 2006)).

The new arm of Maori protest was led by young urban figures who sought to transform their culture to escape the alienating tendencies of urban life (Walker 1983). Early groups, such as the Maori Organisation on Human Rights (MOOHR) had reached the conclusion by 1971 that Maori needed to seek self-determination-maintaining that racial tension would continue as long as Maori felt oppressed by Pakeha-dominated governments (Walker 1983). A conference of young Maori leaders in 1970 saw the birth of Nga Tamatoa ('the young warriors') who, among other achievements, were instrumental in raising Maori consciousness around land issues. Their instigation of nationwide protest on Waitangi Day was an important development which fed into the Maori land rights movement which marched on Parliament in 1975 (Walker 1992). At 300,000 strong the Land March represented the welding of Maori grievances over land into a cohesive movement (Walker 1983), echoing Te Whiti's marches of a century before. The land rights movement saw further expression in land occupations, most notably at Bastion Point in 1977 where 507 days of protest were ended by 600 police officers in the "most powerful show of police force since the dismemberment of Parihaka" (Walker 1983: 8). Rather than crushing the movement this action under the Muldoon government radicalised other Maori (Vasil 2000), with further occupations taking place in Raglan and Pakaitore (in Wanganui).

But the most constant focus of contention for Maori has been the Treaty of Waitangi, which the protest movement can take credit for retrieving from the "dustbin of history" and reminding the nation to take its promises to Maori seriously (Harris 2004). One of the more radical voices to emerge in the Treaty debate taking place in the early 1980s was that of Donna Awatere.

In her influential work Maori Sovereignty Awatere (1984) held that the Maori protest movement's success resulted from tapping into a "ready made radical constituency." She was dismissive of collaboration with Pakeha, whose protest movements she considered bounded by Western capitalist culture. This conclusion reflected her passage through the women's movement (Melbourne 1995), which she saw 
as embodying the class and race ambitions of white bourgeois women (Awatere 1984). The women's movement is considered to have suffered from the same malaise as other white protest movements: confinement within a totalising white culture. Pakehas' "individualist birth heritage" is seen to lead to a Left that is "worse than fragmented. It is the dust which unhappily drifts between the trade unions and the student unions, subject to every whim of wind and puff of change" (Awatere 1984: 50). Such sentiments hit "like a shock wave," writes Bruce Jesson, "hardly a group or movement was left unshaken" (Jesson 2005b: 133). The liberal sections of New Zealand society, who bulked out the protest ranks, struggled with the sovereignty debate since it was aimed at the prevailing liberal orthodoxy; while more orthodox Leftist factions retreated to debating the overlooked class aspects of the issue to try and change the topic. Yet, argued Jesson, a closer reading would find within Maori Sovereignty an offer of alliance-albeit a Maori led one. Alliances were not forthcoming and the movement appears to have developed its own approach to change.

Maori protest derives strength from its roots in racial identity. It cut through the myth of racial harmony within the country. The Left here had developed no strong ties with Maori, and it was the upsurge of the Maori protest movement, as part of the 'social movement industry' of the time, that contributed to a diffusion of protest energy. The radical arguments put forward by Awatere further stimulated ruptures within the community.

She was dismissive of collaboration with Pakeha, whom she regarded as overtly individualistic. The resultant controversy challenged the liberal assumptions of many of those within the Pakeha protest movement. The sense of guilt felt by Pakeha about their colonial heritage did not prove a constructive emotion for facilitating meaningful change. It was the impact of the Maori sovereignty debate, and its repercussions on Pakeha protest that particularises elements of the New Zealand Left's progression-and intensifies trends present within what I have characterised elsewhere as the second intensive transitive period of the Left.

The failure to produce constructive alliances founded on an understanding of the uniqueness of New Zealand's situation, and which addressed the longstanding violence underpinning the state, created an aimlessness amongst an increasingly factionalised New Left at the onset of the 1980s. The Maori protest movement continued its impetus into the 1980s, leaving behind those it had co-existed with in the 
1970s. The problems faced by the movements which emerged from the New Left are most pronounced within the women's movement.

\section{The Women's Movement}

New Zealand Pakeha society has a patriarchal history with the "worst elements of English patriarchy imported here" (Sutch 1973: 12). The majority of the early settlers were males and inclined to a 'larrikinism' at odds with the respectable elements of society (Phillips 1980). When the suffragette movement (or 'first wave' feminism) emerged here it was seen to bring "refinement, morality and culture" to New Zealand, with the female vote balancing out a sordid male population (Phillips 1980). Consequently, when women's suffrage was achieved here in 1893, a world first, it was seen as a victory for conservatives as much as for liberals (Hall 2003). While winning the vote was a great first step, the movement ground to a halt without addressing the complexity of women's needs and priorities (Shields 1993).

It was not until the 1970s, with the emergence of 'second wave' feminism, that such women's issues were addressed. As with other movements of the time, feminism challenged New Zealand's egalitarian myths. Echoing arguments heard overseas it held women were oppressed by the dominant cultural institutions (MaCaskill 1976), trapped in stereotypical roles and penalised for deviating from norms (Brooker et al 1976). The 'progressive' movements of the New Left still assigned women subservient roles, so new networks were developed for furthering women's causes (Coney 1993). Feminist conferences, largely consisting of women connected with existing left wing organisations, were held throughout the country in the early 1970s (Dann 1985); the aim being to liberate women from the "deeply embedded image of their own inferiority" (Women's Liberation Auckland 1993: 164). Issues connected to women's employment, the control of their bodies, public portrayal of women, marriage structures, and the legal and education systems were raised by the moment (Dann 1985; Else and Noonan 1993).

As was the case overseas Innovative protest tactics were used to address these issues. The first widely reported protest in New Zealand, in 1971, involved a mock funeral procession through Albert Park to the statue of Queen Victoria; the message being that there had been no improvement in gender equality since Victoria's reign (Kedgley 1985). More regular tactics, such as mass letter writing, lobbying and street protests were not discarded, but potency seemed to lie within what was new and 
particular to the movement-like the consciousness raising groups run throughout the country. Broadsheet (a journal with a nationwide readership), along with other publications, also gave strength to the movement (Rosier 1992).

Unity in action and shared goals characterised the movement in its early days, but this began to rupture in the mid 1970s. The "radical women's libbers" who founded the movement came to be dominated by liberal (i.e. more state focussed) feminists - who in turn drew critiques from Maori and lesbian feminists (Herd 2005). The movement began to splinter from within while simultaneously facing increasing external backlash and declining numbers. By 1979 it had many workers and volunteers operating facilities such as women's refuges, along with intellectuals addressing gender issues and a separatist wing seeking to withdraw from the male world-but it lacked support from large numbers of ordinary women (Gillespie 1980). That National MP Marilyn Waring was the public face of the movement indicated it had also drifted from its Leftist origins (Coney 1993). Jesson (2005 e) saw the ascendancy of such figures as Waring as indicative of the manner in which women from other organisations labelled themselves 'feminist' to divert the movement towards their own ends.

The final throes of the movement (as a cohesive force) arguably happened at the Women's Liberation Conference at Piha in 1979. Representatives of the increasingly divergent strands of feminism attended the conference: communists, Maori nationalists, lesbian collectives, non-aligned radical feminists and Marxist feminists. Unsurprisingly they clashed; points previously of little importance became major issues. Heated arguments took place between lesbian and heterosexual feminists-heterosexuals were derided for "sleeping with the enemy" and being tarnished by male thought (Jones and Guy 1993). The conference was a debacle.

However, it proved fruitful for Maori feminists who asserted the importance of their identity as Maori, and called attention to issues affirming this identity—such as land, language and colonialism (Dann 1985; Du Pleiss and Alice 1998). Maori women established their own forums and networked with indigenous peoples around the Pacific (Hulkyard-Harawira and Boanas 1993). While Awatere argued against Maori being sidetracked by feminism, Coney saw within Awatere's approach a strategy feminism could learn from: its narrow focus needed to expand to attack racism, sexism and capitalism through building coalitions with other movements, using the momentum gained from the anti-Springbok tour protests (Coney 1992). The moment passed, 
younger women chose to focus on careers and older women returned to "ordinary" life (Herd 2005).

The women's movement may not be dead to the extent that individuals still uphold its values (and organisations like Rape Crisis exist), but it is no longer a movement. Issues that attracted mass outrage from women in 1972 ceased to trouble them twenty years later (Coney 1993). The meteoritic rise of women into positions as government officials or administrators since the 1970s is seen, by Coney (1997), to have led to the creation of a small rightwards drifting elite of women who preside over a large group of struggling low income women. By default representation has fallen on the shoulders of these elite women, yet they shrug it off-no longer seeing gender as an issue-leaving the market to act as the sole vehicle of liberation (Coney 1997). Ironically, it was gains made by the women's movement that enabled the success of this female elite. Unquestioning adherence to the doctrines of individual achievement and the primacy of market forces, it is held, has sapped commitment to feminism, and other movements, so that there are no longer significant numbers of people to rally around important issues, thus leaving inequalities unresolved; this is considered to be true of all western cultures, including New Zealand (Rich 2005). The women's movement is argued to have drifted from its Leftist origins into a tacit acceptance of the neoliberal orderone that came about within this country under a Labour party which has also, arguably, moved from the Left.

\section{Labour, the Left, Neoliberalism}

The Labour Party had taken on a new lease of life in the early 1970s. While largely irrelevant throughout the 1960s-due to declining working class consciousness and an increased parliamentary focus-it benefited greatly from tapping into the country's changing political climate in the early 1970s (Jesson 2005c). Its victory under Kirk in 1973 was indicative of a radicalising country. Many of the activists at the spearhead of this change ended up becoming members of the party (Fyson 1973). For Jesson (2005d), the passage of these radicals into Labour was regrettable as they took up careers and moved into suburban life. While it was able to meet many of the protest generation's wishes Labour struggled to combat the economic crisis following the 1973 oil shock and lost the 1976 election to Robert Muldoon (King 2003).

Muldoon, and his "think big" approach to the economic crisis of the 1970s was 
the last gasp of Keynesianism within the country. While he sought to increase employment through public spending many of his schemes were mismanaged (King 2003). He met with increasing resistance from workers with industrial action increasing from 1968 onwards, having emerged from the hiatus following 1951 (Trotter 2007). Under Muldoon workers faced falling living standards and decreasing pay packetsstrike action increased in frequency while Muldoon sought to impose wage freezes to slow inflation (Boraman 2007). This industrial unrest and the actions of other social movements were met with violence from the state and conservative backlash. The country entered the 1980 s in a restive mood.

Labour was, once again, able to draw strength from the protest movements stirred up by National. As earlier, radicals like Tim Shadbolt were drawn into the party where they became "double reformists," as Jesson puts it, reforming the party "in the hope it will become a reformist party" (Jesson 2005c: 118). The party became dominated by intellectuals and lost touch with its working class origins. As elsewhere in the West, New Zealand in the 1970s had a declining majority group identifiable as, or identifying itself as, 'working class.' Further, as the mouthpiece for many of the voices found within the protest movements of the 1960s and 70s, which were both liberal and Leftist, Labour gained traction in a middle class concerned with the issues raised by these movements. Jesson (2005d) argues that the international perspective of such movements meant that the party, and the movements themselves, failed to adequately address national issues.

As a result, the Left in New Zealand was taken by surprise when the Fourth Labour Government initiated one of the most comprehensive neoliberal programmes ever carried out - a neoliberal 'revolution.' Roger Douglas and his followers within the party used the "crisis atmosphere" created by Muldoon's mismanagement of the country to push through reforms in the face of opposition from within and the Party and wider community (Quiggin 2001). This echoes international trends relating to the introduction of neoliberalism, where a state of crises is exploited to instigate economic changes the population does not want (Klein 2007). The changes initiated in New Zealand included extensive privatisation of state enterprises, the deregulation of the financial market and the phasing out of government subsidies in such areas as agriculture; later, under National, the welfare system was severely reduced (King 2003). For hard Right ideologues, the revolution is incomplete.

The hard Right still bemoans an overly cumbersome state apparatus, but in 
keeping with the theory of 'social strain' neoliberalism (Gamble 2006), the New Zealand government — under both National and more recently Labour- has permitted the market to dominate most aspects of daily life. During the speculative era of the 1980s the government always stepped in to 'pick up the tab' when risky private enterprise initiatives failed (Quiggin 2001). The government continues to rescue entities it had previously privatised, such as Air New Zealand and Tranz Rail. While it may still maintain a reduced welfare system the country also boasts one of the most open and business-friendly economies in the world (Taylor 2005). The elite has room to prosper while the lower orders' are stabilised by the State.

For commentators from the Left the neoliberal 'revolution' is a failed one. It promised that the country's structural adjustment programme would eliminate poverty and promote employment and social integration, but it has not delivered this as:

We live in a society founded on the suppression of Maori economic, political, cultural and spiritual self-determination, compounded by the policies of the present; a deeply divided society riven with growing economic inequality and poverty; a dual labour market that exploits structural unemployment to depress the costs of low skilled wage workers and rewards the entrepreneurial elite; a system of social support and services that fails to provide even a minimal safety net and places the blame on those forced to depend on the rapidly retreating state; a population which is alienated, insecure and disempowered by the imposition of a structural adjustment agenda about which they were never consulted and which they do not support (Kelsey and O’Brien 1995: 63).

Compounding this change is the manner in which the country is open to the flows of globalisation - to which there has been very little opposition, it is as if the population has been cowed by the assertion that there is no alternative (Jesson 1999).

Following Jesson's assertions that the protest movements in New Zealand were largely liberal in their outlook, it would seem there was little organised resistance to neoliberalism from the remnants of the New Left; although some hold there was resistance from other quarters. Kelsey (1995) holds that Rogernomics created an economically illiterate population that was apathetic and stunned. In her view the only significant resistance to New Zealand's neoliberal revolution came from Maori, especially through the growing strength of the tino rangatiratanga movement. Against this "myth of passivity" in the face of neoliberalism Toby Boraman presents a picture of an 
autonomous, mainly working class, resistance in the 1980s to early 90s. Among his examples are the rise of unemployment and poverty action groups, small rural community mobilisations against the closure of public amenities (schools, Post Offices etc.), student protests and a mass movement to oppose the Employment Contracts Act in 1991 (which was co-opted by unions) (Boraman 2005). Between these conflicting views as to the degree of resistance to neoliberalism, what can be seen is the absence of the dynamic sustained widespread movements seen through the 1960s and '70s-as will be explored in Chapter Three, Nicky Hager considers the advent of neoliberalism to have eroded the country's Left and activist circles, which raises questions as to the degree to which a committed community of campaigners is needed for pushing extra-parliamentary politics. Resistance to neoliberalism, as questionable as its history may be, will show itself to be a key concern in upcoming chapters.

\section{Interim Summary}

Contemporary New Zealand rests upon the legacy of violent colonialism and the repression of the more radical arm of the labour movement. As in other core countries (Wallerstein 2002) most of New Zealand's anti-systemic Left was led along a reformist path by the Labour Party-which, by the 1950s, was seen by the remnants of the revolutionary Left as little different from the conservative National Party. Following National's assault on the last show of radical trade union strength in 1951 the country entered a period of conservative stability stretching into the 1960s.

Towards the end of the 1960s a vibrant New Left arose here as elsewhere in the world-leading it to enter what I term the second intensive phase of the Left. From the New Left emerged the peace movement, the anti-apartheid movement, the environmental movement, the Maori protest movement and the women's movement. It would appear that the success of the first three listed above depended upon the ability to appeal to a wide constituency and to employ diverse tactics-as was the case with Save Manapouri and anti-nuclear campaigns. Middleclass support played a major part in these movements effectiveness; which meant these movements always had an overwhelmingly reformist leaning, with revolutionary rhetoric never extending beyond the fringe. The women's movement arguably, here as elsewhere, had the most impact on New Zealand society, but the many theoretical strands which developed within it saw it fracture, and the liberal individualist focus of some of these strands became aligned with the rise of 
neoliberalism. The Maori protest movement gained strength through the 1970s. The unifying aspects of race and shared grievances cut through the fractious elements of the New Left. For other social movements, an international focus came at the expense of national awareness. As a result little opposition could be found to combat Labour's neoliberal turn.

The Labour Party's relationship with these movements makes aspects of the New Zealand example unique; the party was able to rejuvenate itself through the 1960s by aligning itself with aspects of the new political generation. This in turn de-radicalised various movements, while antagonistic National policies had a radicalising effect. The cultural focus, and the close relations shared by much of the New Left generation with Labour, came at the expense of economic awareness. The fractured nature of much of the New Left, and the incorporation of parts of it into Labour, meant that Labour's neoliberal transformation faced little opposition. The strongest opposition came from the Maori protest movement, but it lacked wider alliances.

This brief history of social movements and the Left in New Zealand correlates with many of the international trends depicted within the first chapter. The challenge of the New Left and new social movements to the social democratic consensus led, in part, to restructuring and neoliberalism, globalisation and the political convergence of the major parties. The contemporary Left and social movements' response to these changes will be examined in upcoming chapters within a New Zealand context. Before these chapters, I will briefly attend to questions of methodology.

\section{Methodology}

To this point, my work has sought to develop an overview of the Left and social movements both internationally and within the New Zealand context. In the first chapter consideration was given to the three phases of the Left, along with the economic, theoretical and political transformations linked to these periods of change. Chapter One closed with a treatment and analysis of the contemporary third phase of the Left. In the present chapter I turned to the New Zealand context, looking for similarities to the material surveyed in Chapter One, but also at the specificities of the Left here. The following two chapters are concerned with the third intensive phase of the Left in New Zealand. The questions to be asked of this phase here are: first, are we actually in this phase? Second, if so, then what trends do we share with more general theorisations of 
this phase? And third, what, if anything, is unique about this third phase in New Zealand? In order to approach these broad questions the research I have conducted, following a rising trend in social movement literature (Maddison and Scalmer 2006; Shukaitis and Graeber 2007), approaches activists directly as a means of gaining knowledge.

My investigation of the New Zealand Left centres on relatively informal, face-toface, qualitative, in-person interviews (Shay 2002). Essentially, these interviews were concerned with the Lifeworld' of actors. Through entering this domain it was hoped a 'deeper' sense of the contemporary terrain of social movement actors and the Left would be uncovered. The Lifeworld is understood as that encountered in everyday life through direct and immediate experience (Kvale 1996). Interviews were a useful way of gaining entry to participants Lifeworld in order to develop a more substantive understanding of the topic (Warren 2002).

I chose an 'open-ended,' non-standardised approach for conducting interviews. In trying to understand the complex behaviour and views of participants I have, as much as possible, attempted to avoid any a priori categorisation that could limit my field of inquiry (Punch 2005). While preliminary criteria were employed in approaching interviewees, assumptions about their motives, history and forms of action were left behind as far as possible. Through letting participants speak for themselves it was hoped links and themes would emerge that may have otherwise been suppressed through overly structured interviews-participants were given 'freedom to roam' in order to avoid yes/no answers (Mann 1985). A problem identified with this approach is that the interviewer's biases may leak into the interview, especially when interpreting motives and trends within the research material (Silverman 2006). To help overcome this problem participants' checked all finished work in order that any undue assumptions or interpretations I might have made would be uncovered (which proved to be the case).

While I used an 'unstructured' approach in the interviews it is acknowledged the structured/unstructured divide is, to a degree, false (Gillham 2000). While participants were given a lot of space to determine the course interviews could take, there was an underlying structure to the interviews insofar as I hoped to always touch upon the following questions/themes:

- What are the participant's feelings towards the 'Old Left'?

- Does the participant consider himself or herself part of the Left? And what does 
a sense of the Left mean to them today?

- What is the nature of the relationships existing between groups of the broad Left?

- What is the perceived effectiveness of tactics employed by the group/individual?

- Is the participant involved with multiple groups?

- Is involvement within groups a lifestyle issue? For instance, are they acting towards recognition or redistribution?

- Do participants have a pessimistic/optimistic outlook towards society and social change?

- What are the interviewee's eventual hopes/goals for themselves and their group? Participants were given room however, to raise issues they felt important, an approach which led to interesting results as, unprompted by me, a number of participants raised issues relating to problems with the media and the threat of environmental catastrophe (amongst other things).

Twelve interviews were conducted with respondents who were involved in either one or more of the following: the environmental movement, new unions (to get a new slant on an Old Left category), the peace movement, the indigenous/tino rangatiratanga movement and intentional communities. These areas represented, for me, the different strands that ran through the second intensive phase of the Left. I felt actors involved in these areas were well situated to offer insights towards the third intensive phase of the Left in New Zealand.

I should note that the final list of interview subjects is heavily weighted towards male participants. Early in the project an equal number of men and women were approached, but more male participants agreed to participate in the research than female.

\section{The Participants}

Nandor Tánczos, Catherine Benland and Torrance Hodgson, alongside Keith Orr, Robina McCurdy and Frans Muter from Tui community, were approached due to their backgrounds in environmentalism. Catherine Benland, formerly of Values, was instrumental in taking environmental politics into the parliamentary context. Tánczos, as an MP for the Green Party, was able to offer a contemporary perspective on working within parliament alongside a history of direct action (Green 1999). Hodgson also shares 
a background in direct action, and is a founding member of the "Save Happy Valley Coalition" (SHVC), one of New Zealand's most active environmental protest groups. A committed anarchist, Hodgson's activities stretch across a range of outlets, including the Rebel Press and Peace Action Wellington.

I was attracted to interviewing three members of Tui community, as it has been depicted as a community that combines environmentalism with day-to-day life, and in which members also engage in activism outside the community (Sargisson and Sargent 2004). I was interested in seeing first hand the extent to which intentional communities were able to combine an alternative approach to daily life with wider reaching activities. Further, I wished to explore the degree to which Santos' depiction of communities as vital nodes within alternative networks of production, alongside Hardt and Negri's emphasis on the importance of evacuating sites of power, could be applied to intentional communities within the New Zealand context. Towards such ends, Barbie Cole and Philip Vincent of Riverside were also interviewed.

Riverside, founded by conscientious objectors over 60 years ago, is an intentional community with roots deep within the country's peace movement (Rain 1991). To incorporate another voice associated with the peace movement, I interviewed Nicky Hagar. His work Secret Power (1996) is considered a key text for the country's peace movement (Foote 1997), other works have been concerned with environmental issues (Secrets and Lies (1999) and Seeds of Distrust (2002)), while his research for The Hollow Men (2006) famously undermined National's 2005 election campaign. Alongside his work as an investigative journalist Hagar has a long history of activism.

Another committed activist approached for my research was Teanau Tuiono, who is very active on issues around Maori Sovereignty (Tuiono 2007).

I also spoke with both Matt McCarten (of Unite Union) and Simon Oosterman (formerly of Unite, and now with the National Distribution Union (NDU)) to explore issues around contemporary unionism within the country. Unite was of particular interest for me, as it presents a new approach to unionism within the country (Allen 2006) due to such novel campaigns as Supersizemypay (in which Oosterman was heavily involved) and its ability to represent low paid workers who are normally outside the sphere of trade unions. McCarten, Unite's general secretary, was previously a leading figure in the Alliance Party. Oosterman, who operates from an anarchist or libertarian socialist background, has been involved in a wide range of activist activities. 
As can be seen, participants' actions and histories stretched across a range of concerns central to this research; most participants are, or have been, involved in a number of activities relevant to the work carried out in these pages.

\section{Analysis}

Most of the interviews were recorded and then transcribed in full-with the exception of a few that, due to problems with recording devices, were transcribed at the time of the interview in short hand. Once the interviews were transcribed the key interview themes listed above were lifted from each transcript and collated together. For instance, each respondent's views of the Left were collated in one document, allowing points of difference (and agreement) to be considered together and then compared with arguments developed earlier in this chapter and in Chapter One. Further, as the structure of interviews allowed for respondents to raise their own issues and concerns I was able, after reading through all the interviews a number of times, to see other common themes and draw these together.

What follows in Chapters Three and Four are the outcome of my research set alongside key themes raised in this chapter and Chapter One. The primary concern of the following pages will be to explore the third transitive phase of the Left within New Zealand. 


\section{3}

\section{The Left in New Zealand Today}

I have suggested, from a review of the literature, that the Left has moved through three phases (the first of which is not applicable to New Zealand), with the third phase still underway. This chapter seeks to explore some aspects of this third phase within the New Zealand context, through looking at such themes as the call to move "beyond Left and Right," the role of the state, and relations between social movements and the wider Left to Labour, especially in relation to the neoliberal turn.

Another issue to be considered within the contemporary New Zealand context relates to the lasting effects of the second intensive phase of the Left. Questions will be raised as to the lasting legacy of a New Left, and to the continued salience of the term 'Left.' Such issues as the redistribution/recognition divide, a supposed outcome of the second phase, will be explored. It is asked if the proposition put forward in Chapter One, that the third phase of the Left sees a re-convergence of concerns around redistribution with those more generally associated with new social movements, is applicable to the New Zealand context.

Another issue to be raised within the New Zealand context is the supposed fragmentation and ineffectiveness of the Left, along with the rise of networked forms of cooperation as a means of moving beyond fragmentation. Chapter One raised concerns around social atomisation and the subsequent decline of collective action. This will be considered alongside the continued relevancy of class and 'new unionism.'

Through drawing together the above themes, this chapter seeks to trace the prominent contours in the topography of New Zealand's contemporary Left.

\section{Issues for Considering a Contemporary Left in New Zealand Today}

Discussions of the Left always have to traverse definitional difficulties. The 'classic' socialist definition of the Left oscillates around economic and class considerations and can be very broad. Pat Moloney and Kerry Taylor, in an introduction to a collection of essays on socialism in New Zealand, provide a good example of such a definition. They hold the Left to be "any critical response to industrial capitalism offering collectivist 
solutions aimed at minimising inequalities" (Moloney \& Taylor 2002: 15). Such a definition includes the actions of political parties, unions, organisations associated with the Old Left (such as the NZCP or, contemporaneously, the Workers Party), some New Left groups and anarchist groups. While academic definitions of the Left can be widely inclusive, what constitutes the 'Left' is, in practice, highly contested.

For instance, some anarchists find conventional definitions of the left contentious. As shown in Chapter One, the first phase of the Left was characterised by the split between anarchists and Marxists over debates around the state and political action. Contention still exists within New Zealand today over the degree to which the 'Left' is still conflated with practices that stabilise the state. Tánczos considers anarchism, along with green politics, to be "in a different dimension" than the Left, particularly the statist Old Left. Hodgson similarly struggles to consider himself a part of the Left as:

it's hard to define what that is, especially with anarchism and anti authoritarian politics, as there is definitely a big schism there because a lot of the Left is about strengthening the state as a way of taking on capitalism, whereas anarchist political analysis holds that the state and capitalism are inseparable.

Oosterman shares similar concerns around the conflation of the term 'Left' with practices reinforcing the state, although he does consider his being a "libertarian socialist" to place him within the ambit of a wider Left. His reservations around the term 'Left' are due to it not showing the "significant differences of those within the Left." It appears an anarchist background does not necessarily lead to a wholehearted rejection of the Left. Rather, there is weariness around a term readily associated by others with state affirming practices: the 'Left' should be conceived as much wider than this. I will continue to speak of the Left as encompassing anarchist, Marxist and liberal strains, but acknowledge this 'Left' does not always exist in the eyes of some included within this categorisation.

Further unsettling a sense of the Left is the call to move 'beyond Left and Right' (see Chapter One), with some holding these terms to have lost their relevance within contemporary politics. For instance, it is argued neoliberalism has transformed the Right from a conservative force to a 'radical' one, with the once progressive Left becoming conservative as it struggles to conserve the last vestiges of the welfare state (Giddens 
1995). This argument relates largely to parliamentary politics, making it particularly relevant to New Zealand where it was the parliamentary Left who initiated the neoliberal turn.

The notion of moving 'beyond Left and Right' has been a long-standing issue here. McKnight considers environmentalism an example of how movements have moved beyond Left/ Right classifications (McKnight 2005). Environmental campaigns like Save Manapouri drew from both the conservative and radical concerns of society. Questions around Left/Right categorisation had also been raised in Values. Benland, who avoided the Left/Right distinction when representing Values, remembers many discussions around how 'Left' the party was and whether they were cutting into National or Labour votes. She recalls National voters coming up to her in the 1970s to praise Values' environmental policies. Benland holds Values was "probably Right on the environment per se but couldn't be categorised on many other issues since Values policies were new and original."

Similar debates take place within the Green Party today. Tánczos feels the Green party's Left affiliations undermine its ability to cut across the Left/Right spectrum to promote a different dimension of politics, "One that has preoccupations that are not intrinsically linked to either [Left or Right] and that might include elements of both." $\mathrm{He}$ argues:

There are many people who are naturally sympathetic to Green principles and policies, including socially and economically progressive ones, who are not Left-identified. Part of the reason is that the terms 'Left' and 'Right' have become progressively less meaningful to people (Tánczos 2007).

One problem with being identified as hard Left, for Tánczos, is that it alienates people from other spectrums, in particular those who do not primarily identify themselves on a Left/Right spectrum, at the expense of advancing environmental concerns.

However, calls to move 'beyond' the Left around environmental issues have attracted criticism from some. Hager considers the Greens' one time slogan "Not Left or Right, but in Front" to be "pretentious and disappointing." Oosterman holds "true environmentalism is a social justice and class issue". A position showing that environmental issues are not exempt from traditional Left concerns. He holds that 
"capitalism is the driving force behind environmental destruction. Green capitalism is an oxymoron." The view that capitalism and environmental degradation are intertwined would indicate that, perhaps, the territory attributed to a wider notion of the Left should not be vacated.

That Tánczos moots vacating this territory may reflect, in part, his position in Parliament, where Left/Right categorisation appears particularly fluid. For instance, consider the Labour party's trajectory over the last thirty years: it has moved from being a working class party, to one incorporating New Left concerns, to initiating radical programmes of neoliberal reform, to become, today, a party intent on stabilising neoliberal relations. As a sign of how far New Zealand politics have been pushed to the Right, Hager holds National to have, at times, been more Left than Labour-with National having previously spearheaded economic strategies more Left than Labour's present ones. This blurring of distinctions between Labour and National underlay other interviewees' uneasiness over Left/Right categorisation. McCarten feels "we need to build an independent Left if you like, outside of the Labour party, as Labour is really, I mean economically since the 1980s, there hasn't been any real difference between [it and] National, it's just nuanced." In considering Labour, an impediment to unity in the Left is uncovered.

As Tánczos notes in relation to the Greens, there has always been a strong feeling that allegiance is owed to Labour as the party of the Left. As explored in Chapter Two, both the Third and Fourth Labour governments competently incorporated issues raised by social movements from the Left (an example being the push for nuclear free status). In the contemporary context, with little differentiating Labour from National, most interviewees considered allegiance to Labour, as a party of the Left, misguided. To such an extent that the attitude appeared to be: "if the Left includes Labour, then I'm not Left."

To the extent there was greater affiliation to Labour in the past, and hence a more unified Left, the current Labour government appears to have the opposite effect. Consider Oosterman's position on where he sees himself within the Left/Right spectrum: "I think it's probably better to talk about neoliberal and anti-neoliberal. The Labour party and National are both neoliberal parties, they are both based on the idea of the market, which I'm fundamentally opposed to." Labour's neoliberal turn in the 1980s had a profound effect on the wider Left within New Zealand. As Hager notes: 
While much of population opposed the changes, it seemed little could be done to halt the purchase neoliberalism was gaining in the country. This created a climate of despondency around the Left and activist circles, leading many who were once active to retreat from the public world.

Given the extent of economic convergence between Labour and National, alongside the continuing negative impacts of neoliberalism on the Left, it is understandable that many of those interviewed rejected Labour and any identification with the parliamentary 'Left.'

Yet despite Labour's contentious position, it still appears to stimulate a degree of auto-affiliation from many groups within the ambit of the Left. Tánczos appeared wearied with the readiness of many Greens to fall in line behind Labour. McCarten had similar feelings about the Council of Trade Unions (CTU) relationship with Labour:

\begin{abstract}
Mostly the CTU's leaders, and other unions who are affiliated to a party, are aligned to the Labour party. Their strategy is to get the Labour party elected, I don't buy that. I know they believe it's important, and they can lobby better with Labour, but they trap themselves into saying that we must behave ourselves so Labour can stay in, and if they're out that we must behave ourselves so Labour can get back in. It's a total compromise, so you can't ask if our workers are better off under Labour. The bottom line is we are just as poor as under National.
\end{abstract}

Labour appears to be an unstable attractor within the Left. While it draws some groups towards it — and to this extent still functions as a party of the Left-it simultaneously repels others. Some degree of factitiousness appears inimical to the Left considering the phases it has moved through, in this sense Labour would not appear the cause of disunity within the wider Left. However, the view offered by many of those interviewed presents such a case: that it simultaneously attracts and repels different sections of the Left, that it occupies an ambiguous position within Left/Right categorisation, and that it is seen to be a party supporting neoliberalism, all comes to culminate in a sense of uneasiness around the term 'Left' as long as it associated with Labour.

The New/Old Left divide-which I consider an outcome of the second transitive phase of the Left-further challenges the way individuals see themselves as part of the Left. Within New Zealand, Toby Boraman conjectures what was "new" about 
the New Left was "its questioning and rejecting of the values, ideology and political tactics of the old left, which in New Zealand was represented by the Labour party and various Leninist parties" (Boramon 2002: 118). His discussion of the New Left, like my own in the preceding chapter, sets it alongside social movements related to such issues as race, peace, gender and the environment. The 'Old Left' was associated with a more institutionalised and state centred approach. While some literature concerning the rise of the New Left clearly demarcates it from the Old Left, such distinctions are not always so clear in practice.

Some hold the lineage of such social movements as the environmental one to be inseparable from considerations of the New Left (Wall 1999). However, Tánczos makes it clear he does not see his involvement with environmental issues to be grounds for his inclusion within the Left:

I don't identify as Left... and again it gets into that thing where definitions get difficult, because you can say: "hang on, your ideas might be New Left, or New New Left, or New New New Left," or whatever. But...at what point does New New New Left become just not even Left at all?

Tánczos calls into question the applicability of movements associated with the New Left' to definitions of a wider Left:

The peace movement, the anti nuclear movement, the green and ecology movement...I don't lump them in as Left wing things just because the Left claims those movements under its banner. 'New Left' may be a way for the Left to accommodate itself to other kinds of politics, but it does not necessarily describe what those other politics are.

Hager recalls the peace and environmental movements in which he began his activism to have included many figures from the "Old Left." There was no clear separation between issues relevant to the New Left and the Old Left in New Zealand. For instance, union groups (who are generally associated with the Old Left) were involved in 'New Left' initiatives in the 1960s and '70s such as the anti-base or antiapartheid actions. Despite such intermingling Hager never saw himself as part of the Old Left. Despite having learnt much from Old Left figures, and having a lot of respect for them, any identification he has with the Left is "more in line with what Bruce Jesson 
described as the 'independent left'."

McCarten considers himself to be operating within a New Left. He sees progressive Left movements as having moved away from Marxist analysis, which, he thinks, has "got it wrong in some areas, so I think [this is why] the Old Left is...almost invisible now." While he accepts the validity of class as an analytic category, along with considering competition for resources a prominent feature of contemporary society, he feels "the Left has to go wider." It needs to include the personal, race, indigenous issues, environmental concerns, social justice issues and peoples religious affiliations. He considers Unite part of a 'New Left,' an accommodating one. Such an inclusive view, tied to an awareness of material issues relating to class and capital, is in step with what I consider to be the re-convergence of the two arms of the Left within the contemporary era-as seen within components of the alternative-globalisation movement.

While some of those interviewed distinguish between an Old and New Left, or challenge the basis of such distinctions, others are happy to situate themselves, or at least accept the validity of, a more general definition of the Left; one more in line with the socialist definition offered above by Moloney and Taylor. Cole and Vincent both considered 'socialist' an apt description for Riverside. When asked to define what the Left means to her Cole said it was bound by socialist principles and humanitarianism. It is based around "people being more important than money and business."

In tracing these differing definitional lines, and actor's views towards the applicability of Left categorisation, the difficulties of talking about the Left in New Zealand are apparent. Anarchists will reject what they consider to be cooption by Leftist agendas they feel stabilise the state. A definitional attempt to move beyond this impasse by deploying Old Left/New Left categorisation also proves problematic. Actors may reject such distinctions, or accept them in ways that differ from what theoretical definitions hold them to be.

Another factor in considering the Old/New Left divide is the relation between the New Left and social movements. As noted, a divide has been suggested between what some would consider Old Left groups, who continue to hold that activism should address the structural inequalities inherent to capitalism (redistribution), and New Left groups who focus on single issue causes (recognition). In their study of contemporary activism in Australia, Sarah Maddison and Sean Scalmer (2006) found perceived tensions between redistribution and recognition to be overemphasised in literature on the subject. 
In step with Nancy Fraser's work they found contemporary activists to be acutely aware of how culture and the economy work together to produce injustices. As stated by Fraser, "properly conceived, struggles for recognition can aid the redistribution of power and wealth and can promote interaction and cooperation across gulfs of difference" (Fraser 2000: 109). Issues of redistribution and recognition can be separated between themes relating to the aims of the Old and New Left respectively. However, this is not a clean divide: anarchists have been excluded from definitions of the Old Left, yet are as critical of capitalism as any Old Left group. It was argued at the close of Chapter One that there was a divergence between the concerns of the Old and New Left (in the second phase of the Left), and that these concerns are re-converging in the third phase of the Left. My research indicated such a trend may be present within the contemporary New Zealand context_-as can be seen in McCarten's argument that politics for him has always been about the colours brown, green and red, "the indigenous, the environmental and social justice... its got be a mix of all of those things."

None of those actors interviewed appeared to champion actions solely confined to issues of recognition. For instance, the Save Happy Valley Coalition is a cause-focused movement, yet Hodgson's participation within the coalition relates to his analysis of capitalism - the two cannot be separated. While interviewees from both Riverside and Tui sought recognition for their ways of life-insofar as they consider themselves to present models of alternative living (see Chapter Four)-both communities were founded upon strong socialist principles. To the extent that socialism underpins aspects of their communal life, their very existence operates as a critique of the redistribution of resources within capitalism. Overall, the interviews revealed an awareness of the interrelated nature of struggles. Tuiono, for example, does not consider his work around indigenous issues to be confined to issues of recognition. Echoing Fraser's statement above, Tuiono advocates interaction and cooperation across different causes:

For example, globalisation has negative impacts on pretty much everyone, but in different ways. For indigenous peoples globalisation is just neo-colonisation. Rather than colonisation [by] countries, its colonisation by multi national companies taking over our space... But globalisation also impacts on non-indigenous people as well, a classic example of that is in Palmerston North where I live. They have just shipped out the call centre for the Yellow Pages to the Philippines, and that's just globalisation, you know? The cheapest trick on the block wins. If you look at it on the wider scope of things...you 
can use it to build bridges.

By moving beyond calls for the "recognition" of specific indigenous issues, and through relating concerns to wider issues involving capital or "redistribution," Tuiono indicates how the development of a wider view could lead to a more cohesive resistance movement.

Cohesiveness and fragmentation are major issues in many considerations of the Left. McCarten holds "the problem in New Zealand is that there is not a strong cohesive Left wing." As strength is seen in unity, the desire for a unified Left has been longstanding (Marx \& Engels 1971). Therefore influential commentators like Eric Hobsbawm (1996) have seen the 'fragmentation of the Left' since the 1960s as leading to weakness. Yet, Tánczos asks, is fragmentation such a bad thing:

I am quite suspicious of this idea that we should all be on this one kind of platform together, because inevitably that means some people have to subsume their interests for whatever it is the majority, or more usually a powerful minority, decides we are all about.

Hodgson expresses similar sentiments:

A lot of people call for unity on the Left, and I think that is really dangerous as it always means suppression of actual politics that is going on there, and unity under one person's politics, which is invariably a State form of politics.

A lot of literature on the contemporary Left today, and on social movements, focuses on the manner in which such fears of incorporation can be allayed by non-hierarchical modes of organisation and acting (Diani 2003; Whittier 2002). The dominant metaphor is that of the network where there is a plurality of linked social struggles-each component of which retains its own agenda and values (Castells 2005a). This appeared the preferred mode of action for some of those interviewed (as opposed to seeking total unity). For example, Tuiono holds:

There are commonalities in all our struggles that are enough of a commonality for us all to come together and build on, I'm not talking about total unity, because then you have to water yourself down to the lowest common denominator...but I am talking about 
things that are very clear and common to every struggle. You know, the environmentalist struggle, the anarchist struggle, the whatever struggle, the tino rangatiratanga struggle, Mana Motuheke, all these different sorts of things as well, and I think the positive, if you can pull a positive out of this whole terror raid experience, is that people realise and recognise there are more commonalities.

The notion of total unity is generally anathema to activists in New Zealand today. There is a strategic strength behind such an approach. While actors (individual or organisational) may be unwilling to suspend positions which would preclude their belonging to a "unified Left," they will be willing to work within a coalition towards the achievement of common goals that do not challenge their fundamental beliefs. Hence actors are able to "frequently identify with heterogeneous collectives who are not always compatible among themselves on fundamental issues" (Della Porta \& Diani 2006: 109). Effective collective action can still take place when actors are able to identify an opponent but do not share strong identity links-in this case networks will develop which are purely contingent and instrumental in nature (Diani and Bison 2004). This would seem to be the case for groups within the wider ambit of the New Zealand Left: for example, they can come together to organise protests, but, as Oosterman notes, this does not mean they would cooperate around an election campaign.

While many interviewees appeared willing to cooperate to address wider concerns (going beyond issues of recognition), the most widely identified concern to arise in interviews has still to face a concerted front of resistance: this being the advent of neoliberalism. When Oosterman was asked if the climate created by neoliberalism plays a role in the alleged apathy of people towards social change, he retorted that neoliberalism is "everything," but "it can only exist because there is a lack of collective resistance to it." He considered neoliberal reform to have led to lower wages and people paying more for water, food and electricity, so in this sense it should be the basis for collective organisation. This is a point picked up by Tánczos, who mentions that it is easy for people to identify neoliberalism with perceived social ills, but there has been little strategy developed to deal with it: "people are up against a very powerful, coordinated, strategic regime of...neo-colonial corporate globalisation, and it's pretty difficult to resist that unless people are, or can be, coordinated."

As shown in Chapter Two, some social movement/Left researchers have argued 
there was a widespread failure to resist neoliberalism in this country in the 1980s and '90s. While this view was contested by Boraman (2005), some of those interviewed seemed to support notions of failure. Tuiono argues the failure to resist neoliberal reform is partially attributable to Pakeha activists being unable to collaborate with Maori (echoing sentiments found in Chapter Two)—which, for Tuiono, begs questions of racism. Hager traces some the difficulties faced in opposing neoliberalism to the impacts it had had on social justice movements in New Zealand:

Under the sweeping reforms of Rogernomics and their continuation under Ruth Richardson, it was as if a plague swept through the country and most of those involved in agitating for change or social justice issues succumbed to the sickness of perceived powerlessness-although much of the population opposed the changes it seemed that little could be done to halt the purchase neoliberalism was gaining in the country. This created a climate of despondency around the Left and activist circles, leading many who were once active to retreat from the public world.

Tánczos agrees with Hager's theory that the Fourth Labour government "destroyed a whole stratum [of activists]."

Alongside the perceived defeat of active campaigners at the grassroots level, McCarten feels any opposition movement to neoliberalism was betrayed by "the intellectual laziness" of academics. As a member of the Alliance party he feels he played his part in opposing neoliberalism and was disappointed academics neglected their role.

I'll do my bit and those brainy ones can do theirs [was my approach], but right through the $80 \mathrm{~s}$ where the fuck were they, the ones in the universities? Where were the political heavy weights? You had Jane Kelsey and one or two others, but by and large they were completely apolitical...you have all these professors and lecturers that get their high salaries and their sabbaticals to do research and thinking, but what the fuck were they doing? Fucking nothing, and the whole country was being wrecked. So I think there's been an abdication of responsibility from academics and intellectuals, people like Bruce Jesson were involved, but they weren't at the universities.

McCarten's critique of academics, and the role of universities, had echoes in other interviews, with Tuiono and Oosterman both critiquing the direction universities have 
taken. Overall, the argument is that universities within the contemporary age are unable to stimulate political consciousness and have a declining roster of staff sympathetic to the Left. Under neoliberalism universities are seen as having become jeopardised by corporate demands, a picture painted of universities throughout the West (Hayes Wynyard 2002; Saul 1997; Shukaitis \& Graeber 2007). An element of this may be attributed to a 'cultural-turn' in theory that drew many academics away from notably Left, social justice politics (as shown in Chapter One). However, the dominant issue appears to be the marketisation of the university. McCarten feels education has ceased to be a community good and has become a market good. If students pay for education themselves, holds McCarten, they will leave the academy feeling they owe nothing to society.

The picture given of resistance to neoliberalism in New Zealand is one of failure through despondency, missed opportunities and lack of unified purpose; the Left and activist circles were eroded by neoliberalism and the academy failed to stimulate or support resistance. A part of the Left considered to have been particularly hard hit by neoliberalism, and to have also failed in terms of resistance, is that of unionism.

\section{New-Unionism and the Continued Saliency of Class}

Moving beyond general considerations of the Left in New Zealand this chapter will now turn to the more specific sphere of unionism. Through looking at unions some key themes can be explored in more detail: such as the effects of neoliberalism on collective action. Further, the notion of 'new unionism' will be raised. It will be argued that there are concerted efforts to build stronger links between the divergent arms of the Left, and to bring the Left closer to a wider constituency - a constituency in which class is still an important category. New unionism can be seen as an attempt to move beyond the impasse outlined above, in which, while neoliberalism has been identified as a key problem, there has been no wide-spread collaborative resistance.

Following ruptures inherent to the second phase of the Left, and changes to the state under neoliberalism, there has been a decline in Western unionism. Most unions in New Zealand have been closely aligned to the state (with some exceptions, see Chapter Two) and the vagaries of the Labour party; consequently they have suffered greatly from the neoliberal turn. National's 1991 Employment Contracts Act (ECA), which made unionism voluntary-leading to a 60\% fall in union membership by 2001 (Boxall et al 
2005) — is a classic example of neoliberal reform that 'empowered' individual employees to exercise 'free choice' when dealing with employers, while ignoring power imbalances between employers and employees (Roper 2005). The ECA is charged with the demise of collective bargaining, the depletion of unions' resources and memberships-with fierce competition for members undermining inter-union solidarity-and a decline in the social movement orientation of unions, with unions having contracted their role to the representation of paid members only (Harré 2007).

Laila Harré (2007) argues it is not a rejection of collective actions that has led to declining union effectiveness. Rather it is due to policy, declining numbers of employees in traditional areas of union strength and growing employment in non-unionised areasshe argues unions have failed to strategically respond to changes. The costs of union failures are seen to extend beyond workers into economic, social and democratic spheres: "damaging our prospects to preserve national values like solidarity and justice under threat from globalisation and market forces" (Harré 2007: 7).

From the picture given above it can be seen that the onset of neoliberalism, and the issues associated with it — such as the decline of civil society, 'social atomisation,' the erosion of collective action-have undermined unions in the country.

Alongside considerations of the historical decline of unions under neoliberalism Oosterman raises concerns over union structure-echoing challenges to anti-systemic movements raised in the 1960s. He considers the top down approach of union organisation to be a long-standing problem that leads to a "self organising" passivity amongst workers.

If the union doesn't mean much to a union member, or he or she doesn't have to do anything apart from paying their dues to get a pay rise every year, well, it's not surprising that they aren't empowered.... You can't rely on that sort of union structure to guarantee peoples involvement and empowerment. It is only through the experience of collective struggle that self-organising will germinate.

Union leaders are seen as the main cause of unions' structural problems, as workers come to associate strong leaders with the ability to win benefits, rather than seeing the power to create change lying within their own actions or potential. Oosterman's interest in union activity relates to the potential empowerment of workers and a desire to see 
them take a more active role within unions - he articulates his position as one addressing the problem of "followship" as much as "leadership." Hodgson shares some similar objections:

I think unions are [flawed] in terms of how they are structured, for most union organisers it's a job, and their aim is to make jobs stable... and a lot of it is not very empowering. I was listening [to] someone talking about a union and they basically saw it as giving the union a few dollars a week and then the union negotiates wages on their behalf...there's that complete separation between the union and themselves. I am all for unions taking on action, but that's often not what unions are about.

The views held by Oosterman and Hodgson are in keeping with their grounding in anarchist praxis: empowerment of the individual through collective action is of the utmost importance, which involves calling attention to the embedded hierarchies found within most social and organisational structures.

This scepticism has not stopped Oosterman from developing a pragmatic approach to working within unions-although he is torn between the 'benefits' of working within the union office (access to people and resources) and the desire to be involved in grassroots union activity opening spaces for self-organisation within nonunionised workplaces. For Oosterman unions provide the opportunity to act and strategise in ways not possible within the wider activist community. Although, he states, this is only because no other spaces exist where this could happen, and, he asks, who is going to build these spaces "if not the revolutionary anarchists and socialists who are too busy working in unions to do so?" As it stands however, unions are seen to be the most likely place to develop practical skills (more consideration will be given to such issues in Chapter Four). A point Tuiono gives credence to through observing that a lot of Maori activists have developed useful tools through union work. Structural issues aside, unions are currently one of the few extra-parliamentary spaces where skills can be learnt for effecting change.

To keep in step with changing times, it is argued, unions need to develop their structures and address critiques of their being overly bureaucratic (Clawson and Clawson 1999). McCarten, in his work with Unite, is aware of the need for change and avoids following a traditional union blueprint: "I don't want to be in a trade union, if I wanted 
to be a trade union bureaucrat I could have joined another union 3 or 4 years ago, but why...would I want to do that?" Other unions, and especially the CTU, are characterised as bureaucracies dealing with other bureaucracies. He is more interested in workers dealing with other workers, an example of this being actions taken against Starbucks: "What we did with Starbucks, was link Starbucks workers with workers in other parts of the world, and had them talk to each other in a chat room, it seems to me it's more to do with the workers - not up through bureaucracies then back down."

McCarten questions the relevancy of contemporary unions within developed countries, as they are:

by nature, defensive organisations and have retreated back to the crafts and trades, and public servants... They are not unions really, they are more staff associations, they'd be there regardless of who's in government really, the police association, fire fighters, teachers union etcetera, you have those everywhere, because people make careers from it... and they have one big employer—be it a hospital or a council etc—and therefore they organise themselves as staff associations. That's what they do, you don't need outside union professionals to do that, the workers themselves will do it anyway.

McCarten's approach to his work within Unite shows a desire to avoid the bureaucratic shortfalls attributed to other unions, along with addressing the need to see greater worker participation within union structures.

To increase participation, and to move issues forward, some of those interviewed argued for an increased politicisation of workers. Some literature has suggested this is unlikely due to increasingly atomised, apolitical and apathetic populations who are adverse to collective action (see Chapter One). Yet, views tracing low union density to the 'individualisation' of younger workers have proved, to some extent, contestable. Younger workers are arguably more responsive to joining unions than their older counterparts. It is held "younger workers are not switched off or too infected with individualistic attitudes to see the benefits of collective pursuit for their work interests" (Boxall et al 2005: 110). Rather, the problem is that workers are frequently in hard to reach or small workplaces (Boxall et al 2005). This can be seen as an organisational problem due to unions' inability to reach such workplaces.

Unite's approach shows an astute awareness of this untapped constituency of workers. They show an ability to address the greatest representation gap within unions, 
that existing amongst "younger and lower paid workers in smaller organisations in the business services, hospitality and primary industries" (Boxall and Haynes 2003: 2). McCarten sees this representation gap as a failing of other unions, as "the workers who need a union don't get one." He continues: "What we have done in recent times is just go after the big corporations, and gone after those who the other unions don't because it's too hard. So we go in and do most of the fast food chains and hotel chains." Alongside these hard to reach workplaces Unite has targeted new migrants-who, McCarten states, constitute a quarter of their membership.

Through reaching workers untouched by other unions Unite has entered new territory, a territory where the obstacle of high employee turnover must be faced. It is held that young people, despite an increasing interest in unions, "continue to exhibit in their behaviour a high propensity to exit less satisfactory situations" (Boxall et al 2005: 112). Unite addresses this issue by organising around workers rather than bosses. McCarten critiques other unions for being overly focussed on bosses: "You organise them [the bosses] and get a collective agreement but of course when the worker leaves they're no longer in the union, so what's the good of that?" McCarten considers it important to acknowledge that workers will be re-employed elsewhere in the workforce: "I want to build a model that says you're a worker, you're part of the working class, and we should try and build a life long relationship with you." Unite's approach towards union activity could be considered part of a 'new unionism.' Unite appears to be aware of the need to adapt unionism to the age of 'informationalism,' and to address the high turnover in employment generated by flexible labour patterns. Rather than lamenting the demise of working class power they have recognised that its composition has changed.

Following Harré's earlier concern that unions are drifting from their social movement base, it could be argued Unite is moving in the opposite direction. Insofar as a social movement includes a variety of actors who maintain their independence while engaging in a sustained action towards a common goal (Della Porta and Diani 2006), Unite displays social movement attributes. For instance, Unite's staff includes veteran activists (John Minto, Mike Treen), anarchists, Marxists and socialists; while there are obviously theoretical divergences at play, differences do not preclude cooperation. Unite is also active in building relationships with other organisations, an example being Unite's relationship with Te Wananga Aotearoa who runs courses for Unite's members. Further proof of their existence within a wider community can be found in half of their funding 
coming from outside the union, from what McCarten calls "Left entrepreneurialism." The ability to reach out into the wider community is an important aspect of Unite's success.

In keeping with trends in some social movement theory (Oliver and Myers 2003; Mische 2003), I see the success of new unionism to be dependent on its ability to develop strong ties with the wider community. As held by Oosterman, if a union wants to win something then they need to get the community on board. Harré (2007) also identifies the role played by the wider community as key to a successful action. She gives the example of a recent campaign where there was a genuine culture of inter-union solidarity amongst workers; she saw this culture being extended into churches, political parties, and into social justice, welfare and cultural organisations "whose own social capital was invested in this battle;" paradoxically, she saw the absence of a large union strike fund as a strength of the campaign, as this made it important for workers and the union to catch the public eye to raise funds. Harré holds that:

Leadership in building these [supportive] communities came from the workers themselves, their partners and social networks.... The workers realised that they could make a difference by bringing about social change through collective action (Harré 2007: 8).

It is worthwhile noting that while Unite is on the forefront of what I would call 'new unionism' in the country, NDU has not been slow to follow their lead in some areas. Oosterman noted that NDU and Unite, along with the Service and Food Workers Union, are on the verge of a merger at the time of writing.

As far as I have put forward the notion of a new unionism it would be to assert that there is a shift towards the politicisation of workers, the development of wider community links and the reassertion of the power of collective struggle (as opposed to bureaucratic management and conciliation). Creativity becomes an important factor in achieving success, hence the paradoxical statement made above by Harré: that a lack of resources made the campaign in question successful. Worker's knowledge informs action, rather than action being deferred to "bureaucrats dealing with bureaucrats" as McCarten would put it.

New unionism is in part a return to earlier forms of unionism within the country, 
as seen in the creative means deployed by the Red Feds (Hickey 1980). As noted in Chapter Two, the Red Feds were affiliated with, and followed similar tactics to, the International Workers of the World. Comprising anarchists, socialists and union activists, the Wobblies sought to create one big union for all workers, including immigrants, women, and blacks-workers not touched by other unions. To overcome language difficulties inherent to their constituency, the Wobblies pioneered the use of song and art to convey a universal message (Brunn et al 2007). The Wobblies were also radical in championing direct action over political action (Carter 1973). In their drive to reach migrants and other workers not touched by current unions, with a staff composed of (at different times) anarchists, Marxists and union activists, and in the novel tactics they use (a discussion of which takes place in Chapter Four), Unite represents a rebirth of some of the ideals found in the Wobblies—although some argue the syndicalist elements of the Wobblies are not present within Unite (Aotearoa Anarchist Network 2008). Nevertheless, with the NDU adopting a similar approach to union activity (Anis 2008) it could be argued there is a new face to unionism appearing within New Zealand.

A final point to consider in relation to new unionism, or unionism more generally, is that of class. Previously a unifying concept for the Left, 'class' as an analytic category has come to face many challenges (see Chapter One). Within my research class still appeared an important category for some. Oosterman considered class to be "one of the most important things, because class ties into all forms of oppression and all forms of oppression are used to subjugate the working class," yet, he argues, it is ignored by most activists (although, he adds, "this is not to say that other forms of oppression do not exist on their own in fact some, sexism for example, probably pre-date class"). Behind this rejection of class is the perceived capture of politics by the middle class. McCarten, despite being supportive of the Greens, argued:

their social base is very middle class, and their attitudes are very middle class, and they are liberals. Ultimately I think a movement has got be of the people, not of the same class. I have seen the middle class capture of the all the high ground of the political institutions, including political institutions with a small 'p,' all the NGOs, the union movement and the parliamentary parties are all middle class in attitude. So the poor are marginalised even though they are the majority. Media is dominated by middle class lobbying, bringing in an attitude of getting a decent career, wage, etcetera. 
Rather than disappearing, it is argued the disparity between classes is increasing, as can be seen within current trends in the housing market (Cox and Pavletich 2008), which Orr argued was creating renting and owning classes. While the statements above attest to the marginalisation of class by many, it can be seen that class concerns have not disappeared. With the rise of new unionism (whose tactics will be considered in Chapter Four), which combines trends seen within new social movements with the longstanding redistributive concerns of unions, class may again become an increasingly important categoryespecially if some activists hopes for the increased politicisation of workers come to fruition.

\section{Conclusion}

Definitions of the Left are always troublesome. Frequently they are based along socialist lines, but the perceived confluence of socialism with the state leads some anarchists to reject inclusion within what is categorised as the Left. The very notion of there being a 'Left' is challenged. Some contend it has no contemporary relevance, especially in relation to such areas as environmentalism-where it has been argued that overt association with the Left detracts from the cause. Environmentalism has been attributed as a New Left cause, yet the delineation between an Old and New Left did not appear as strong as some literature suggests. A strong area of concern in my research was the rightward drifting Labour party's role in national politics-association with the 'Left' appeared to be rejected by some because of the term also including Labour.

Such contention fed into wider concerns around unity and solidarity. While 'unity' may lead to strength, it was argued to have the potential costs of cooption or the subsumption of minority interests. A fragmented Left may be the outcome of such concerns, but, provided groups can retain their autonomy, there was a willingness to engage in more networked forms of association which could address strategic targets. Insofar as actors are unlikely to separate issues relating to redistribution or recognition, there is a strong likelihood that common causes can be found. For instance, there was a widespread acknowledgement of neoliberalism as being one of today's chief concerns.

New unionism is, tentatively, considered to be an area in which challenges are being mounted to some of the economic effects produced by neoliberalism. Here workers' knowledge and community ties are, potentially, being married to concerns of a 
wider Left—producing a more social movement orientated unionism. While this does not necessarily correlate to a strengthening of a wider Left it does signal a continued desire to be involved in collective action to challenge the conditions imposed on workers by capital. The degree to which this can be equated with the potential radicalisation of workers is open to debate: it is a flash of gold rather than the striking of a deep vein.

New unionism challenges some of the conceptions developed in Chapter Twoone of these being a turn away from collective action, another being the notion of class. Alongside concerns about the middle class capture of politics, class showed itself to be an ongoing concern for some of those interviewed. I would argue the reduction of action to prime considerations of class is unlikely to happen-actors are aware of the problematic nature of reducing analysis, or activism, to the one axis. The hypothesis put forward in Chapter One, that the third phase of the Left involves a re-convergence of issues relevant to the 'Old Left' with the concerns and tactics seen within the New Left and social movements, seems to have some credence within the contemporary New Zealand context.

While the 'Left' continues to be a contested term in New Zealand we are clearly not beyond Left and Right. Such categorisations have yet to loose their usefulness, even if it is a contentious term for some. Organisations associated with elements of the Left it is argued by some are in decline, as is the previously central category of class. However, my findings would not support the notion of a total decline. While the 'Left' may not be a unified field of action, nor be showing any tendency towards unification, longstanding concerns of the Left are still salient-and continue to be important considerations on an intellectual level. 


\section{4}

\section{Extra-Parliamentary Politics in New Zealand Today}

While Chapter Three was primarily concerned with conceptualising what form New Zealand's Left is taking in the third phase of the Left, this chapter turns towards issues of tactics and organisation and returns to the issue of "post-politics" as raised in Chapter One. A common argument here is that political debate has been captured by a parliamentary elite and trivialised by the media, alienating an atomised and apathetic public. This chapter explores the New Zealand political landscape through the eyes of activists.

Conjectures around post-politics hold that social movements are the most likely means of reinvigorating politics. If this is the case, then what tactics would social movements use today to push for change? Some of those interviewed suggested there has been a turn from expressive (symbolic) actions towards more instrumental ones, bolstering claims made in Chapter One that the third phase of the Left includes a resurgent anarchism. A feature of this resurgence is an increased emphasis on direct action. The rise of anarchism here, as elsewhere, feeds into tensions around organisation; these tensions have extended into a debate around the role of an 'activist strata' acting as an impediment to, or promoter of, wider action.

In considering such a stratum, and other organisational issues, the role of networks in activism arises, as raised by Castells. Alongside networks, Castells regards local action as having a primary role in resistance movements today, as does Santos. This assertion will be approached through considerations of intentional communities in this chapter.

\section{Post-Politics and 'Mainstream' New Zealand}

In considering the space of extra-parliamentary politics in New Zealand today, it is interesting to explore the contours of the post-politics debate-in particular the role 
played by the media and concerns around parliamentary politics. Of the latter, the following concerns were raised in interviews: that there was a perceived inefficiency or an over-legislative role being played by government, and that government structures have a negative impact upon individuals working within them.

Tuiono saw New Zealand's parliamentary system to be inefficient and plagued with juvenile behaviour. Orr and Tánczos both derided it for passing too much legislation. Tánczos also felt it lacked restraint (with an election every three years not being enough restraint) and, consistent with post-democracy arguments in Chapter One, he argued Parliament was monopolised by lobby groups and parliamentarians.

Parliamentarianism was a concern for many interviewed. McCarten considered it to have contributed to Alliance's decline, as members ceased to be delegates for a movement and became "MPs like everyone else in Parliament." Parliament's structures were seen to weaken some people's principles and to diminish their ability to act effectively. Hager holds that:

Parliament is not for me because I think I can achieve more outside. I also think it can be a pretty inhumane environment that tends to suit the sort of people we least need running the country. Of course we need decent people to choose that life and there are good people who do.

The Greens were considered by some to be an exception within Parliament. McCarten considered them closest in action to the old socialist movement.

Alongside critiques of parliamentary elitism the post-democracy debate includes a critical examination of the media, which is seen to trivialise issues through focusing on personality politics, and reducing everything to sensationalist sound-bites rather than engaging in, and stimulating, reflective thinking (see Chapter One).

Tuiono held there to be a lack of information in the country "because TV1 and TV3 don't give a shit if people are informed or not, they just want to sell you products in between the News breaks." This as a problem because "participation relies on good information," argues Tánczos:

We are very poorly served by our media as far as providing any critical analysis of what's going on, or providing people with the opportunity to participate.... I think the media is based 
on a fundamental contempt for the audience.... [With the] idea that the public's got a reading age of ten, so don't give them anything complicated they don't understand-I don't think this is true, people understand very complex issues.

Interviewees were sceptical about the quality of the media. While they have to engage with the media to reach the wider populace their engagement comes with the assumption their message will be distorted in transmission.

Activists have come up with tactics to harness the sensationalist tendencies of the media, as can be seen in the Supersizemypay campaign which, along with strike actions, used novel, loud, provocative protests to attract the media. McCarten considered the media coverage garnered an important aspect of the campaign's success.

Another means of mitigating the failings of the mass media is to develop your own media. McCarten speaks of the need to promote "heavy weight debate" around the Left in New Zealand, and considers ownership of a media source with nation-wide coverage a valuable way of promoting this. Benland recalled the impact made by Values' manifestoes and the party newspaper Values Vibes, which were both accessible and widely distributed. Hager's decision to move from being a "veteran activist" to author also reflects recognition of the need to get information to the public without depending entirely on the mainstream media to do so.

While much has been made of the Internet's ability to provide activist-controlled media (Castells 2005c) it was not raised as an issue within interviews, although it clearly plays a role. Independent Media Aotearoa, as a local node in the global Indymedia network, is heavily utilised by activists, as is Scoop Independent Media. The internet enables activists to bypass the problems of mainstream media. However, such media is unlikely to have a wide readership, while mainstream media, by its very nature, is read widely by 'mainstream' New Zealand.

Some activists expressed concerns about a perceived de-politicised mass-culture, as discussed in Chapter One. While some were optimistic about the potential liberation of individuals, reaching society as a whole is seen to be problematic. Again, the media is considered instrumental here-if the 'truth' could be widely conveyed, many activists argued, change would be forth coming.

Tuiono talked of the "ignorant middle class masses of New Zealand," who are held back by a lack of information. He is "pessimistic about that large amount of people 
in New Zealand that are uniformed, or don't care to be informed, [as] they are... holding this country back." Hodgson spoke of there being a myth amongst activists of appealing to "middle New Zealand." He feels this will never happen as, no matter how nice people are as individuals, we are all confined by a "concrete wall of power." To the degree that people are confined they are also rendered apathetic, with Oosterman attributing apathy to social structures. The product of these structures is 'mainstream society' which, while not necessarily actively hostile to activism, is apathetic towards it.

Juxtaposed against this view is that of the Right, which considers 'mainstream' New Zealand its constituency. For instance, National's ex-leader Don Brash, consciously following the Australian Right's approach in their 'culture wars,' derided Labour as a "seething mass of minority agendas," holding that the country was not "being governed by mainstream New Zealanders, or in the interests of mainstream New Zealanders" (Hager 2006: 178). David McKnight (2005) considers that the Left's cultural-turn (see Chapter One) has given the Right the space to utilise the notion of there being a 'mainstream' misrepresented by a 'culturally elitist' Left championing minority interests.

Between the activists' negative view and the positive view of the Right (Key 2007) the arguably fictitious constituency of 'mainstream' New Zealand becomes the site of a political battle - with one force trying to blow it apart, releasing individuals from the hegemonic sway of mass society and the other actively seeking to strengthen it, to build the "Kiwi Way" (Key 2007). The problems faced by the contemporary Left in mobilising the wider populace differentiates it from the New Left and social movements in New Zealand during the 1960s and '70s (as seen in Chapter Two)-Oosterman feels there is no corollary today to the upsurge of consciousness seen then.

\section{Effective Action}

The effectiveness of different forms of action, when pursuing such aims as the mobilisation of the wider populace, is the subject of much consideration for activists. Action for social movements and activists could loosely be split between "expressive" and "instrumental" categories. Expressive (or symbolic) actions are the means by which social movements seek to convey concerns to the wider public, through such means as protest marches, street theatre, or symbolic action. The 'political gimmick' can be an important political resource for the shaping of politics and activism, although a tension exists between the desire to catch the public eye and the need to achieve goals through 
more instrumental forms of action (Maddison \& Scalmer 2006). Maddison and Scalmer (2006: 68) consider "the defined and tangible goals of instrumental action [to] offer a more serious and strategic way of engaging in the political process and pursuing meaningful change." They hold instrumental action to often be more staid, involving lobbying and advocacy around an issue. The general theme emerging from my interviews was the favouring of instrumental action (including a far from staid interest in direct action) over expressive action.

Expressive actions, especially marches, were viewed by a number of interviewees as ineffective. Tánczos spoke of seeing "the same old faces waving a few placards and thinking we're doing really well if we get a march with 10,000 people, but that doesn't change anything." The legacy of marches is called into question. While some theory holds marches useful for building solidarity (Augustyn et al 2001), Hodgson considers such unity illusory: “They come together for a day, people don't really talk to each other, they don't get involved, there's nothing lasting after the day itself." The legacy of such protest for Hodgson is, if you are lucky, a brief mention in the news. Further, as indicated by Oosterman, ineffective symbolic marches can be disempowering, especially when a large number of people have been involved "and it is your main political strategy (symbolic action) separate from a long-term participatory (direct action) strategy." An example of this disempowerment was the antiwar marches held throughout New Zealand and the world, in opposition to the US invasion of Iraq in 2003. While upwards of 24,000 people protested, in possibly the biggest anti-war march in New Zealand's history (Stephen 2007), there was no sustained mass opposition to the invasion, a trend seen worldwide (Ali 2008). The marches were the first experience of mass action for many of those involved (Stephen 2007), and it is possible people were disenchanted by the failure of the protests to gain momentum.

The diminished effectiveness of marches, as conceived by interviewees, appears to have some generational aspects. Benland mentions that in the early 1960s they would protest "at the drop of a hat." She characterises the period as one where protest marches were perceived to have strong transformative powers: "The first half of the sixties... were characterised by the belief that we had only to point out what was wrong by marching, and we would affect society...we would point out a solution, and things would change." Hager also gives an example of protest having been an effective means of achieving change in the past, but as a part of a wider campaign. He considered the success of the 
Native Forest Action Council in the 1980s to be due, in part, to tapping into a growing environmental awareness in the country, and utilising "high visibility, public education campaigns...street protests and letter writing." It would seem that protest marches are most effective when combined with other actions.

Overall, a trend emerging from my research was the turn from expressive actions (such as protest marches) to instrumental ones. An aspect of this appears to be the perceived ineffectiveness of reaching 'mainstream' society through public protestcoupled with the notion of how ineffective protests damage political movements. In place of symbolic protest there is push from some activists to adopt direct action. Examples of direct action can be wide ranging, including blockades, pickets, occupations, sit-ins, the establishment of food co-ops, general strikes and industrial actions (Sparrow 2008). Some consider protest marches direct actions; however, as it is the protesters themselves who determine if an action is direct or not (Carter 1973), and as most of those interviewed saw marches as something different to direct action, I have not included them in considerations of direct action. Generally, it is held there are clear links between the tactics and goals of a direct action (Carter 2005): an example being Tánczos's role in the uprooting of Genetically Engineered (GE) plants in opposition to GE in New Zealand (Greens 1999).

Some hold direct action to be for those without access to channels used by the elite (Carter 2005) and as the recourse of "frustrated radicals" (Lunori 2008). However, even if those advocating direct action did have access to the higher echelons of society they would not necessarily wish to use such channels. While liberals may see direct action as a means of achieving ends, direct action is a treasured centrepiece in anarchist theory where it is generally seen as an end itself.

From an anarchist perspective (and others too), direct action is a constructive process (Carter 2005) which emphasises the empowerment of individuals. As defined by Murray Bookchin (1971: 74):

Direct action is a basic revolutionary strategy, a mode of praxis intended to promote the individualisation of the "masses." Its function is to assert the identity of the particular within the framework of the general. More important than its political implications are its psychological effects, for direct action makes people aware of themselves as individuals who can affect their own destiny. 
This focus on the transformative aspects of direct action is echoed in the approaches taken by Oosterman, Tánczos and Hodgson. Hodgson considers a protest he was part of at Te Papa, which turned into an occupation, to be one of the most effective actions he has been a part of as it empowered others. He feels:

it has to have had some sort of radicalising tendency....Same with effective strikes, you keep your job which is mundane, but the fact is that a lot of people find out what happens when you work together and take on the powers that be. That's perhaps the most important aspect of what comes out of it: the collective strength and the willingness to take action.

In line with Bookchin's definition, what is important for Hodgson is the empowerment of others: "we want to see it [activism] as a role that everyone can take on."

Tánczos shares a similar view. For him involvement within any organisation needs to lead to other people becoming involved in actions: "because being active is being free... [its] asserting your ability to operate as a human being." He cites this as the reason for his past involvement with the National Organisation for the Reform of Marijuana Laws. The legalisation of cannabis was the "biggest issue" in many peoples' lives, hence one they would become involved in. Despite the campaign's lack of success, Tánczos considers it was valuable as it motivated many people to become active. In place of seeking to influence the population as a whole, direct action builds resistance from below - a slower, but potentially more effective tactic.

Strikes have been a long standing form of direct action, although the categorisation of union-led strikes as a form of direct action has been contested by some (Lunori 2008). Union involvement, argue some, leads to the institutionalisation of rebellion, and hence the nullification of strikes as rebellious acts (Carter 1973). Such views were contested by some of those interviewed. Hodgson holds that it is not the issue of union involvement in strikes that is contestable, but rather the structure of the union: "if the union is horizontal, if there is no separation between workers and the union, that is to say, if the workers and the union are the same thing, then striking is absolutely direct action." While Oosterman has some misgivings about union structures-and is only involved in unions as there are no non-union workplace 
movements-he contends that "being in a union can be a direct action. Direct action isn't just protest and strikes, it's about doing things for yourself." Further, his notion of direct action holds it to be more effective when it involves more people, with strikes being a good example of collective direct action. To underline this point Oosterman gives the example of:

the $\$ 80,000$ of illegal night time activity during the Progressive lockout (smashed windows, glued or broken locks, product damage, flooding) with the $\$ 1,000,000$ a day losses caused by industrial action. In other words, strike action, done by workers themselves, can have more economic impact that illegal activity by a small group of activists.

In line with literature stressing the importance of social movement participation rising out of life experience (Giugni and Passy 2000), Oosterman feels it is through the workplace that people are most likely to become involved in mass action ("though not with a 'click of the fingers,' it requires long term action"). The strike, supported by the union, is a means of politicising individuals within the workplace. A successful outcome in a strike, for Oosterman, is the awakening of an individual to the power of collective action.

Following considerations of new unionism in Chapter Three, Unites' 2005 "Supersizemypay" campaign signals a major turn in union activity within New Zealand. Oosterman considers it to have been a shock to other unions:

We felt like it woke a lot of officials up in other unions to what they thought could and couldn't be done-like organising in a completely de-unionised industry. The fact that young people were involved also broke down some ideas people had about young people not wanting to join a union and organise collectively. Then there is the fact that people took action when they had never done so before with very little prompting from officials. Some of the strategies and tactics that we used-which would seem completely obvious to non-union activists who have developed these strategies in the absence of having the power of industrial action-like using the media and creative actions to get publicity was also new to some unionists.

A large part of the campaign was theatrical. Oosterman considered it to have used 
"guerrilla tactics" to make it appear larger than it was, which created an impact on the media who gave it wide coverage. Such tactics helped lead the campaign to success, with it achieving most of its goals. The intangible, but perhaps greatest, success of the campaign was the introduction of a new generation to industrial action-which, for Oosterman, makes the campaign one of the most successful he has been involved with. He adds that at the same time that:

the bad thing about the campaign was that we didn't look at our strategies and tactics and develop better ways to involve members and create more member led action. It was perhaps not as successful as some people think, I think that it broke down some barriers or previously held ideas, which was a bigger win than what we won on the ground-the confidence it gave to people.

Overall, while it used expressive tactics Supersizemypay was grounded in instrumental strike actions; its success can be attributed, in part, to cleverly intertwining the two.

A component of the Supersizemypay campaign was the direct targeting of the fast food restaurant brands managed by Restaurant Brands. As held by McCarten, the success of campaigns like Supersizemypay comes from "embarrassing them [the companies], we try and embarrass them in the public arena, hit their brand." The prominence of a company's brand is the source of their strength but also, as many activists have discovered, its Achilles heel (Bennet 2004).

Oosterman considers continuous, planned, strategic direct action against brands, as part of a clear long term strategy, to be more satisfying and successful than reactionary one-off protests. In particular, he mentions action taken against GE in New Zealand. There had been a series of high attendance marches, but it was felt they were achieving little:

A small group of us were...a bit annoyed with the way we were doing activism. We wanted to do an actual campaign against a company. We chose KFC and held sustained protest action against them to force them to stop using genetically engineered feed. We always seem to do a big symbolic protest every five years for the new big issue, but if we can target a company, as well as [deliver] a political message, we've got much more chance... of affecting it, on hitting their bottom dollar, than we do on changing the government... It's very important to win something so people know their actions can 
create change. By building up wins we can build people's confidence and power to change government.

The strategic targeting of brands has proven an effective strategy as it cuts into a company's profit and forces them to change their actions. A similar logic can be seen at play within SHVC's campaign, Hodgson contends that actions against Solid Energy (whose proposed mine the coalition opposes) have cost the company a lot of money, "which is one of our programme goals, and that comes into out economic analysis: they think in terms of profit and we cut into that." Activists in New Zealand can use attacks against a company's brand, and threats to its profit margins, to great effect.

This is indicative of what would appear to be a wider trend in contemporary New Zealand activism, where there has been a turn from expressive (or symbolic) actions to more instrumental, and often direct, actions. While there appears to be a high degree of agreement around what constitutes successful tactics, there is a degree of divergence around organisational issues.

\section{Organisational Issues and the Activist Strata}

The third phase of the Left, I have suggested, involves a re-convergence of different strands of the Left. However, this phase is not without the organisational tensions seen within both the first and second phases of the Left (see Chapter One). These tensions can be seen within the contemporary New Zealand context and will be explored through looking at issues within Unite, and unions more generally, against wider considerations of activism.

Despite the success of Supersizemypay and Unite more generally, there were critiques of both. It is held that once the campaign began, many of the young striking workers started to self-organise and hold their own wildcat strikes. An article posted on Aotearoa Anarchist Network critiques Unite's response to this, holding that Unite used grassroots activity to start the campaign, and then turned its back on this once a point had been reached where negotiations with bosses could begin. The rank-and-file membership, it is argued, were not adequately consulted, proving Unite to be another hierarchical union. Therefore, Supersizemypay is seen as a conventional union drive that used unconventional tactics (Anarchist Aotearoa Network 2007).

McCarten expresses annoyance with these critiques and at some aspects of 
anarchist thinking. He contends these critiques “don't understand that sustained organisation is the key. Actions in themselves are nothing (if not somewhat indulgent) if you don't build. Every fight is about the next fight." He holds that the only negative feedback he has received is "from non-members and some of the crew who worked on the campaign, which given their hard work is understandable." However, all delegates involved in the campaign approved of its outcomes. Overall, McCarten feels there needs to be more critical comparison between anarchist and socialist models of organisation: "I think the bureaucratic arguments by anarchists [as seen in Chapter Three] are just blatantly wrong and I don't think there is any evidence that suggests it should be given serious credibility." The Supersizemypay campaign showed that tensions seen within the contemporary Left internationally are apparent within New Zealand also.

To some degree the tensions presented above represent a clash between the organisational practicalities faced by Unite and the relatively unbounded space of activism in general. Oosterman, despite misgivings around union structures, feels they have many benefits considering problems he faced when operating within the more fluid realm of activism:

Outside of Unite and NDU there aren't really clear long-term goals or campaigns held by many activists. There doesn't seem to be a [prioritisation towards producing] structures or education for getting new people involved in activism. It may be my own interpretation, and I'm not saying I'm any better, but activism seems to be poorly coordinated and ad hoc. There aren't any well known mechanisms for building people's skills and learning from past experiences. People generally build their skills through doing protests and actions but it [activism] also doesn't have the necessary channels for analysing our successes and assessing it, when necessary...[for] strategic planning. This situation really frustrated me and pushed me towards being more involved in unions.

Unions provide a structural grounding for Oosterman's actions. Further, the organisational structure of unions is seen to be useful for building links with other groups and organisations. Whereas a group of activists can move from one issue to another changing name and form as they go. Due to this, holds Oosterman, community organisations are unable to recognise they are dealing with essentially the same group of activists. The group's "profile starts from scratch each time, except for a general feeling of 'its rent-a-mob'." It would appear that unions, or other more consistent and 
persevering groups, may be more effective in building and maintaining enduring networks.

The maintenance of links between different actors and organisations is a central feature of network theory. Through developing more links the strength of the wider network is held to grow incrementally (Urry 2003). The nature of my research made it hard to ascertain the degree to which links between different groups existed. Tánczos expressed a high degree of interest in how to link "organisations and communities into networks, or into confederations, or mutually supportive cooperatives or whatever." In the absence of organisational bodies putting energy into the development of links between groups, what emerges are more ephemeral shifting links.

Hodgson does not see the ephemeral nature of the networks and organisational processes of activism as being necessarily problematic, he holds that links and organisational structures emerge when they are needed: "Lots of people push organisation as the be-all and end-all, but I find if organisation is needed it will come about." In keeping with trends seen in some social movement literature (Klatch 2002; Passy 2003; Jasper and Polletta 2001), Hodgson considers some of the most valuable links to be informal personal ones-he considered the Aotearoa Social Forum (affiliated to the World Social Forum), which was held with explicit purpose of developing networks between activists (Aotearoa Social Forum 2003), to be "totally liberal and totally dumb," yet it allowed him to develop some lasting personal links. However, Hodgson considers these links — existing within the fluid spaces of activism-to be problematic in a sense, because as a "way of communicating it...excludes others who don't have those ties."

This notion of unintended exclusivity feeds into a wider concern raised within my research, that of an imagined stratum of activists emerging. Some spoke of the importance of a group of committed activists for enacting change, while others felt such a stratum diminishes the likelihood of the wider populace becoming involved in action. Hager argued strongly in favour of a "group of organised and committed campaigners," who are needed to:

organise, mobilise and direct the energy of the wider populace onto issues they are concerned about. This group of campaigners is able to articulate concerns that already exist within the wider populace and coordinate their efforts towards the attainment of a 
particular goal. Humans are political animals so they will always be concerned and hold opinions about the things they see happening around them, but if there is no coordinated organised group of campaigners around, then there is unlikely to be significant change.

Hager argued this committed group is needed to start wider actions. Oosterman, while not entirely diverging from Hager's view, is concerned about the creation of a:

class of activists that are separate from everyday people like a professional class which is an authority or a hierarchy unto itself... I just don't want to create a situation where people are idolising individuals for the things they do rather than people realising they've got the strength in collective power.

Oosterman holds that those opposing authority structures need to avoid rebuilding them within the activist sphere, a common problem being that people come to see leaders as creating change rather than participating in collective power. While individuals may initiate campaigns around certain issues Oosterman considers it important that structural leadership is avoided.

Tánczos presents a similar argument, holding "the point of the organisation should be to generate people's ability to be active." However, he feels it is difficult to avoid the establishment of a stratum of activists (a long standing problem within movements, see Freeman 1972)—as some people are really good at being activists and enjoy it, while:

some people don't really want to spend their life butting their head against a wall—which is really what it feels like a lot of the time.... If people are organised, you do end up with a strata of people who are politically minded because there is a whole lot of stuff that needs to be done, and people don't want to participate in every decision, so that's okay, as long as people have the ability and the opportunity to get involved when things matter [to them].... and actually have a meaningful say.

Tánczos's position is similar to Hager's: the stratum of activists, or campaigners, is to some degree inevitable. McCarten occupies similar ground; in the case of unions he holds that: 
To build anything you need some element of full-time and dedicated leadership and cadre. To think that rank and file members have time to learn all the skills to take on corporates, as well as hold down a job, is ridiculous.

Rather than being a bar to wider involvement, the stratum could be considered a valve through which the normally latent political activity of the wider population is able to escape when placed under pressure.

This stratum can also provide an informal learning environment for emerging activists. Tánczos speaks of the importance of established activists being able to pass skills onto others and share experiences (a similar argument can be seen in Maddison and Scalmer 2006). He feels that "one of the problems at the moment is that there are a lot of people wanting to become active and they've got no clue how to go about it." This relates to Hager's earlier comments about this culture eroding with the advent of neoliberalism; it also speaks to Oosterman's decision to operate within unions as there was no analogous space within activism (see Chapter Three).

There seems to be an inevitable practicality to the creation of a stratum of activists, or the need for a more tightly organised body of campaigners, as can be seen within unions. It would also seem inevitable, as can be seen, that such an approach will attract criticism. Key concerns appear between the practicality of enduring organisational structures-which provide resources, develop lasting links between groups and free individuals to work on behalf of others-against concerns of rigidified leadership positions, or of an exclusive stratum of activists, which diminish the likelihood of the wider populace taking active roles and recognising the strength of collective action. The tensions present here mirror those seen elsewhere within the contemporary Left. One point that did find wide acceptance however, was the importance of a strong activist culture. Intentional communities are considered by some an important means for strengthening such a culture (Crossley 1999).

\section{Intentional Communities and a Constructive Programme for the Left}

Intentional communities are considered here as a means of approaching a strong theme running through much theorisation of resistance today, that of the role played by the "local." Santos and Castells consider the local to be site from which counter-hegemonic globalisation is most likely to arise. Santos considers the local as the space where "new 
fields of possibility" are opened. Are such hopes applicable to intentional communities? Which have been labelled by some as 'working utopias:' experiments in every day life grounded in social movement praxis that bolster the imaginative momentum of wider activist community (Crossly 1999). Can intentional communities in New Zealand be considered part of the wider social movement community and do they play a role in building an alternative social order?

For Hardt and Negri (2001) resistance can take the form of evacuating places of power. For many of those interviewed within intentional communities, it would appear such an evacuation consciously took place. Some held that the change they wished to see could not be made while they lived in mainstream society, echoing anarchist sentiments of "living the revolution." McCurdy found such issues as economic inequality too huge and intangible for her to have any real impact on through working directly within society. Cole also found society as it stood in the 1970s an impediment to "going forward." The time she spent as a teacher, working within the culture of schools, showed her "another way might be better." Through becoming involved in intentional communities actors hoped to evade, to some degree, the confines of dominant social structures in the hope something better could be constructed, holding that this alternative could be rooted in everyday life.

In this sense intentional communities are constructive projects, as opposed to the short term, reactive elements of many other forms of protest. Muter spoke of his involvement in intentional communities as "something positive I could do rather than agitating around issues, which I had been doing for years and had only been getting frustrated by." A member of Riverside offered similar sentiments, for who being involved in community was a means of moving beyond the frustrations of "manning the barricades," which he considered an unsustainable practice in the long run. Tánczos also praised the constructive elements of intentional communities, along with other cooperative initiatives, considering them part of "our positive programme, as opposed to our demonstration protest stuff, it's about building examples of how to organise ourselves and how to work together." This positive programme, inherent in the founding of intentional communities, represents a constructive move beyond protest activity.

The outcome of this positive programme for those interviewed from intentional communities, beyond improving the conditions of their own everyday life, is to offer a viable alternative to mainstream society. They see their role as being action through 
influence. McCurdy was motivated to become a founding member of Tui in order to create "a living example of sustainability—a beacon of light on the planet-to demonstrate sustainability, equality and healthy human relationships." Orr sees Tui as providing an example to others, which, he feels "is probably the best thing we do."

For 'action as influence' to have a wider effect, it needs to reach a wider community. The degree to which the community interacts with others-on a more formal or organised manner, rather than informal social or familial ties-is important to consider when conjecturing the extent to which intentional communities are an active part of a wider social movement, and also in trying to map links to a wider movement network, if such a thing exists. When asked about the contacts Tui had with other communities Orr held:

There's not a lot of 'social movement' going on here, it might be nice in theory, and over the years we have tried to be something. Like when we created Tui Tamala [the meditation centre] in 1990 there were people going on about the Findhorn of the Southern hemisphere.... But slowly...its got to a stage where just being who you are, if it can be genuine and good, is worth more than having an active social movement. But if that happened spontaneously and people were really fed from it, that would be great, but that doesn't really happen here.

Orr felt it was more valuable for a few people to move through the community and have a depth of experience than for many people to pass through the community and have a more superficial one.

Orr noted that McCurdy is perhaps more active in trying to foster ties outside the community. McCurdy's life in Tui is integrated within a wider range of activities concerned with her goal of re-connecting nature and culture (Green World 2008). She plays an active role within the wider environmental movement through designing and teaching permaculture systems, developing environment educational resources and sharing her experiences of participatory processes for decision making and collective action-both nationally and internationally. A number of these educational initiatives are run by McCurdy at Tui. Other programmes are also run through the Tui Trust, but these are generally more focussed on self empowerment or realisation as related to gender, examples being the "rites of passage" programmes held "for boys becoming Young 
Men" and "girls becoming Young Women" (Tui Trust 2007). Tui's Bee-Balm co-op can also be seen as developing links, to some degree, outside the community through donating a third of its profits to outside charities (with the other two thirds going to the Tui Trust); Muter also hoped to share the co-op's business model with others.

None of these initiatives represent any fixed model of involvement with other intentional communities or wider social movement groups. However, there are a number of informal interpersonal links to points outside the community, along with some members of Tui having more formal links with outside organisations; as can be seen with McCurdy who has received funding for her projects from both governmental and non governmental organisations (Green World 2008). While it is difficult to map Tui, as a community, within a network of groups active within what could be considered an 'environmental social movement,' it does appear to have a large amount of informal ties to a wider movement; for instance, a number of informal contacts appeared to exist between Tui and Riverside.

The number of links between Riverside and other groups is also hard to quantify. In the past it had more definite links with other communities. Vincent spoke of their previously providing interest free loans to other intentional communities, although they were no longer in a financial position where they could do so now. As recounted by Cole, the community also gives their blessings and financial support to any of its members who wish to attend peace events in the country-with members having attended the protests at Te-Papa Hodgson spoke of earlier, and with Vincent being a regular protester at Waihopai every year. Riverside also hosts events to raise awareness around peace issues, one of these being the Parihaka Peace Festival they have begun to hold annually, along with providing a venue for peace groups and other such organisation to hold meetings.

Overall, it can be seen that intentional communities are not, from the observations I was able to make, enmeshed within particularly dense networks of social movement action. There are many personal, informal links, along with an openness within the communities to passing on skills or offering the use of their resources to others, but the extent to which they could be considered an active node within a wider network of resistance would require more research to ascertain.

A feature they did share with the wider social movement community was a negative reaction to the neoliberal turn. This could be seen in McCurdy's overview of the 
transitive phases Tui had passed through. Originally the community was founded on an explicitly socialist approach, with all incomes pooled, and a belief that this would "bring a greater quality of life, a more cohesive sense of community along with a higher productivity of labour and goods." This was combined with an ethos of living as "lightly on the planet" as possible. Early on the community was able to receive some government assistance, but this was taking place around 1984, a year McCurdy considers to have been the end of era in New Zealand history, an era in which "everyone was 'guaranteed to have enough'."

The development of Tui from this point seems to reflect wider societal changes during the ascendancy of neoliberalism. McCurdy tells of richer members moving into the community during the early 1990s, bringing a pressure to bear on other members to be financially self-supporting and introducing a consumer ethos. Overall, in recent years there has been a declining focus on community and a "rise in individual freedom and choice." Similar trends, though less marked, were seen at Riverside. However, saving Riverside from the predicament faced by Tui, holds McCurdy, is that the community trust owns all the houses in Riverside. Collective ownership of houses in Tui would, to some degree, have allayed "the socialist and capitalist mix at Tui, [which is like] oil and water." Tui has struggled to find a middle ground between the two.

Intentional communities, for all the potential they may offer as alternative sites of resistance, or for the production of alternative meanings, have in the cases considered above not shown themselves immune to wider social changes. Neoliberalism, and its individualistic focus, have impacted on Tui despite the founders desire to create a working example of eco-socialism. The hopes pinned on alternative communities are not necessarily ill-founded, but the New Zealand cases are evidence that they are fragile. While the notion of evacuating the sites of enemy's power as put forward by Hardt and Negri seems attractive, in looking at the case of intentional communities it is hard to imagine how this evacuation could ever be complete. The more realistic view of what is possible, perhaps, is presented by Santos, who feels the creation of alternative sites of production needs to happen within the limitations of capitalism as they stand at this point (Santos 2005b).

The key to transcending the limitations of capitalism, and to produce an alternative society, is arguably related to the strength of the alternative networks that can be built. As seen in the case of the communities studied here, the links outside of the 
community were relatively informal and fluid. It is interesting to raise the question of how stronger cooperative links between communities, and other social movement groups and organisations, could potentially strengthen the ability to resist the dominant social/capital practices to which intentional communities, at this point in time, are not immune.

Communities do, however, present the constructive possibility of building the alternative here and now. Fredric Jameson has famously claimed that it is now easier to imagine the end of the world than the end of capitalism (Jameson 1994). This statement seems relevant to contemporary New Zealand activism. When asked about his optimism towards significant social change, Muter quipped he could see hope in the sea levels rising. Tánczos, Oosterman and Hodgson all raised the issue of impending environmental catastrophe as foregrounding the possibility of substantial changes in human relations-for better or worse. The impression given was that activism as it currently stands is not enough to cut through embedded habits of consumption and socialisation-only crises could precipitate meaningful change. The lesson would seem clear, either begin to construct alternatives or, as Tánczos stated, more authoritarian modes of thinking may prevail. While Chapter One suggested there may be a rising optimism in the Left, it would seem a high degree of scepticism prevailed here-if environmental catastrophe is seen as the most likely arbiter of positive social change, then optimism has taken a strange form. Nevertheless, despite intentional communities' shortcomings, they did present a constructive project already underway that is engaging with some of the environmental concerns present today (other examples of constructive projects would be community gardens within cities, or the anarchist-run bike repair workshop in Wellington).

A greater emphasis on constructive projects for the Left would seem important within the contemporary era, where some have begun to equate activism with terrorism following 9/11.9/11 and the resultant 'war against terror' have had negative impacts on activism and extra-parliamentary politics worldwide (Falk 2005; Kaldor 2005; Starr 2003). It was clear these trends would visit New Zealand activism (Morse 2007), and the 'anti terrorist' Operation Eight, that led to a series of raids and arrests targeting indigenous, peace and environmental activists, is seen to express a view that activism has come to equate terrorism for some within New Zealand (Jackson 2007).

Tuiono contends that what the police and state did not expect, following the 
arrests, "is that the different activist communities would pull together and support each other" - a point also made in other interviews. While the arrests had unifying effects, they also highlighted some of the fundamental divisions in the wider movement. Hodgson speaks of it highlighting the division in politics between anarchists and liberals, as liberals call for the terrorist bill to be repealed while ultimately believing the justice system is fine. For him, “it's hard to sympathise and work with those people when they are basically calling for our friends to be punished, and just being interested in a difference of law." While the arrests highlighted the need to come together to fight a common threat and, I would argue, show the importance of developing a constructive programme for the Left, Hodgson's comments attest to the fact that there are many unresolved tensions within the extra-parliamentary Left.

\section{Conclusion}

Members of New Zealand's extra-parliamentary Left, and even Tánczos who was an MP at the time of his interview, were sceptical of the country's parliamentary system. It was seen by some as an ineffective sphere of action with structures, or a culture that undermined individual politician's convictions; parliamentarianism was sited as a problem. Such views echoed aspects of the post-politics debate, as did a widespread disillusionment with a sensationalist mainstream media; although some activists were able to effectively harness this sensationalism, others advocated developing a separate media. An issue that arose from such considerations is that of reaching 'mainstream' New Zealand, an apparently problematic constituency for the Left.

In keeping with scepticism about the media, and the difficulty of reaching 'mainstream' New Zealand, there appeared to be a rejection of solely expressive (or symbolic) forms of action in favour of instrumental actions, or 'direct action,' a term reflecting the anarchist influence within the third phase of the Left. This influence heightens debate around organisational forms. A debate arose that oscillated around the manner in which strong organisation is seen to have practical outcomes-such as the development and maintenance of links with other organisations-but may lead to the creation of an activist stratum, at the expense of promoting collective action through the wider society (although most did agree that a strong activist culture is important). However, it was argued by some that being an activist is a frustrating, often reactive role that not everyone would wish to take on. 
In light of the limitations of reactive activism, consideration of constructive projects becomes important. Intentional communities present such a project through seeking to ground social movement values in everyday life. However, these communities did not appear immune to wider social changes. While they present the potential to be strong local sites of resistance, the degree to which they could be charted within a wider network of resistance is still unclear. 


\section{Conclusion: Renewal}

In answer to the question opening this work, I would tentatively suggest that the Left is undergoing renewal. While ample cause for pessimism can still be found in the literature explored in the preceding pages, I believe that the Left has moved past the point of historic failure Anderson marked eight years ago

After contending that there were three historic phases to the Left, I suggested in the First Chapter that the third phase presented a potential re-convergence of the Left, with concerns of redistribution being married to those of recognition. Much of the literature posits social movements, in both form and action, as forces of renewal in a world smothered by neoliberalism. The anti-globalisation movement, Global Civil Society and the World Social Forum are often taken as signs of an emerging network of resistance; "the local," specific localities developing alternative social forms, are frequently considered prized nodes within this network. For Hardt and Negri the most potent act of resistance is the evacuation of the enemy's sites of power, testifying to the importance of developing alternative networks to challenge those of Empire. A chapter that opened with a narrative of the Left's decline closed with suggestions of renewal.

Chapter Two explored the first two phases of the Left within New Zealand. The first phase of the Left was not pronounced here. The Old Left embarked on a reformist, state-focussed path, from early in the country's development; along with Maori resistance groups, radical expressions of Left activity were violently, and effectively, crushed by the state. The second phase of the Left was prominent in New Zealand, as seen within the activities of various social movements. With the exception of the Maori protest movement, it was suggested that these movements were largely reformist, with their demands easily absorbed by the Labour Party. Further, a strong liberal individualism, coupled with an internationalist outlook, saw these movements caught off-guard by the onset of neoliberalism under the Labour party. It was suggested that within New Zealand, as elsewhere, the New Left, and the social movements associated with it, were partially responsible for opening the space in which neoliberalism gained purchase. Despite these shortcomings, the second phase of the Left in New Zealand generated widespread positive social changes. Such victories as a nuclear free New Zealand are partially attributable to the Left's, and associated social movements, ability to mobilise, or 
inspire, the wider populace.

Chapters Three and Four sought to asses the fit between theoretical literature and the experiences of those involved in Left social movements in this country. In Chapter Three I focussed on issues of the third phase of the Left in New Zealand. Notions of "the Left" were found problematic. Anarchism's prominence in the third phase leads to contentions around the manner in which the Left is often conflated with state affirming practices. More widespread was the view of the Labour party as problematic-a point which seems to follow the manner in which it disempowered the New Left and introduced neoliberalism. As was the case internationally, the extra-parliamentary Left here strongly opposes neoliberalism. However, shared opposition does not lead to unification. The Left here has remained fragmented, although this fragmentation is not seen as a bar to cooperation-provided groups can retain their autonomy. Further, there was evidence of the proposed re-convergence of issues relating to redistribution and recognition. New unionism provides an example of such convergences, with longstanding categories like class being combined with a social movement style of unionism. Also, in contrast to contentions in the literature, there appeared a willingness to engage in collective action. It would appear the New Zealand Left is not in decline, but it is a site of continuing contention - a feature found within the third phase of the Left elsewhere.

Continuing with explorations of the third phase, Chapter Four opened with considerations of the space in which New Zealand's contemporary Left operated. In common with "post-democractic" trends seen elsewhere, parliamentarianism and a sensationalist media were identified as key problems. Tied to these problems was, for some, the difficulty of interacting with 'mainstream' New Zealand. Such difficulty appears to have lead to a rejection of explicitly "expressive" forms of protest in favour of "instrumental" ones; with instrumental actions, or direct actions, valued as a means of empowering others. As articulated by an interviewee from an intentional community, the depth of experience is more important than wide ranging superficial ones. Intentional communities provide examples of viable constructive projects, but the ability to vacate the enemy's sites of power (as enthused over by Hardt and Negri) was problematic to the degree that, while this had been a motive (to some extent) for some found in communities, the communities themselves were not immune to the vagaries of wider social change. The notion of the local, as explored in the context of the intentional 
communities, was not discredited by such a finding, but it does appear to be surrounded by difficulties.

In terms of future research, I feel a more in depth study of Unite, and the unions it may be merging with, would be valuable for exploring the notion of "new unionism." Further, a more detailed study of what is considered by activists and social movement actors to be 'constructive' projects would be useful for gaining a clearer notion of what the future may hold. Relating to such issues, would be the usefulness of trying to develop a more systematic understanding of the links between groups: if alternative networks are an important element of resistance, then what shape are these networks taking? On a another front, following research for Chapter Two, a strong link between resistance in this country and religion appeared—stretching from such figures as Te Whiti, to conscientious objectors, to the Peace Squadron, to the recent actions of Ploughshares at Waihopai (Converge 2008) — that has yet to be explored in detail.

Overall the trends I found within my research suggest the Left is not in terminal decline. While there are no mass movements in place today, many activists seemed intent on building solid foundations from which to act in the future. These building sites do not rest upon the foundations of a unified Left. Rather, each site follows its own blueprint, its own structure. However, reflecting wider considerations of the importance of networks, it would appear there is a willingness to see roads built between each site. What traffic these roads will see is a question for the future. For the meantime, to build is enough-it is a sign of renewal. 


\section{Bibliography}

Adorno, Theodor \& Max Horkheimer. (1989) "The Culture Industry: Enlightenment as Mass Deception” From: Dialectic of Enlightenment. New York: Continuum.

Albrow, Martin \& Helmut Anheier. (2007) "Violence and the Possibilty of Global Civility." From: Global Civil Society 2006/7. (Ed.s) Mary Kaldor, Martin Albrow, Helmut Anheir and Marlies Glasius. London: Sage

Alexander, Jeffrey C. (2006) The Civil Sphere. Oxford: Oxford University Press.

Ali, Tariq. (2008) "Where Has All the Rage Gone?"

Http://www.guardian.co.uk/politics/2008/mar/22/vietnamwar. Accessed: 16/04/2008.

Allen, Sue. (2006) “Super Size My Pay.” From: The Dominion Post, 18/02.

Amin, Ash. (1995) "Post-Fordism: Models, Fantasies and Phantoms of Transition." From: Post-Fordism: A Reader. Oxford: Blackwell.

Anae, Milani. (2006) Polynesian Panthers: the crucible years, 1971-74. Auckland: Reed.

Anderson, Perry. (2000) "Renewals." New Left Review 1. Jan Feb.

Anis, Roger. (2008) "New Zealand Union Campaigns to Organize Young Workers" Http://www.unite.org.nz/?q=node/178. Accessed: 18/02/2008.

Aotearoa Anarchist Network. (2008) "Super Size My Pay - Fast food workers in New Zealand organise for better pay and conditions, 2005-6" 2007.

Http://anarchism.net.nz/node/11. Accessed: 23/02/2008.

Aotearoa Social Forum. (2008) Http://www.socialforum.org.nz. Accessed 10/03/08.

Archie, Carol. (1995) Maori Sovereignty: The Pakeha Perspective. Auckland: Hodder Moa Beckett.

Arrighi, Giovani. (1990) "Marxist Century, American Century: The Making and Remaking of the World Labour Movement." New Left Review 79. Jan Feb.

Arrighi, Giovani, Terrance K. Hopkins \& Immanuel Wallerstein. (1989) Antisystemic Movements. London: Verso.

Augustyn, Boguslaw, Jackie Smith, John D. McCarthy \& Clark McPhail. (2001) "From Protest to Agenda Building: Description Bias in Media Coverage of Protest Events in Washington, D.C." Social Forces, Vol. 79, No. 4 Jun.

Awatere, Donna. (1984) Maori Sovereignty. Auckland: Broadsheet.

Badiou, Alain. (2008) “The Communist Hypothesis.” New Left Review 49. Jan Feb. 
Bagdikian, Ben H. (1997) The Media monopoly. New York: Beacon Press.

Ballvé, Teo. (2006) "From Resistance to Offensive: NACLA and Latin America." From: Dispatches from Latin America. (Ed.s) Teo Ballvé \& Vijay Prashad. Cambridge: South End Press.

Bakunin, Mikhail. (1972) 'Preface to Second Instalment of L'Empire Knouto-

Germainque." From: The Paris Commune of 1871: The View from the Left. London: Jonathan Cape.

Barkham, Patrick. (2007) “16,000 Police Deployed to Halt Violence.” The Guardian. Tuesday June 5.

Barnes, Jock. (1998) Never a White Flag: the memoirs of Jock Barnes, waterfront leader. (Ed.):

Tom Bramble. Wellington: Victoria University Press.

Barber, Benjamin. (2001) Jihad vs. Moworld. New York: Ballantine Books.

Basset, Michael. (1972) Confrontation '51: the 1951 waterfront dispute. Wellington: Reed.

Baudrillard, Jean. (2005) The Intelligence of Evil or the Lucidity Pact. New York: Berg.

Baxter, James K. (1971) Jerusalem Daybook. Wellington: Price Milburn.

Belich, James. (2001) Paradise Reforged: A History of the New Zealanders From the 1880s to the Year 2000. Auckland: Allen Lane/Penguin.

Bendien, Jurriaan. (1980) Left In New Zealand. Christchurch: Unpublished.

Bennet, Lance W. (2004) "Branded Political Communication: Lifestyle Products, Logo Campaigns, and the Rise of Global Citizenship". From: Politics, Products, and Markets: Exploring Political Consumerism Past and Present. New Brunswick: Transaction Publishers.

Boltanski, Luc. (2002) “The Left After May 1968 and the Longing for Total Revolution." Theses 11, 69.

Bookchin, Murray. (1971) Post Scarcity Anarchism. Berkley: The Ramparts Press.

Boraman, Toby. (2007) Rabble Rousers and Merry Pranksters: A History of Anarchism in Aotearoa/New Zealand From the Mid 1950s to the Early 1980s. Christchurch: Katipo Books.

—(2005) “The Myth of Passivity.” From: Red \& Green. Vol. 5.

-(2002) "The New Left in New Zealand" From: On The Left: Essays on Socialism in New Zealand. (Ed.s): Pat Moloney and Kerry Taylor. Dunedin: Otago Universtiy Press.

Bowring, Finn. (2002) "Post-Fordism and the End of Work." Futures 34. 
Boxall, Peter and Peter Haynes. (2008) 'New Zealanders' Influence at Work: Report on the New Zealand Worker Representation \& Participation Survey." 2003.

Http://www.psa.org.nz/library/other/Miscellaneous\%20Papers/Haynes\%20Boxall\%20 and $\% 20 \mathrm{Macky} \% 20$ -

0Worker $\% 20$ Representation $\% 20$ and $\% 20$ Participation $\% 20$ in $\% 20$ NZ $\% 20-\% 202003$.doc. Accessed: 20/02/2008.

Boxall, Peter. Jack Vowles and Peter Boxall. (2005) "Explaining the Younger-Older Worker Union Density Gap: Evidence from New Zealand." British Journal of Industrial Relations. 43:1 March.

Braunthal, Julius. (1966) History of the International 1864-1914. London: Nelson.

Brooker, Paul. Warren Feek, Dianna Latta, Krishna Menon, Clare McAloon \& Christopher Wainwright. (1976) "Sexism in New Zealand." From: Learning About Sexism in New Zealand. (Ed.s): Phillidda Bunkle, Stephen Levine \& Christopher Wainwright. Wellington: Learnmonth.

Brunn, Erik. Sheryl Lechner \& Frank Lowenstein. (2007) Voices of Protest: Documents of Courage and Dissent. New York: Black Dog and Leventhal.

Butler, Judith. (1998) "Merely Cultural” New Left Review 227, Jan Feb.

Callinicos, Alex \& Chris Nineham. (2007) "At an Impasse? Anti-Capitalism and the Social Forums Today." From: International Socialism. Issue 115. July.

Castells, Manuel. (2005c) “Grassrooting the Space of Flows.” From: The Global Resistance Reader. (Ed.) Louise Amoore. New York: Routledge.

- (2005a) The Rise of Network Society (Volume I of the Information Age: Economy, Society and Culture) (second edition). Malden: Blackwell.

-(2005b) The Power of Identity (Volume II of the Information Age: Economy, Society and Culture) (second edition). Malden: Blackwell.

Carter, April (2005). Direct Action and Democracy Today. Cambridge: Polity.

—(1973) Direct Action and Liberal Democracy. London: Routledge and Kegan Paul.

—(1971) The Political Theory of Anarchism. London: Routledge \& Keegan Paul.

Chubarov, Alexander. (2001) Russia's Bitter Path to Modernity. New York: Continuum.

Clawson, Dan \& Mary Ann Clawson. (1999) "What Has Happened to the US Labour Movement? Union Decline and Renewal. Annual Review of Sociology. Vol. 25.

Clements, Kevin. (1988) Back From the Brink. Wellington: Allen \& Unwin.

Coney, Sandra. (1992) “Coalition Politics.” From: Been Around For Quite A While: Twenty 
Years of Broadsheet magazine. (Ed.) Pat Rosier. Auckland: New Women’s Press.

-(1997) Into the Fire: Writings on Women, Politics and New Zealand in the Age of the New Right. Auckland: Tandem.

—(1993) "Why the Women's Movement Ran Out of Steam." From: Heading Nowhere in a Navy Blue Suit and other Tales from the Feminist Revolution. (Ed.s) Sue Kedgley \& Mary Varnham. Wellington: Daphne Brasell Associated Press.

Converge. (2008) “ANZAC Ploughshares Deflate Waihopai Spy Dome.” Http://www.converge.org.nz/pma/plshares.htm. Accessed: 09/05/2008.

Cornford, James \& Patricia Hewitt. (1994) "Dos and Don'ts for Social Democrats." From: Reinventing the Left. (Ed.) David Miliband. Cambridge: Polity Press.

Cox, Robert W. (2005) "Civil Society at the turn of the Millennium: Prospects for an Alternative World Order.” From: The Global Resistance Reader. (Ed.) Louise Amoore. New York: Routledge.

Cox, Wendell \& Hugh Pavletich. (2008) "4th Annual Demographia International Housing Affordability Survey: 2008 Ratings for Major Urban Markets." Http://www.demographia.com/dhi.pdf. Accessed: 19/02/2008.

Crossley, Nick. (1999) "Working Utopias and Social Movements: An Investigation Using Case Study Materials from Radical Mental Health Movements in Britain.” Sociology. Vol. 33, No. 4. November.

Crouch, Colin. (2004) Post-Democracy. Cambridge: Polity.

Dahlberg, Lincoln \& Eugenia Siapera. (2007) "Tracing Radical Democracy and the Internet." From: Radical Democracy and the Internet: Interrogating Theory and Practice. (Ed.s) Lincoln Dahlberg \& Eugenia Siapera. New York: Palgrave Macmillan.

Dann, Christine. (2008) "Greens in Time and Space: The History of The Green Party" 2000. Http://www.greens.org.nz/about/history.htm. Accessed: 04/05/08.

-(1985) Up From Under: Women and Liberation in New Zealand 1970-1985. Wellington: Allen \& Unwin.

Dean, Jodi. Jon W. Anderson \& Geert Lovink. (2006) "The Postdemocratic Governmentality of Networked Societies." From: Reformatting Politics: Information Technology and Global Civil Society. (Ed.s) Jodi Dean, Jon W. Anderson \& Geert Lovink. New York: Routledge.

Debord, Guy. (2008) Comments on the Society of the Spectacle.

Http://www.notbored.org/commentaires.html. Accessed: 20/04/08.

-(2004) The Society of the Spectacle. New York: Zone. 
DeLanda, Manuel. (2008) "Deleuze and the Open-Ended Becoming of the World." Http://www.cddc.vt.edu/host/delanda/pages/becoming.htm. Accessed: 08/05/2008.

Della Porta, Donna \& Mario Diani. (2006) Social Movements: An Introduction (second edition). Malden: Blackwell.

Denning, Michael. (2004) Culture in the Age of Three Worlds. London: Verso.

Derby, Mark. (2007) “A Country Considered to be Free” Wellington: Unpublished seminar paper.

Diani, Mario. (2003) “Leaders' or Brokers? Positions and Influence in Social Movement Networks." From: Social Movements and Networks: Relational Approaches to Collective Action. (Ed.s) Mario Diani \& Doug McAdam. New York: Oxford.

Diani, Mario \& Ivano Bison. (2004) "Organisations, Coalitions, and Movements" Theory and Society, Vol. 33, No. 3/4, Jun-Aug.

Dunstall, Graeme. (2002) "Governments, the Police and the Left, 1912-51" From: On The Left: Essays on Socialism in New Zealand. (Ed.s): Pat Moloney and Kerry Taylor.

Dundedin: Otago Universtiy Press.

Du Pleiss, Rosemary \& Lynne Alice. (1998) Feminist Thought in Aotearoa New Zealand: Connections and Differences. Auckland: Oxford.

Dyer-Witherford, Nick. (1999) Cyber-Marx: Cycles and Circuits of Struggle in High-Technology Capitalism. Urbana: University of Illinois Press.

Eley, Geoff. (2002) Forging Democracy: The History of the Left in Europe, 1850-2000. New York: Oxford.

Else, Anne. \& Rosslyn Noonan. (1993) "Unfinished Business." From: Heading Nowhere in a Navy Blue Suit and other Tales from the Feminist Revolution. (Ed.s) Sue Kedgley \& Mary Varnham. Wellington: Daphne Brasell Associated Press.

el-Ojeili, Chamsy. (2008) “Post-Marxist Trajectories.” Sociological Inquiry, Fall.

Falk, Richard. (2005) "The Changing Role of Global Civil Society." From: Global Civil Society: Contested Futures. (Ed.s) Gideon Baker \& David Chandler. London: Routledge.

Faludi, Susan. (1992) Backlash : The Undeclared War Against Women. London: Chatto \& Windus.

Fitzsimons, Jeanette. (2008) "Jeanette Fitzsimons"

Http://www.greens.org.nz/people/fitzsimons_j.asp. Accessed: 04/05/2008.

Flacks, Dick. (2006) “C. Wright Mills, Tom Hayden, and the New Left.” From: Radical Nomad: C. Wright Mills and His Times. Tom Hayden. Boulder: Paradigm Publishers. 
Flaherty, John. (2008) "World Social Forum Goes to Africa."

Http://www.indypendent.org/2007/02/12/world-social-forum-goes-to-africa/ Accessed: 26/04/2008.

Foote, W.J. (1997) Quest For Peace: Confessions, Lies and Heroes. Nelson: Self published.

Fraser, Nancy. (2000) “Rethinking Recognition.” New Left Review 3. May June.

Freeman, Jo. (1972) "The Tyranny of Structurelessness." Berkeley Journal of Sociology. Vol. 17.

Friedman, Milton and Rose Friedman. (1980) Free To Choose. Middlesex: Penguin.

Fukuyama, Francis. (2002) The End of History and the Last Man. New York: Perennial.

Fyson, George. (1972) The New Wave of Protest: A Socialist Strategy For New Zealand. Wellington: Socialist Books.

Gamble, Andrew. (2006) “Two Faces of Neo-Liberalism.” From: The Neo-Liberal Revolution: Forging the Market State. (Ed.) Richard Robinson. New York: Palgrave Macmillan.

Page: 100

Gauchet. M. (2000) "A New Age of Personality: An Essay on the Psychology of our Times". From: Thesis Eleven, Number 60.

Giddens, Anthony. (1996) Beyond Left and Right: The Future of Radical Politics. Cambridge: Polity Press.

Gillespie, Christine. (1980) "The Road Ahead for the Women's Movement-Out of the Womb and into the World." From: Women in New Zealand Society. (Ed.s) Phillida Bunkle \& Beryl Hughes. Auckland: Allen \& Unwin.

Gindin, Jonah. (2006) "Chavistas in the Halls of Power, Chavistas in the Streets." From: Dispatches from Latin America. (Ed.s) Teo Ballvé \& Vijay Prashad. Cambridge: South End Press.

Gillham, Bill. (2000)The Research Interview. London: Continuum.

Giugni, Marco \& Florence Passy. (2000) "Life-Spheres, Networks and Sustained Participation in Social Movements: A Phenomenological Approach to Political Commitment. Sociological Forum, Vol. 15. No. 1. March.

Graeber, David. (2002) “The New Anarchists.” New Left Review13. Jan Feb.

Green Party. (2008) "Press Release," 12th March 1999.

Http://www.greens.org.nz/people/tanczos_n.asp. Accessed: 22/02/2008.

Green World (2008) Http://www.greenworld-earthcare.org/aboutus.html. Accessed: 
12/03/2008.

Guattari, Felix. (2007) “The Proliferation of Margins." From: Autonomia: Post-Political Politics. (Ed.s) Sylvere Lotringer \& Christian Marazzi. Los Angeles: Semiotext.

Hadley, Stephen. (2005) New Zealand and France: Politics, Diplomacy and Dispute Management. Wellington: New Zealand Institute of Foreign Affairs.

Hager, Nicky. (2006) The Hollow Men: A Study in the Politics of Deception. Nelson: Craig Potton.

Hall, Lesley Margaret. (2003) Better Red Than Wed? Gender Relations and the Role of Women in the Communist Party of New Zealand, 1921-1970. Unpublished PhD Thesis, Victoria University of Wellington.

Hardt, Michael \& Antonio Negri. (2001) Empire. Cambridge: Harvard University Press.

-(2004) Multitude: War and Democracy in the Age of Empire. New York: Penguin.

Harré, Laila. (2007) “Union Relevance in Aotearoa in the 21 $1^{\text {st }}$ Century.” Bruce Jesson Memorial Lecture, Unpublished.

Harris, Aroha. (2004) Hikoi: Forty Years of Maori Protest. Wellington: Huia.

Hayes, Dennis \& Robin Wynyard. (2002) "Whimpering Into the Good Night: Resisting McUniversity" From: McDonaldization: The Reader (Ed) George Ritzer. Thousand Oaks: Pine Forge Press.

Heartfield, James. (2005) “Contextualising the 'Anti-Capitalism' Movement in Global Civil Society." From: Global Civil Society: Contested Futures. (Ed.s) Gideon Baker \& David Chandler. London: Routledge.

Held, David. (2000) "The Changing Contours of the Political Community." From: Global Democracy: Key Debates. (Ed.) Barry Holden. London: Routledge.

Held, David and Anthony McGrew. (2002) "Introduction" to Governing Globalisation: Power, Authority and Global Governance. (Ed.s) David Held and Anthony McGrew. Cambridge: Polity.

Heraldo, Munoz. (2006) “The Growing Community of Democracies.” From: Democracy Rising: Assessing the Global Challenges. (Ed.) Heraldo Munoz. Boulder: Lynne Rienner.

Herd, Joyce. (2005) Cracks in a Glass Ceiling: New Zealand Women 1975-2004. Dunedin: New Zealand Federation of Graduate Women.

Hickey, P. H. (1980) “Red” Fed. Memoirs. Wellington: New Zealand Worker Print.

Hobsbawm, Eric. (2006) The Age of Extremes: 1914-1991. London: Abacus. 
—(1973a) "Bolshevism and the Anarchists" From: Revolutionaries: Contemporary Essays. New York: Pantheon.

—(1996) “Identity Politics and the Left". New Left Review 217, May June.

— (1973b) "May 1968" From: Revolutionaries: Contemporary Essays. New York: Pantheon.

— "Reflections on Anarchism." From: Revolutionaries: Contemporary Essays. Pantheon. New York: 1973c.

Horton, Murray. (1976) “The Secret History of World War Two" From: Red Papers on New Zealand. Series One, May 1976. Auckland: Marxist Publishing Group.

Hulkyard-Harawira, Hilda. \& Katie Boanas. (1993) "Pacific Connections: Women and the Peace Movement in Aotearoa." From: Feminist Voices: Women's Studies Texts from New Zealand. Auckland: Oxford.

Hutchinson, Robert H. (1916) The "Socialism" of New Zealand. New York: New Review.

Jackson, Moana. (2007) "Back in the Mists of Fear: A primer on the allegations of terrorism made during the week 15-19 October, 2007.” (Pamphlet) Wellington: Self Published.

James, Bev \& Kay Saville-Smith. (1994) Gender Culture \& Power: Challenging New Zealand's Gendered Culture (Second Edition). Oxford: Oxford University Press.

Jameson, Fredric. (1994) The Seed of Time. New York: Columbia University Press.

-(2005) Postmodernism: or, the Logic of Late Capitalism. Durham: Duke University Press.

Jasper, James M. \& Francesca Polletta. (2001) "Collective Identity and Social

Movements." Annual Review of Sociology, Vol. 27.

Jesson, Bruce. (1976) "The Family Affair: Wealth and Power in New Zealand.” From: Red Papers on New Zealand. Series One, May 1976. Auckland: Marxist Publishing Group.

- (2005c) "Looking at the Labour Party: Where Have All the Workers Gone?" From: To Build a Nation: Collected Writings 1975-1999. (Ed.) Andrew Sharp. Auckland: Penguin.

—(2005d) "The Lost Causes.” From: To Build a Nation: Collected Writings 1975-1999. (Ed.) Andrew Sharp. Auckland: Penguin.

—(2005a) "Maori Radicalism: Confronting the Pakeha Establishment." From: To Build a Nation: Collected Writings 1975-1999. (Ed.) Andrew Sharp. Auckland: Penguin.

—(2005e) "Marilyn Waring-Conflicting Interests?" From: To Build a Nation: Collected Writings 1975-1999. (Ed.) Andrew Sharp. Auckland: Penguin.

—(1999) Only Their Purpose is Mad: The Money Men Take Over New Zealand. Palmerston 
North: The Dunmore Press.

— (2005b) "Reviewing the 'Maori Sovereignty' Debate." From: To Build a Nation: Collected Writings 1975-1999. (Ed.) Andrew Sharp. Auckland: Penguin.

Jessop, Bob. (1995) "Post-Fordism and the State." From: Post-Fordism: A Reader. Oxford: Blackwell.

Jones, Alison. \& Camille Guy. (1993) "Radical Feminism in New Zealand: From Piha to Newtown." From: Feminist Voices: Women's Studies Texts from New Zealand. Auckland: Oxford.

Kaldor, Mary. (2003) Global Civil Society: An Answer to War. Cambridge: Polity.

—(2005) "The Idea of Global Civil Society." From: Global Civil Society: Contested Futures. (Ed.s) Gideon Baker \& David Chandler. London: Routledge.

Kaldor, Mary. Helmut Anheir \& Marlies Glasius. (2003) "Global Civil Society in an Era of Regressive Globalisation." From: Global Civil Society 2003. (Ed.s) Mary Kaldor, Helmut Anheir \& Marlies Glasius. Oxford: Oxford University Press.

Katsiaficas, George. (1987) The Imagination of the New Left. Boston: South End Press.

Kedgley, Sue. (1985) The Sexual Wilderness: Men and Women in New Zealand Society. Auckland: Reed Methuen.

Kelsey, Jane. (1990) A Question of Honour? Labour and the Treaty: 1984-1989. Wellington: Allen \& Unwin.

—(1995) Economic Fundamentalism. London: Pluto Press.

Kelsey, Jane \& Mike O’Brien. (1995) Setting the Record Straight: Social Development in Aotearoa/New Zealand. Wellington: Association of Non Governmental Organisations of Aotearoa.

Key, John. (2008) "The Kiwi Way: A Fair Go For All: A State of the Nation Speech." Delivered: 30 January 2007. Http://johnkey.co.nz/index.php?/archives/35-The-KiwiWay-A-Fair-Go-For-All.html. Accessed: 28/02/2008.

King, Michael. (2003) History of New Zealand. Auckland: Penguin.

Klatch, Rebecca E. (2002) "The Development of Individual Identity and Consciousness among Movements of the Left and Right." From: Social Movements: Identity, Culture and the State. (Ed.s) David S. Meyer, Nancy Whittier and Belinda Robnett. New York: Oxford.

Klein, Naomi. (2001) "Reclaiming the Commons." New Left Review 9. May June.

—(2007) The Shock Doctrine: the rise of disaster capitalism. New York: Metropolitan Books/Henry Holt. 
Kukathas, Chandran. (1998) "Friedrich Hayek: Elitism and Democracy." From: Liberal Democracy and its Critics. (Ed.s) April Carter \& Geoffrey Stokes. Cambridge: Polity Press.

Kvale, Steiner. (1996) Interviews. California: Sage.

Lee, J.A. (1938) Socialism in New Zealand. London: T. Werner Laurie Ltd.

Le Heron \& Eric Pawson. (1996) "Sure to Rise" From: Changing Places: New Zealand in the Nineties. (Ed.s) Richard Le Heron \& Eric Pawson. Auckland: Longman Paul.

Lipietz, Alain. (1997) “The Post-Fordist World: Labour Relations, International Hierarchy and Global Ecology.” Review of International Political Economy. 4:1 Spring.

Locke, Eslie. (1992) Peace People: A History of Peace Activists in New Zealand. Christchurch: Hazard Press.

Lotringer, Sylvere. (2007) "In the Shadow of the Red Brigades." From: Autonomia: PostPolitical Politics. (Ed.s) Sylvere Lotringer \& Christian Marazzi. Los Angeles: Semiotext.

Lotringer, Sylvere. \& Christian Marazzi. (2007) “The Return of Politics.” From:

Autonomia: Post-Political Politics. (Ed.s) Sylvere Lotringer \& Christian Marazzi. Los Angeles: Semiotext.

Lunori, Gina. (2008) "Direct Action."

Http://www.sniggle.net/Manifesti/directAction.php. Accessed: 22/02/2008.

MaCaskill, Shona. (1976) "Sexism and the Egalitarian Myth in New Zealand Society." From: Learning About Sexism in New Zealand. (Ed.s) Phillidda Bunkle, Stephen Levine \& Christopher Wainwright. Wellington: Learnmonth.

Maddison, Sarah \& Sean Scalmer. (2006) Activist Wisdom: Practical Knowledge and Creative Tension in Social Movements. Syndey: UNSW Press.

Mair, Peter. (2006) "Ruling the Void?" New Left Review 42, Nov Dec.

Mandel, Ernest. (1990) “Introduction.” From: Capital: Volume 1 Karl Marx. London: Penguin.

Mann, Peter H. (1985) Methods of Social Investigation. New York: Basil/Blackwell.

Marx, Karl \& Friedrich Engels. (1971) The Manifesto of the Communist Party. From: The Essential Left. London: Unwin Books.

Melbourne, Hineani. (1995) Maori Sovereignty: The Maori Perspective. Auckland: Hodder Moa Beckett.

Miliband, Ralph. (1989) "Marx and the State." From: Democracy and the Capitalist State. (Ed.) Graeme Duncan. New York: Cambridge University Press. 
Millar, Paul. (2005) "The Rent Due For A Skull: James K. Baxter and the Legacy of Parihaka" From: Paribaka: The Art of Passive Resistance. (Ed.s): Te Miringa Hohaia, Gregory O’Brian \& Lara Strongman. Wellington: Victoria University Press.

Mische, Ann. (2003) "Cross Talk in Movements: Reconceiving the Culture-Network Link." From: Social Movements and Networks: Relational Approaches to Collective Action. (Ed.s) Mario Diani and Doug McAdam. Oxford: Oxford University Press.

McNeish, James. (2007) "Hidden History of the New Zealand Cold War" From: North and South, October.

McKnight, David. (2005) Beyond Right and Left: New Politics and the Culture Wars. Crows Nest: Allen \& Unwin.

McLellen, David. (1980) Marxism after Marx (2nd ed.). London: Macmillon.

Moloney, Pat. (2002) "State Socialism and William Pember Reeves: A Reassessment." From: On The Left: Essays on Socialism in New Zealand. (Ed.s) Pat Moloney and Kerry Taylor. Dunedin: Otago Universtiy Press.

Moloney, Pat and Kerry Taylor. (2002) "Bringing the Left Back In." From: On The Left: Essays on Socialism in New Zealand. (Ed.s) Pat Moloney and Kerry Taylor. Dunedin: Otago Universtiy Press.

Morse, Valerie. (2007) Against Freedom: The War on Terrorism in Everyday New Zealand Life. Wellington: Rebel Press.

Munck, Ronaldo. (2007) Globalisation and Contestation. London: Routledge.

Negri, Antonio. (1987) “A Marxist Doctrine of the State? A reply.” From: Bobbio, Norberto. Which Socialism: Marxism, Socialism and Demcocracy. Oxford: Polity Press.

Newnham, Tom. (1986) Peace Squadron: The sharp end of nuclear protest in New Zealand. Auckland: Graphic.

Novack, George, David Frankel \& Fred Feldman. (1974) The First Three Internationals: Their History and Lessons. New York: Pathfinder.

Oliver, Pamela E. \& Daniel J. Myers. (2003) "Networks, Diffusion, and Cycles of Collective Action." From: Social Movements and Networks: Relational Approaches to Collective Action. (Ed.s) Mario Diani and Doug McAdam. Oxford: Oxford University Press.

Passy, Florence. (2003) "Social Networks Matter. But How?" From: Social Movements and Networks: Relational Approaches to Collective Action. (Ed.s) Mario Diani \& Doug McAdam. New York: Oxford.

Peat, Neville. (1994) Manapouri Saved: New Zealand's First Great Conservation Success Story. Dunedin: Longacre Press. 
Phillips, Jock. (1980) "Mummy's Boys: Pakeha Men and Male Culture in New Zealand." From: Women in New Zealand Society. (Ed.s) Phillida Bunkle \& Beryl Hughes. Auckland: Allen \& Unwin.

Powles, Guy. (1975) "The Future of Dissent" From: Spirit of an Age: New Zealand in the Seventies; Essays in honour of W.B. Sutch. (Ed.s) Jack Shallcross \& John L. Robinson. Wellington: Reed.

Pringle, Richard. (2002) "Living the Contradictions: A Foucauldian Examination of My Youthful Rugby Experiences." From: The Life of Brian: Masculinities, Sexualities and Health in New Zealand. (Ed.s) Heather Worth, Anna Paris and Louisa Allen. Dunedin: Otago University Press.

Punch, Keith F. (2005) Introduction to Social Research: Quantitative and Qualitative Approaches (Second Edition). London: Sage.

Putnam, Robert D. (2000) Bowling Alone: The Collapse and Revival of American Community. New York: Simon \& Schuster.

Quayle, Simon P. (1984) Two Tactics for Social Democracy in New Zealand. Christchurch: The Grinding Axe.

Quiggin, John. (2001) "Social Democracy and Market Reform in Australia and New Zealand." From: Social Democracy in Neoliberal Times: The Left and Economic Policy since 1980. (Ed.) Andrew Glyn. New York: Oxford.

Rata, Elizabeth. (1996) “'Goodness and Power”: The Sociology of Liberal Guilt”. New Zealand Soiciology 11 (2) November.

Rich, Emma. (2005) "Young Women, Feminist Identities and Neo-Liberalism," Women's Studies International Forum. Vol. 28.

Richards, Trevor. (1999) Dancing On Our Bones: New Zealand, South Africa, Rugby and Racism. Wellington: Bridget Williams Books.

Ritzer, George. (2004) The Globalization of Nothing. Thousand Oaks: Pine Forge Press.

Robie, David. (1986) “Challenging Goliath” From: New Internationalist, Issue 163, September.

Robinson, Richard. (2006) "Neo-liberalism and the Market State: What is the Ideal Shell?" From: The Neo-Liberal Revolution: Forging the Market State. (Ed.) Richard Robinson. New York: Palgrave Macmillan.

Roper, Brian S. (2005) Prosperity for All? Economic, Social and Political Change in New Zealand Since 1935. Victoria: Thomson.

Rosier, Pat. (1992) Been Around For Quite A While: Twenty Years of Broadsheet magazine. 
Selected and introduced by Pat Rosier. Auckland: New Women's Press.

Ross, Stephanie. (2002) "Is This What Democracy Looks Like? The Politics of the AntiGlobalisation Movement in North America." From: The Socialist Register 2003: Fighting Identities: Race, Religion and Ethno-Nationalism. (Eds. Leo Panitch and Colin Leys. London: Merlin Press.

Roth, Bert. (1974) Trade Unions in New Zealand. Wellington: Reed.

Santos, Boaventura De Sousa. (2005b) "Introduction" to Another Production is Possible: Beyond the Capitalist Canon. London: Verso.

—(2005a) "Preface" to Democratising Democracy: Beyond the Liberal Democratic Canon.

London: Verso.

—(2006) The Rise of the Global Left. London: Zed.

Santos, Boaventura De Sousa \& Leonardo Avritzer. (2005) "Opening up the Canon of Democracy" From: Democratising Democracy: Beyond the Liberal Democratic Canon. London: Verso.

Sargisson, Lucy \& Lyman Tower Sargent. (2004) Living in Utopia: New Zealand's Intentional Communities. Aldershot: Ashgate.

Saul, John Ralson. (1997) The Unconscious Civilization. Sydney: Penguin.

Scholte, Jan Aart. (2001) “The Globalisation of World Politics." From: The Globalisation of World Politics (2nd Ed.). Oxford. (Ed.s) John Baylis \& Steve Smith. Oxford: Oxford.

Scott, Dick. (2004) A Radical Writer's Life. Auckland: Reed.

—(1987) Ask That Mountain: The Story of Paribaka. Auckland: Heinman/Southern Cross.

-(1951) 151 Days: History of the great waterfront lockout and supporting strikes, February 15July 15, 1951. Auckland: New Zealand Waterside Workers' Union.

Shadbolt, Tim (1971). Bullshit and Jellbeans. Wellington: Alister Taylor.

Sharp, Richard (1997). Justice and the Maori: The Philosophy and Practice of Maori Claims in New Zealand since the 1970s (Second Edition). Auckland: Oxford.

Shay, Roger W. (2002) "In-Person versus Telephone Interviewing." From: Handbook of Interview Research: Context and Method. (Ed.s): Jaber F. Gubrium \& James A. Holstein. LosAngeles: Sage.

Shields, Margaret. (1993) "New Zealand and the International Women's Movement." Walking Backwards into the Future. Hamilton: The Women's Electoral Lobby.

Shukaitis Stevphen \& David Graeber. (2007) “Introduction” From: Constituent Imagination: 
Militant Investigations / Collective Theorisation. (Ed.s) Stevphen Shukaitis \& David Graeber. Oakland: AK Press.

Sinclair, Keith. (1986) A Destiny Apart: New Zealand's Search for National Identity. Wellington: Allen \& Unwin.

—(1973) A History of New Zealand. Middlesex: Penguin. Middlesex.

Silverman, David. (2006) Interpreting Qualitative Data (Third Edition). London: Sage.

Sparrow, Rob. (2008) "Anarchist Politics and Direct Action."

Http://www.spunk.org/library/intro/sp001641.html. Accessed: 22/02/2008.

Spoonley, Paul. (1993) Racism and Ethnicity (second edition). Oxford: Oxford.

Starr, Amory. (2002) "Is the North American Anti-Globalisation Movement Racist? Critical Reflections." From: The Socialist Register 2003: Fighting Identities: Race, Religion and Ethno-Nationalism. (Eds.) Leo Panitch and Colin Leys. London: Merlin Press.

Stephen, Mathew. (2007) "The post-September 11 Anti-War Movement in New Zealand.” Red \& Green 6.

Sutch, W.B. (1973) Women with a Cause. Wellington: New Zealand University Press.

Tánczos, Nandor. (2007) “The Greens are Not a Left Wing Party?”

Http://www.nandor.net.nz/journal/2006/06/greens-are-not-left-wing-party.php. Accessed: 20/08/2007.

Tarnass, Richard. (1998) The Passion of the Western Mind. London: Pimlico.

Taylor, David. (2008) "Globalisation and New Zealand."

Http:/ $/$ www.nzembassy.com/info.cfm?c $=8 \& \mathrm{l}=39 \&$ CFID $=502 \& C F T O K E N=9968121$ $7 \& s=$ go\&p $=62177$. Accessed: 25/04/2008.

Taylor, Kerry. (2002) "The Communist Party of New Zealand and Maori 1921-52." From: On The Left: Essays on Socialism in New Zealand. (Ed.s): Pat Moloney and Kerry Taylor. Dunedin: Otago Universtiy Press.

Templeton, Malcolm. (1998) Human Rights and Sporting Contacts: New Zealand Attitudes to Race Relations in South Africa 1921-94. Auckland: Auckland University Press.

Therbon, Goran. (2007) "After Dialectics: Radical Social Theory in a Post-Communist World." New Left Review 43. Jan Feb.

Thomas, Paul. (1980) Karl Marx and the Anarchists. London: Routledge and Keegan Paul.

Thompson, John B. (1996) “Tradition and Self in a Mediated World". From:

Detraditionalization. London: Blackwell. 
Tomlinson, John. (1999) Globalization and Culture. London: University of Chicago Press.

Touraine, Alain. (2001) Beyond Neoliberalsim. Cambridge: Polity.

—(1971) The Post Industrial Society. New York: Random House.

Trotter, Chris. (2007) No Left Turn: The distortion of New Zealand's history by greed, bigotry and right-wing politics. Auckland: Random House.

Tui Trust. (2007) “Tui Trust Events Programme 2007/2008.” Wainui Bay: Self published.

Tuiono, Teanau. (2007) "Like a Bridge Over Troubled Waters..."

Http://www.conscious.maori.nz/news.php?extend.12. Accessed: 19/09/2007.

Urry, James. (2003) Global Complexity. Cambridge: Polity.

Values Party. (1975) “Beyond Tomorrow: 1975 Values Party Manifesto.” Wellington: Self published.

—(1978)“Critical Issues ’78.” Wellington: Self published.

Vaneigem, Raoul. (2006) The Revolution of Everyday Life. London: Rebel Press.

Vasil, Raj. (2000)Biculturalism: Reconciling Aotearoa with New Zealand. Wellington: Institute of Policy Studies.

Virno, Paulo. (2004) A Grammar of the Multitude. Los Angeles: Semiotext(e).

Walker, Ranganui. (1983) History of Maori Activism. Auckland: NCC Program on Racism.

-(1992) "Sovereignty: Te Tino Rangatiratanga" From: New Zealand in Crises: A Debate About Today's Critical Issues. (Ed.s) David Novitz and Bill Willmott. Wellington: GP Publications.

Wall, Derek. (1999) Earth First! And The Anti-Roads Movement: Radical Environmentalism and Comparative Social Movements. New York: Routledge.

Wallerstein, Immaneul. (2002) "New Revolts Against the System.” New Left Review 18, Nov Dec.

Ward, Colin. (2005) “The Anarchist Contribution.” From: Participatory Democracy: Prospects for Democratising Democracy. (Ed.s) Dimitrios Roussopoulos \& C. George Benello. Montreal: Black Rose.

Warren, Carol A. B. (2002) "Qualitative Interviewing." From: Handbook of Interview Research: Context and Method. (Ed.s) Jaber F. Gubrium \& James A. Holstein. California: Sage. 
Whittier, Nancy. (2002) "Meaning and Structure in Social Movements." From: Social Movements: Identity, Culture and the State. (Ed.s) David S. Meyer, Nancy Whittier and Belinda Robnett. New York: Oxford.

Wicks, Robert. (2003) Modern French Philosophy: From Existentialism to Postmodernism. Oxford: Oneworld.

Wilkes, Owen. (1973) Protest. Wellington: Alister Taylor.

Women's Liberation Auckland. (1993) 'Women's Liberation: An introduction to the aims and ideas of the Women's Liberation Movement in Auckland." From: The Vote, the Pill and the Demon Drink. (Ed.) Charlotte MacDonald. Wellington: Bridget Williams Books.

Wood, G.A. \& Chris Rudd. (2004) The Politics and Government of New Zealand: Robust, Innovative and Challanged. Dunedin: Otago University Press.

World Social Forum. (2008) “About the WSF” Http://wsf2008.net/eng/about. Accessed: 25/04/2008.

Zizek, Slavoj. (2001) "Have Michael Hardt and Antonio Negri Rewritten the Communist Manifesto for the Twentieth Century?" Rethinking Marxism. Volume 13, Numbers 34/September. 